\begin{tabular}{|c|c|c|c|c|c|c|}
\hline \multicolumn{7}{|c|}{ DISTRIBUTION SHEET } \\
\hline \multirow{2}{*}{\multicolumn{2}{|c|}{$\begin{array}{l}\text { To } \\
\text { Characterization Engineering }\end{array}$}} & \multirow{2}{*}{\multicolumn{3}{|c|}{$\begin{array}{l}\text { From } \\
\text { Upgrades Technical Support }\end{array}$}} & \multicolumn{2}{|c|}{ Page 1 of 1} \\
\hline & & & & & \multicolumn{2}{|c|}{ DateFebruary 28, 1995} \\
\hline \multicolumn{5}{|c|}{ Project Title/Work Order } & \multicolumn{2}{|c|}{ EDT No. 603048} \\
\hline \multicolumn{5}{|c|}{ Rotary Mode Core Sample System Availability Improvement } & \multicolumn{2}{|c|}{ ECN No. } \\
\hline & & MSIN & $\begin{array}{l}\text { Text } \\
\text { With All } \\
\text { Attach. }\end{array}$ & Text Only & $\begin{array}{l}\text { Attach.l } \\
\text { Appendix } \\
\text { Only }\end{array}$ & $\begin{array}{l}\text { EDT/ECN } \\
\text { Only }\end{array}$ \\
\hline $\begin{array}{l}\text { J. C. Akers } \\
\text { R. R. Bafus } \\
\text { K. L. Bennett } \\
\text { R. J. Blanchard } \\
\text { G. J. Bogen } \\
\text { J. M. Burkes } \\
\text { A. B. Cockrell } \\
\text { B. T. Cross } \\
\text { G. M. Crummel } \\
\text { L. L. Dean } \\
\text { C. W. Dunbar } \\
\text { J. E. Dunks } \\
\text { L. F. Ermold } \\
\text { J. Guerra } \\
\text { D. W. Hamilton } \\
\text { D. C. Hartley } \\
\text { T. D. Jarecki } \\
\text { W. W. Jenkins } \\
\text { B. R. Johns } \\
\text { M. C. Jones } \\
\text { P. A. Katsel } \\
\text { T. J. Kelley } \\
\text { D. B. Klos } \\
\text { J. S. Lee } \\
\text { D. E. Melville } \\
\text { B. H. Morrison } \\
\text { A. P. Mousel } \\
\text { D. R. Myers } \\
\text { A. D. Olguin } \\
\text { R. S. Popielarczyk } \\
\text { J. D. Potter } \\
\text { J. D. Robinson } \\
\text { A. C. Rogers } \\
\text { H. J. Schmidt } \\
\text { J. S. Schofield } \\
\text { J. L. Smalley } \\
\text { G. A. Stanton } \\
\text { R. H. Stubbs } \\
\text { P. H. Thomsen } \\
\text { A. M. Umek } \\
\text { E. J. Waldo } \\
\text { E. J. Watter } \\
\text { G. W. Wilson } \\
\text { Central Files } \\
\text { O.S.T.I. (2) } \\
\end{array}$ & . & 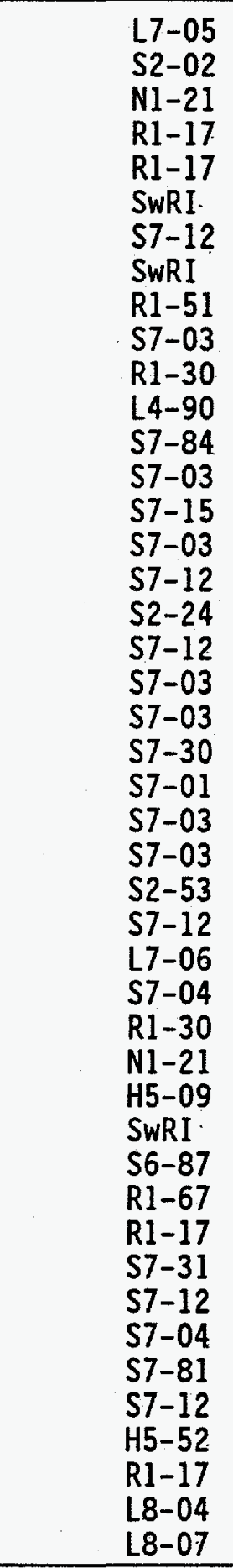 & $\begin{array}{l}x \\
x \\
x \\
x \\
x \\
x \\
x \\
x \\
x \\
x \\
x \\
x \\
x \\
x \\
x \\
x \\
x \\
x \\
x \\
x \\
x \\
x \\
x \\
x \\
x \\
x \\
x \\
x \\
x \\
x \\
x \\
x \\
x \\
x \\
x \\
x \\
x \\
x \\
x \\
x \\
x \\
x \\
x \\
x \\
x \\
\end{array}$ & & $\begin{array}{l}\text { COEIVE } \\
\text { AAR } 2219 \\
\text { OST }\end{array}$ & \\
\hline
\end{tabular}




\section{DISCLAIMER}

Portions of this document may be illegible in electronic image products. Images are produced from the best available original document. 
2. To: (Receiving Organization)

Characterization

Engineering, 71500

71620

8. Originator Renarks:

ETN \# 94-0001. This document provides a priority 1 isting of hardware and administrative changes that are recommended for improving the availability of the Rotary Mode Core Sample System (RMCSS).

11. Receiver Remarks:
3. From: (Originating Organization)

TWRS Engineering Upgrades Technical Support

6. Cog. Engr.:

J. D. Potter
5. Proj./Prog./Dept.10iv.:

4. Related EDT No.:

$N / A$

7. Purchase Order No.:

$N / A$

9. Equip./Component Ho.:

$N / A$

10. System/Bldg./Facility:

12. Major Assm. Dwg. No.:

$N / A$

13. Permit/Permit Application No.: $N / A$

14. Required Response Date: $02 / 28 / 95$

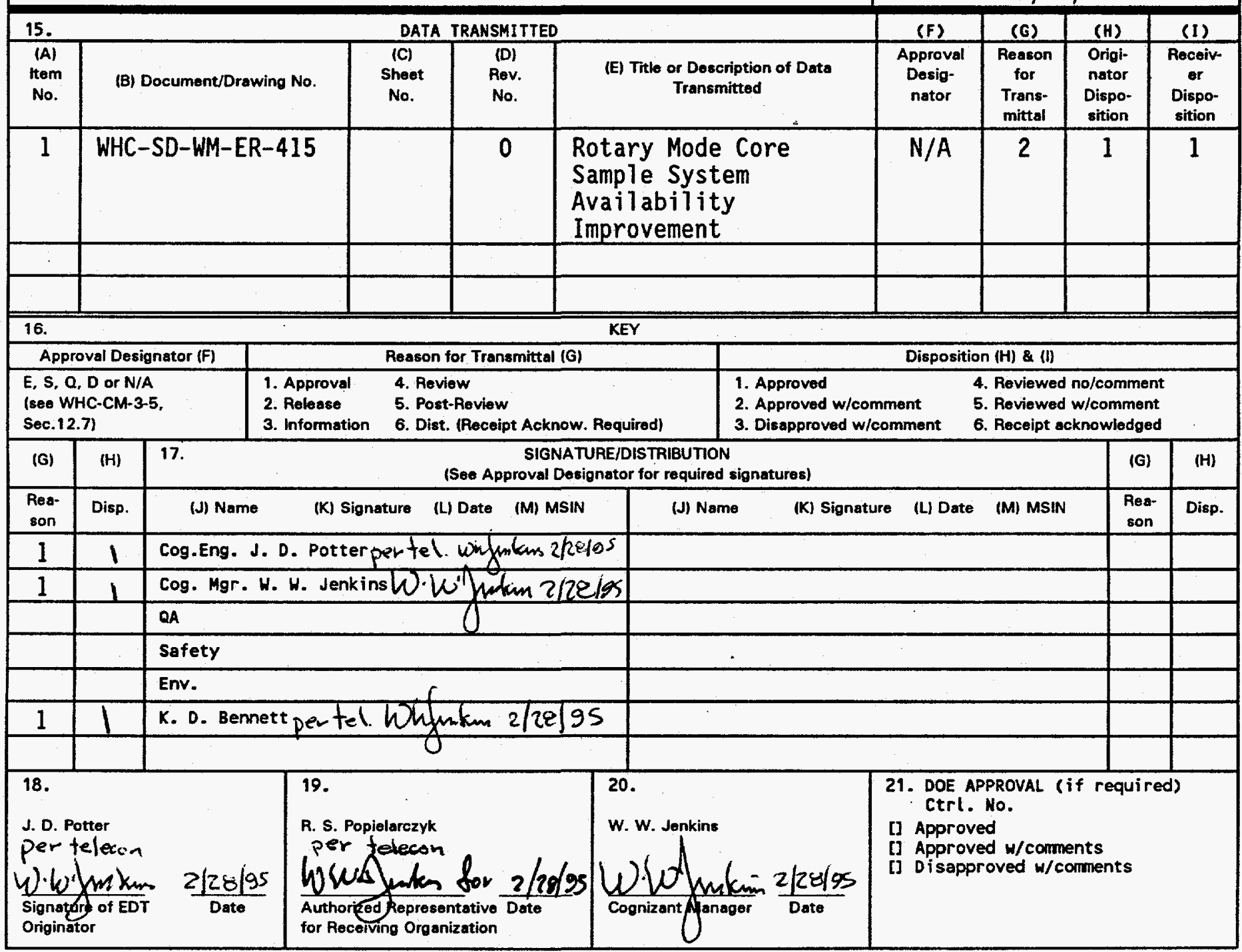




\section{RELEASE AUTHORIZATION}

Document Number: WHC-SD-WM-ER-415, REV.0

Document Title: $\quad$ Rotary Mode Core Sample System Availability

Improvement

Release Date: $\quad$ February 28, 1995

\section{This document was reviewed following the procedures described in WHC-CM-3-4 and is:}

\section{APPROVED FOR PUBLIC RELEASE}

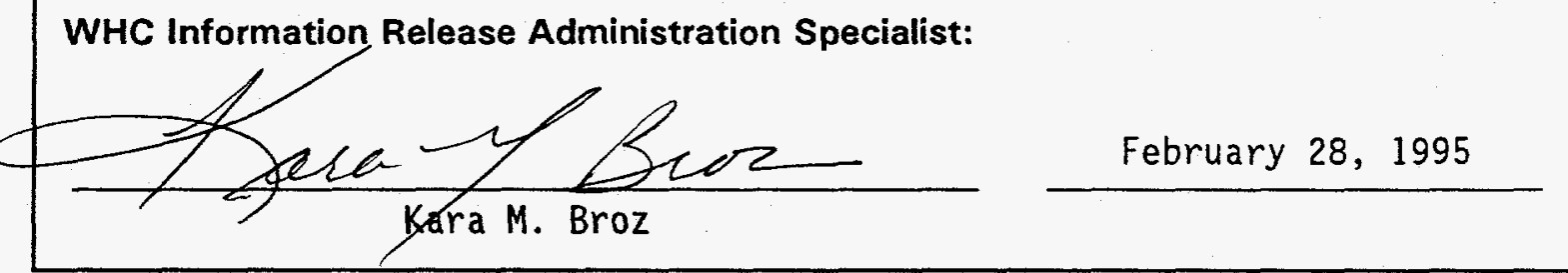

TRADEMARK DISCLAIMER. Reference herein to any specific commercjal product, process, or service by trade name, trademark, manufacturer, or otherwise, does not necessarily constitute or imply its endorsement, recommendation, or favoring by the United States Government or any agency thereof or its contractors or subcontractors.

This report has been reproduced from the best available copy. Available in paper copy and microfiche. Printed in the United States of America. Available to the U.S. Department of Energy and its contractors from:

U.S. Department of Energy

office of Scientific and Technical Information (OSTI)

P.O. Box 62

Oak Ridge, TN 37831

Telephone: (615) 576-8401

Available to the public from:

U.S. Department of Commerce

National Technical Information Service (NTIS)

5285 Port Royal Road

Springfield, VA 22161

Telephone: (703) $487-4650$ 


\begin{tabular}{|c|c|c|}
\hline $\begin{array}{l}\text { 2. Title } \\
\text { Rotary Mode Core Sample System Availability } \\
\text { Improvement }\end{array}$ & $\begin{array}{l}\text { 3. Number } \\
\text { WHC-SD-WM-ER-415 }\end{array}$ & $\begin{array}{c}\text { 4. Rev No. } \\
0\end{array}$ \\
\hline $\begin{array}{l}\text { 5. Key Hords } \\
\text { Rotary } \\
\text { Sample } \\
\text { Truck } \\
\text { Availability } \\
\text { Reliability }\end{array}$ & 6. Author & $30-71620$ \\
\hline
\end{tabular}

7. Abstract

This document provides a priority listing of hardware and administrative changes that are recommended for improving the availability of the Rotary Mode Core Sample System (RMCSS). 


\title{
Rotary Mode Core Sample System Availability Improvement Engineering Report
}

\author{
DISCLAIMER
}

This report was prepared as an account of work sponsored by an agency of the United States Government. Neither the United States Government nor any agency thereof, nor any of their employees, makes any warranty, express or implied, or assumes any legal liability or responsibility for the accuracy, completeness, or usefulness of any information, apparatus, product, or process disclosed, or represents that its use would not infringe privately owned rights. Reference herein to any specific commercial product, process, or service by trade name, trademark, manufacturer, or otherwise does not necessarily constitute or imply its endorsement, recommendation, or favoring by the United States Government or any agency thereof. The views and opinions of authors expressed herein do not necessarily state or reflect those of the United States Government or any agency thereof.

Prepared for the U.S. Department of Energy Office of Environmental Restoration and

Waste Management
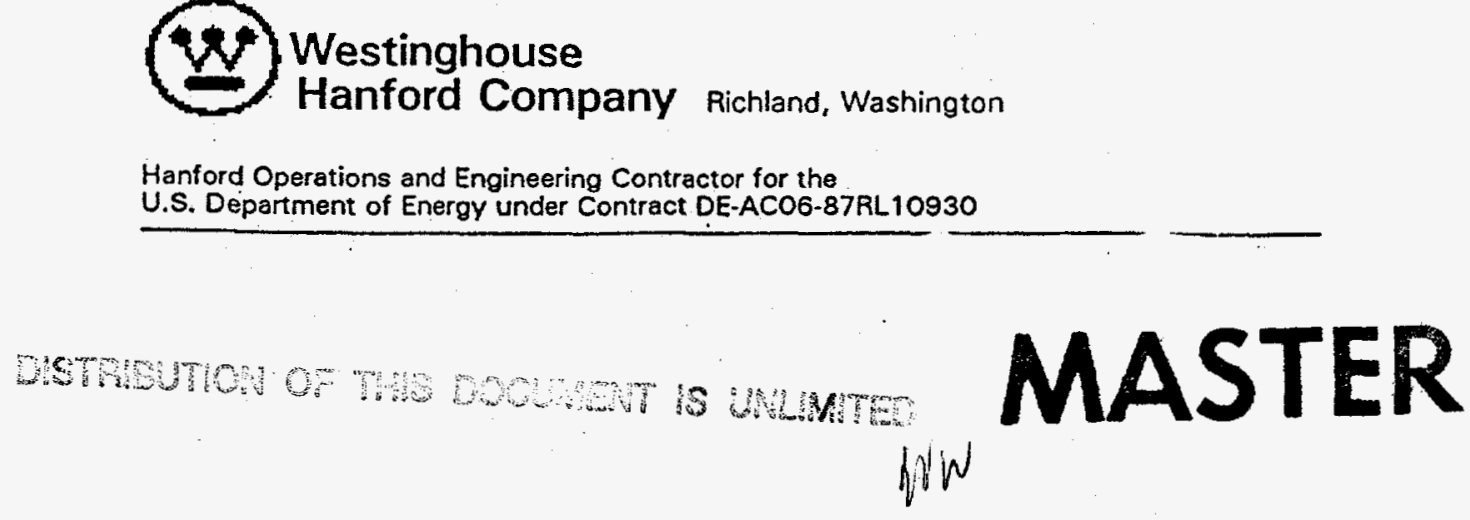


\title{
Rotary Mode Core Sample System Availability Improvement
}

\author{
W. W. Jenkins \\ K. L. Bennett \\ J. D. Potter \\ Westinghouse Hanford Company \\ B. T. Cross \\ J. M. Burkes \\ A. C. Rogers \\ Southwest Research Institute \\ Date Published \\ February 1995
}

Prepared for the U.S. Department of Energy

Office of Environmental Restoration and

Waste Management

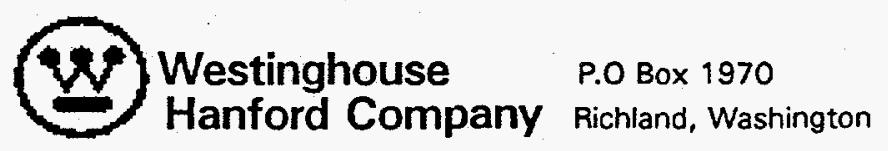

Hanford Operations and Engineering Contractor for the

U.S. Department of Energy under Contract DE-AC06-87RL10930 


\section{CONTENTS}

1.0 INTRODUCTION $\ldots \ldots \ldots \ldots \ldots \ldots \ldots$

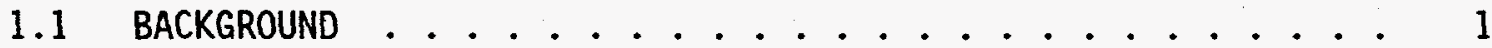

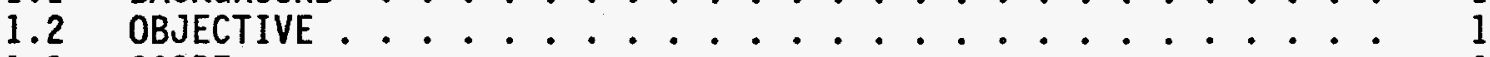

1.3 SCOPE ......................... 2

2.0 SUMMARY . . . . . . . . . . . . . . . . 2

Table 1-1 Summary of Probiems and Corrective Actions ..... 3

3.0 PROBLEMS AND RECOMMENDATIONS ................... 6

4.0 DISCUSSION ...................... . . . 6

Figure 1-1. Time Reiationships............ 8

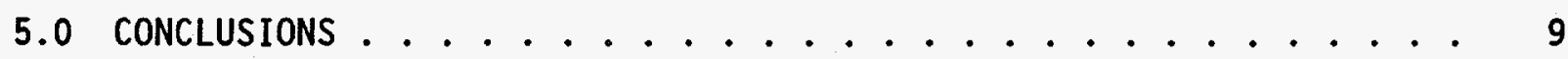

\section{APPENDICES}

A RECOMMENDED ACTIONS TO IMPROVE AVAILABILITY . . . . . . . . A A-1

B METHODOLOGY AND PRIORITIZATION ............ B-1

Table 1 List of Known Problems (Mechanical) ......... B-6

Table 2 List of Potential Problems (Mechanical) . . . . . . B-7

Table 3 List of Known Problems (Hydraulics).......... B-8

Table 4 List of Potential Problems (Hydraulics) . . . . . . B-10

Table 5 List of Known Problems (I\&C) ............ B-12

Table 6 List of Potential Problems (I\&C) . . . . . . . . B-14

Table 7 List of Known Problems (Electrical) . . . . . . . . B-15

Table 8 List of Potential Problems (Electrical) ........ B-16

Table 9 List of Known Problems (Other) . . . . . . . . . B-17

Table 10 List of Potential Problems (0ther) . . . . . . . . . B-18

Table la Determination of Impact on Availability........ B-20

Table 2a Determination of Impact on Availability ......... B-21

Table 3a Determination of Impact on Availability ......... B-22

Table 4a Determination of Impact on Availability.......... B-23

Table 5a Determination of Impact on Availability ......... B-24

Table 6a Determination of Impact on Availability........ B-25

Table 7a Determination of Impact on Availability ........ B-26

Table 8a Determination of Impact on Availability........ B-27

Table 9a Determination of Impact on Availability ........ B-28

Table 10a Determination of Impact on Availability ...... . B-29

Table 11 Tables 1-10, Ordered by Impact on Availability . . . . B-30

Table 12 Tables 1-8, Ordered by Impact on Availability . . . . . B-35

Table 13 Tables 9 \& 10, Ordered by Impact on Availability . . . B-38

c DOWNTIME HISTORY OF RMCSS ................. C-1

D CONTACTS AND RESPONSIBLE PERSONS ............. . . . . . 
WHC-SD-WM-ER-415, Rev. 0

\section{LIST OF ACRONYMS}

$\begin{array}{ll}\text { CAM } & \text { Continuous Air Monitors } \\ \text { DCI } & \text { Digital Control Indicators } \\ \text { EROM } & \text { Estimated Rough Order of Magnitude } \\ \text { N/A } & \text { Not Applicable } \\ \text { PIC } & \text { Person in Charge } \\ \text { PM } & \text { Preventative Maintenance } \\ \text { PMP } & \text { Preventative Maintenance Procedure } \\ \text { RCA } & \text { Radiologically Controlled Area } \\ \text { RLU } & \text { Remote Latch Unit } \\ \text { RMCSS } & \text { Rotary Mode Core Sample System } \\ \text { RMCST } & \text { Rotary Mode Core Sample Truck } \\ \text { SOV } & \text { Solenoid Operated Valve } \\ \text { SWRI } & \text { Southwest Research Institute } \\ \text { TBD } & \text { To Be Determined } \\ \text { TWRS } & \text { Tank Waste Remediation Systems } \\ \text { WHC } & \text { Westinghouse Hanford Company }\end{array}$


WHC-SD-WM-ER-415, Rev. 0

ROTARY MODE CORE SAMPLE SYSTEM AVAILABILITY IMPROVEMENT

\subsection{INTRODUCTION}

\subsection{BACKGROUND}

The Rotary Mode Core Sample System (RMCSS) is used to obtain stratified samples of the waste deposits in single-shell and double-shell waste tanks at the Hanford Site. The samples are used to characterize the waste in support of ongoing and future waste remediation efforts. Four sampling trucks have been developed to obtain these samples. Truck 1 was the first in operation and is currently being used to obtain samples where the push mode is appropriate (i.e., no rotation of drill). Truck 2 is similar to truck 1 , except for added safety features, and is in operation to obtain samples using either a push mode or rotary drill mode. Trucks 3 and 4 are now being fabricated to be essentially identical to truck 2.

Since its introduction into the field, the RMCSS (using truck 2) has been beset by a number of problems that have reduced the system's availability to an unacceptable level. As such, the system and its ability to meet critical milestones has come under intensive review.

It has become critical that the operational availability of the RMCSS be improved to the level that core sampling can be accomplished in accordance with required schedules. As part of an overall effort to improve the performance of the RMCSS, a task team was formed and chartered with the task of recommending achievable improvements to the existing RMCSS. The task team consisted of three engineers from Westinghouse Hanford Company (WHC) and three engineers from Southwest Research Institute (SWRI). Engineering disciplines covered by the team include hydraulics, mechanical, electrical, and instrumentation and controls.

\subsection{OBJECTIVE}

The task team's primary objective was to identify previously undetected problems that could have potentially significant impact on the availability of the RMCSS. Known problems, previously identified, were also reviewed. Problems were to be ranked and prioritized relative to their impact on RMCSS availability, and recommendations made regarding near term corrective actions that should be implemented to eliminate these problems in an affordable and timely manner. The task team's primary focus was on reliability and maintainability of the RMCSS hardware items associated with truck \#2; however, where the need for significant improvements were noted in the area of administrative support, they were also ranked and prioritized with regard to impact on availability. 
WHC-SD-WM-ER-415, Rev. 0

\subsection{SCOPE}

The RMCSS consists of a rotary mode core sample truck, exhauster, diesel generator, service trailer, electrical distribution trailer, (proposed) breathing air compressor, nitrogen purge trailer, support truck, cask truck, and light plant. The team was directed to address operational availability of the RMCSS that is associated with truck \#2. Deficiencies in hardware, controls, software, or operational procedures that may present a significant likelihood of impacting RMCSS availability were to be identified, categorized, and prioritized as to which corrective actions should be implemented first. The team was instructed not to address the sampler or the processes involved with obtaining the samples, as these matters were already being handled by others. Safety aspects of the system have been previously addressed; any recommended changes to the existing system, including procedures, were evaluated with regard to impact on safety.

\subsection{SUMMARY}

The causes of low availability are many, and are primarily because the RMCSS truck 2 is still a prototype. In normal industrial practices such a prototype would undergo a break-in period during which crews become more experienced, protocols are refined and optimized, and design deficiencies are identified and corrected. Following such practice, the availability of the RMCSS would progressively increase with operating time and experience, even without the efforts of the task team. By its independent assessment, the team has identified areas that should be addressed to expedite the improvement in RMCSS availability.

In the process of identifying problems (both known and potential) the team interviewed personnel directly involved with design, testing, training, field operation, and maintenance of the RMCSS, and reviewed RMCSS documentation (e.g., drawings, operating procedures, maintenance procedures, and truck $\log$ books). The team has evaluated these problems and their potential solutions, and have provided recommended corrective actions that will give the greatest near-term payback in system availability improvement, if implemented.

The problem areas that the team recommends be addressed are listed in decreasing order of priority in Table 1-1, and are discussed in the appendices to this report.

The following list summarizes specific problems and tabulates them in the order by which TWRS should resolve them. For details of these problems and their recommended corrective actions see Appendix A. For details of the methodology used in determining their prioritization see Appendix $B$.

Each specific problem has a unique Item Number assigned to it, which directly correlates to the table number and item number of the tables in Appendix $B$. For example: The unique number 3-4, refers to Table 3, Item 4, in Appendix $B$. 
It also refers to Item 3-4 in Appendix $A$. This numbering system is used in Table 1-1, and is common throughout the report.

Table 1-1. Summary of Problems and Corrective Actions.

\begin{tabular}{|c|c|c|}
\hline Item No. & Description & $\begin{array}{l}\text { Impact } \\
\text { value }\end{array}$ \\
\hline $1-5$ & Remote Latch & 3600 \\
\hline $7-2$ & Power Source Unreliable & 3600 \\
\hline $9-2$ & Spare Parts & 3360 \\
\hline $2-3$ & Exhauster & 3150 \\
\hline $10-7$ & Mechanical PMPs Not Available & 2940 \\
\hline $10-5$ & Requirements Complexity & 2550 \\
\hline $5-4$ & Monitor Tank Exhaust Gases & 2400 \\
\hline $9-5$ & In Field Technical Support & 1800 \\
\hline $1-2$ & Exhaust Prefilter & 1560 \\
\hline $10-11$ & Preventive Maintenance Trending & 1470 \\
\hline $1-7$ & Shielded Receiver Position System & 1161 \\
\hline $10-6$ & H2 Monitor Technical Complexity & 1110 \\
\hline $1-1$ & Shielded Receiver Winch & 950 \\
\hline $5-7$ & Emergency Shutdown & 855 \\
\hline $6-3$ & Instrument Rack "Power Up" Cycle & 800 \\
\hline $4-1$ & HydrauTic Hoses Rub/Pinch & 743 \\
\hline $10-2$ & RMCSS Operating Crew Training & 720 \\
\hline $3-2$ & Hydraulic Cylinder Leaks & 570 \\
\hline $4-6$ & Hydraulic Hose Failure & 425 \\
\hline $5-9$ & Exhauster Beta Cam & 408 \\
\hline $5-10$ & DCI Meter Failure & 400 \\
\hline $2-6$ & Truck Engine Failure to Start & 360 \\
\hline $1-4$ & Shielded Receiver and Quill Rod Bent & 276 \\
\hline $3-1$ & Ram Pressure Surge & 240 \\
\hline $4-3$ & Pressure Control & 240 \\
\hline $2-5$ & Sample Latch & 240 \\
\hline $10-9$ & Instrument Self-Check & 216 \\
\hline $5-3$ & Hoffer Calibration & 192 \\
\hline $5-5$ & Purge Gas Transducers & 192 \\
\hline $10-10$ & Calibrated Spares & 192 \\
\hline
\end{tabular}


WHC-SD-WM-ER-415, Rev. 0

Table 1-1. Summary of Problems and Corrective Actions.

\begin{tabular}{|c|c|c|}
\hline Item No. & Description & $\begin{array}{r}\text { Impact } \\
\text { value }\end{array}$ \\
\hline $8-1$ & Electrical Cable Pinch/Rub & 180 \\
\hline $2-2$ & Grapple/Sample Box Moisture & 162 \\
\hline $10-8$ & Pressure Transducer Calibration & 160 \\
\hline $4-4$ & Pump Drive Idle & 144 \\
\hline $2-4$ & Grapple Hoist Bird Nest & 120 \\
\hline $2-1$ & Bellows Assembly & 108 \\
\hline $5-1$ & Nitrogen and Hydraulics Ports & 102 \\
\hline $6-4$ & Mass Flow Calibration Difficult & 96 \\
\hline $3-4$ & Truck Jacks & 96 \\
\hline $3-5$ & Linear Traverse Creep & 54 \\
\hline $9-1$ & Small Components & 16 \\
\hline $6-5$ & Operator Interface & 12 \\
\hline $5-2$ & Instrument Status & 8 \\
\hline $4-5$ & High Residual Pressure & 7 \\
\hline $5-6$ & Cabinet Limited Access & 5 \\
\hline $6-1$ & Electrical Connection Use & 2 \\
\hline $6-2$ & Remote Data Monitor & 2 \\
\hline $1-3$ & Drill Bit Plugging & (note 2) \\
\hline $1-6$ & Gear Reducer Key Shear & (note 3 ) \\
\hline $3-3$ & Turret Control Valve & (note 6) \\
\hline $4-2$ & Redundant Hydraulic Components & (note 7) \\
\hline $5-11$ & Sierra Flow Meters & (note 5) \\
\hline $7-1$ & Generator & (note 4) \\
\hline $10-1$ & Dedicated Test Equipment & (note 9). \\
\hline $10-4$ & Need New Availability Baseline & (note 8$)$ \\
\hline $9-3$ & Purge Gas Blows Sample & (note 2) \\
\hline $5-8$ & Rosemont Calibration Gas & (note 1$)$ \\
\hline $9-4$ & Wind/Rain & (note 2) \\
\hline $10-3$ & Infrastructure Inhibits Upgrades & (note 2) \\
\hline
\end{tabular}


WHC-SD-WM-ER-415, Rev. 0

Table 1-1. Summary of Problems and Corrective Actions.

Notes:

1. Remedial action undertaken as of February 1, 1995

2. Out-of-scope

3. Problem has been corrected

4. Equipment is being repaired

5. Manufacturer is upgrading equipment

6. Corrective action implemented

7. Operations wants to retain feature

8. Required for future assessments

9. Not deemed cost effective

10. Recent information provided to team indicates this problem has been resolved by QC verification check 
WHC-SD-WM-ER-415, Rev. 0

\subsection{PROBLEMS AND RECOMNENDATIONS}

A detailed description of each identified problem likely to impact the availability of the RMCSS for sampling operations is provided in Appendix A. Team recommendations for corrective action(s) to correct these problems are also included, along with a brief discussion of the benefits to be gained by implementing the corrective action. An estimated rough order of magnitude (EROM) of hardware cost and time for implementation is also included where appropriate.

There are several cases in which the corrective action for one identified problem will also resolve other identified problems. Corrective actions of this type should be implemented whenever possible to increase the cost effectiveness of the problem resolution. A Related Issues Index located in the front of Appendix A, identifies all such cases. The team has identified the following two cases to be worthy of TWRS giving a high priority in consideration for implementation:

Case 1: Replacement of the existing hydraulic Vickers "fixed displacement/fixed set pressure" type pump with an electrically controlled "variable displacement/variable set pressure" type pump. This corrective action would resolve most of the hydraulic problems (reference items $3-1,3-2,4-3,4-4$, and 4-5).

Case 2: Installation of $480 \mathrm{vac}$, 3-phase, 200 ampere temporary service to each tank farm (outside the radiologically controlled area where practical) would allow full time operation of the exhauster without shutdown, as experienced by the existing use of a diesel generator. Utilities would provide power to the service trailer as well as other uses such as lighting. The diesel generator would be used only for operation of the breathing air compressor and as a backup power supply. This corrective action, in combination with changes in permitting, would resolve most of the problems encountered by the exhauster (reference items 7-2, 2-3, and 5-10).

\subsection{DISCUSSION}

The recommendations in this report are hardware related as well as administrative or "infrastructure" related. Although the team was requested to focus on reliability improvements to hardware, the work effort was expanded on two fronts. One was to address system maintainability as well as reliability, and the other was to include administrative improvements, as well as hardware improvements, that will increase system availability. The reason for this expanded approach was to identify all known areas of improvement that 
would result in an increase in the time that the RMCSS systems could be used for core sampling. This is the definition of "availability" as used in this report. Availability, as used herein is expressed as follows:

$$
\text { Availability }=\frac{\text { Up Time }}{\text { Total Time }}=\frac{\text { MTBF }}{\text { MTBF }+ \text { MTTR }+ \text { MISC }}
$$

Where: MTBF is mean time between failures

$$
\text { MTTR is mean time to repair, and }
$$

MISC accounts for all remaining time of interest

From the above, availability will be increased if MTBF is increased (reliability improved), MTTR is decreased (maintainability improved), and MISC is decreased. MISC includes activities such as waiting for replacement parts, waiting for paperwork, waiting for support personnel, and waiting for management decisions. The items that need to be considered in making up the three elements shown above are illustrated in Figure 1-1.

In an attempt to quantify the various elements of availability (or nonavailability), the Rotary Truck Core Sampling Operations Logbook \#1 was reviewed for the period October 21, 1994 to January 30, 1995. This is the initial "in the field" period for RMCSS system \#2. The logbook contains sufficient information to conclude that significant availability improvements can be made by addressing all three elements of the availability equation shown above. This information is shown graphically in Appendix $C$. Based on the above, the team chose to address each element of the availability equation in this report.

Based on a review of the Logbook, and in particular, the team's discussions with operators, engineers and maintenance personnel, it became apparent that improving the infrastructure that is needed to support the operation of the RMCSS systems would have a significant positive impact on availability. Improving the infrastructure will have a positive affect on all three elements of the availability equation above. An example is the current progress being made in reducing the time required to prepare and release Job Control System work packages to the field. Infrastructure items of an administrative nature that should be addressed are identified and ranked by priority in Table 1-1 and in Tables 9, 10 and 13 of Appendix B. Future efforts should cont inue to look at areas of hardware as well as infrastructure improvements since opportunities for improving RMCSS availability exist in both areas. 
$\infty$

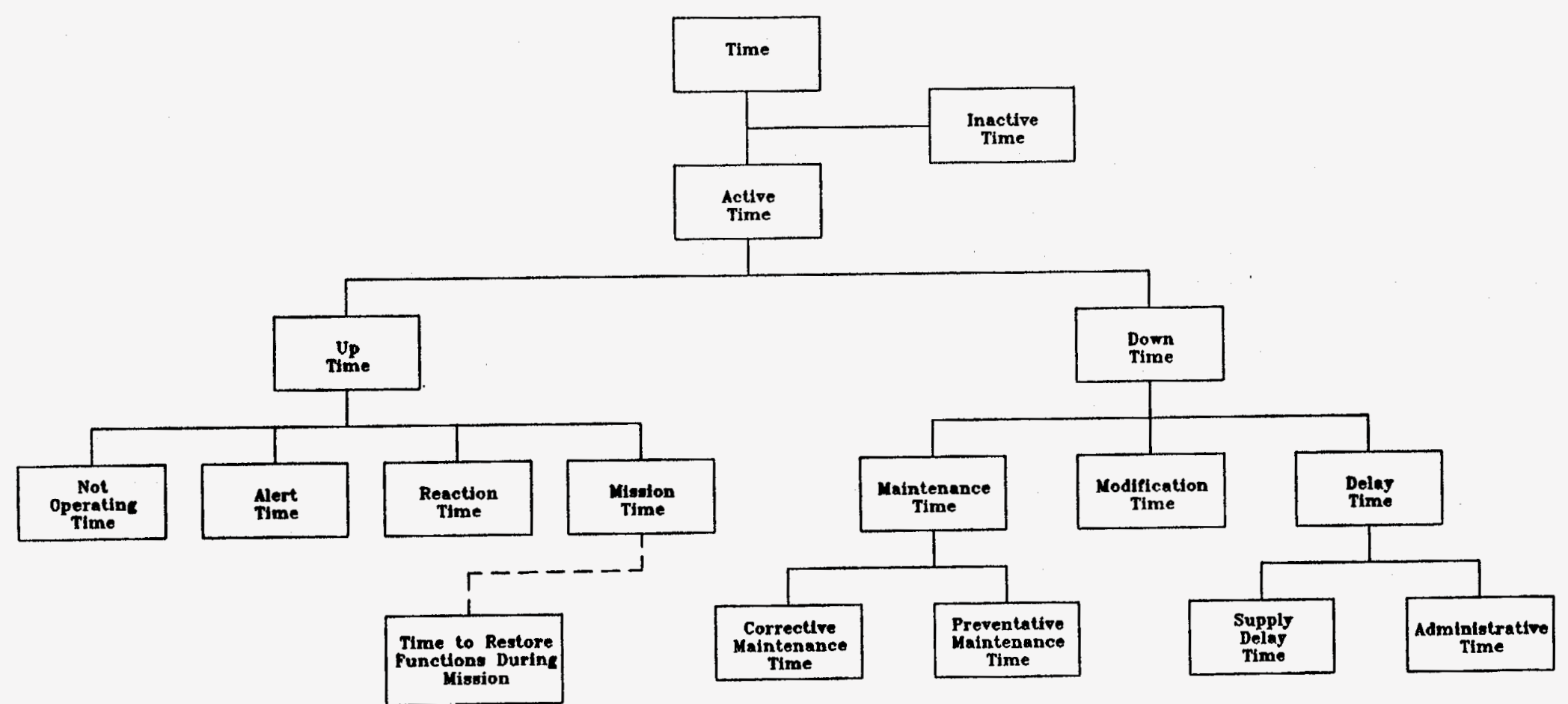

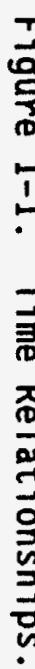

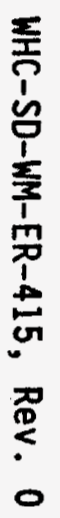


WHC-SD-WM-ER-415, Rev. 0

\subsection{CONCLUSIONS}

It is concluded that significant improvements can be made in the availability of the RMCSS systems associated with RMCSS trucks \#1 through \#4. Furthermore, a number of these improvements can be made with minimum impact to sampling schedules (systems \#1 and \#2) and fabrication schedules (systems \#3 and \#4).

The prioritized list of recommended improvements is shown in Table 1-1 (Section 2.0). Each recommended improvement is discussed in more detail in Appendices $A$ and $B$. These improvements have been prioritized from the standpoint of providing the greatest improvement for the time required to implement. In some cases, the implementation time (impact on sampling and fabrication schedules) is negligible. They include design changes, changes in the methods of system operation, changes to self-imposed and overly restrictive operating requirements and changes to the infrastructure that is relied upon to provide operational support.

In general, the systems reflect a high degree of consideration for the safety of operating personne1. Although the system performance of RMCSS system \#2, since it was sent to the field on October 21, 1994, needs much improvement, there were no areas identified that required a major redesign effort to achieve a reasonable degree of system availability. The availability achieved to date is characteristic of a combination of new, one of a kind equipment, new operators and a cumbersome operational support system. RMCSS system \#2 availability will improve with time without implementing the recommendations herein. Significant near term improvements can be achieved by implementing the recommendations in the order identified in Table 1-1. 
WHC-SD-WM-ER-415, Rev. 0

This page intentionally left blank. 
WHC-SD-WM-ER-415, Rev. 0

APPENDIX A

RECOMMENDED ACTIONS TO IMPROVE AVAILABILITY

OF THE ROTARY MODE CORE SAMPLE SYSTEM 
WHC-SD-WM-ER-415, Rev. 0

This page intentionally left blank.

.

A-2 


\section{APPENDIX A}

\section{RECOMMENDED ACTIONS TO IMPROVE AVAILABILITY OF THE ROTARY MODE CORE SAMPLE SYSTEM}

Each specific problem in this appendix has a unique Item Number assigned to it, which directly correlates to the Table Number and Item Number of the tables in the appendix in which the problem was categorized and prioritized. For example: The unique number 3-4, refers to Table 3, Item 4, in Appendix B. This numbering system is commonly used throughout the report.

There are several cases in which the corrective action for one identified problem will also resolve other identified problems. A "Related Issues Index" located in the front of this appendix identifies al1 such cases.

The contents of this appendix are arranged by table number and item number within each table (i.e. Tables 1 through 10 of Appendix B). 


\section{RELATED ISSUES INDEX for TABLES 1-10}

\section{Item \# Description}

$\begin{array}{ll}\text { 1-1 } & \text { Shielded Receiver Winch } \\ 1-2 & \text { Exhauster prefilter } \\ 1-3 & \text { Drill Bit plug } \\ 1-4 & \text { Shielded Receiver \& } \\ & \text { Quill Rod Bent } \\ 1-5 & \text { Remote Latch } \\ 1-6 & \text { Gear Reducer, turret } \\ 1-7 & \begin{array}{l}\text { Shielded Receiver } \\ \text { position system }\end{array} \\ & \text { Bellows } \\ 2-1 & \text { Condensation } \\ 2-2 & \text { Exhauster } \\ 2-3 & \end{array}$

$\begin{array}{ll}2-4 & \text { Grapple Hoist } \\ 2-5 & \text { Sampler latch } \\ 2-6 & \text { Truck engine }\end{array}$

3-1 Ram pressure surge

$\begin{array}{ll}3-2 & \text { Cylinder/seal leaks } \\ 3-3 & \text { Turret control } \\ 3-4 & \text { Truck jacks } \\ 3-5 & \text { Linear Traverse Creep }\end{array}$

4-1 Hydraulic Hose rub/pinch

4-2 Components redundant

4-3 Pressure Control

4-4 Pump drive engine idle

4-5 High residual pressure

4-6 Hydrautic Hose Failure

5-1 N2 \& Hydrautic ports

5-2 Instrument status

5-3 Hoffer calibration

5-4 Monitor Exhaust gases

5-5 Purge Press. Transducers

5-6 Cabinet access

5-7 Emergency shutdown
Related Item(s)

2-2 (Grapple Hoist)

2-3 (Exhauster)

$\mathrm{n} / \mathrm{a}$

none

none

$\mathrm{n} / \mathrm{a}$

4-6 (Hose Failure)

none

none

1-2 (prefilter), 5-4 (Rosemont),

5-8 (Gas bottles), 5-9 (CAM),

7-2 (utilities), 10-5 (Requirements)

1-1 (Shielded Receiver Wench)

none

10-7 (Mech PMP's), 7-2 (Utilities power)

3-2 (leaks), 4-3 (press surges), 4-4 (Idle speed)

3-1

$\mathrm{n} / \mathrm{a}$

4-5 (residual pressure)

none

4-6 (Shld.Rec.Drop), 8-1 (Cable rub)

$\mathrm{n} / \mathrm{a}$

3-1 (press.surge), 3-2 (leaks),

4-4 (pump)

4-3 (pressure control)

3-4 (Truck jacks), 4-3 (pressure control)

4-1 (Hose rub/pinch), 1-7

(Shielded Rec.)

5-5 (transducer calibration)

5-6 (Cabinet access),

6-2 (remote display)

6-4 (Cal. difficult),

10-10 (Cal.spares)

2-3 (Exhauster), 7-2 (utilities)

5-6 (Cabinet access), 5-2 (status)

5-2 (Instrument status)

none 
Item No. Description

5-8 Exhauster $\mathrm{Cal}$ Gas use

5-9 Exhauster Beta CAM

5-10 DCI meter failures

5-11 Purge gas flow meters

6-1 Electrical Connectors

6-2 Remote monitor/display

6-3 Instrument powerup

6-4 Mass flow Cal difficult

6-5 Operator Interface

7-1 Generator

7-2 Power source unreliable

8-1 Electrical Cable rub/pinch

9-1 Small parts

9-2 Spare parts

9-3 Purge gas blows sample

9-4 wind/rain protection

9-5 In Field Cog Eng

10-1 Dedicated test equip.

10-2 Training of operators

10-3 Infrastructure inhibits upgrades

10-4 New Availability Benchmark

10-5. Requirement Complexity

10-6 Exhauster H2 monitor

10-7 Mechanical PMP's not

10-8 Press.Transducer Calibration

10-9 Pre Ops Instrument checks

10-10 Calibrated spares

10-11 Preventative Maintenance trending.
Related Item(s)

2-3 (Exhauster), 5-4 (Monitor Exhaust)

5-1 (Calibration Ports/Valves)

2-3 (Exhauster)

6-3 (power up), 7-2 (utilities)

$\mathrm{n} / \mathrm{a}$

8-1 (Elect.Cable rub), 4-1 (hose rub)

5-2 (status), 5-6 (access),

5-5 (transducers), 6-4 (mass flow)

5-10 (DCI meters)

5-2 (Hoffer Cal)

5-2 (Instru. status),

6-2 (remote monitor)

$\mathrm{n} / \mathrm{a}$

2-3 (exhauster), 5-10 (DCI meters)

4-1 (hose rub), 6-1 (connectors)

1-5 (remote 1atch),

1-1 (Shielded Receiver Wench

10-7 (Mech.PMP's), 10-10 (Cal.spares)

$n / a$

$n / a$

none

none

none

most al1 items, 10-4 (Benchmark)

most all items

2-3 (Exhauster), 5-4 (Rosemont)

5-9 (CAM), 5-3 (Hoffer)

5-9 (CAM)

2-6 (failure to start),

10-11 (trending) available

9-2 (spares)

5-1 (Cal ports), 5-5 (transducers) none

5-3 (Hoffer ca7), 10-8 (Transducer

Cal.)

10-7 (Preventative Maintenance) 
WHC-SD-WM-ER-415, Rev. 0

\section{RECOMMENDED ACTIONS TO IMPROVE AVAILABILITY \\ OF THE ROTARY MODE CORE SAMPLE SYSTEM}

Item No. $1-1$

Action Title: Shielded Receiver Winch

\subsection{DESCRIPTION OF PROBLEM}

In reviewing the Shielded Receiver Winch; several design aspects were identified that may reduce RMCSS availability. One area has to do with the limitations of the mechanical mechanisms used to spool the cable and the other with the long-term performance of the mechanism lubricants when exposed to the nitrogen environment that exists within the hoist enclosure.

With regard to the first of these problems, the spooling system is not designed to accommodate the angular offsets that occur between the sheave and drum as cable is paid-in and out. As a consequence, the system is inherently prone to "side-tracking", particularly when cable tension is low or the cable becomes slack. A side-track in the cable lay not only increases the potential for the cable to become fouled (by a wrap jumping off the drum), but also affects the ability of the mechanical counter to accurately indicate the relative position of the remote latch unit.

To reduce the tendency for side tracking, the present design does include a slack detection mechanism and a "level-wind" feature. The level-wind design, however, relies on friction between the cable and spooling sheave to produce the lateral offset needed to make the cable lay on the drum in the proper configuration. Again, when cable tension is low or when the frictional properties of the system change (e.g. when the cable is wet or when the lead screw lube gets cold and stiff), it is possible that the cable will not produce sufficient torque to cause the spooling sheave to advance "in sync" with the drum wrap. As a consequence, a "timing" problem develops that increases the potential for cable fouling and/or damage in other parts of the system.

The basic enclosure for the hoist also includes a wiper, through which the cable must past. Should this wiper become fouled with muck or should the "pack-off" pressure be excessive, the drag on the cable can increase to the point that a "pay-out" condition (i.e. spooling cable off the drum) can introduce slack by virtue of the fact that the force induced by wiper friction is higher than the weight of the remote latch unit. Consequently, the cable becomes slack and may loop off the drum. 
Besides the frictional behavior of the wiper unit, it is also possible that any residue removed from the wiper line can accumulate and eventually become deposited on the "crow's foot" that activates the remote latch upper travel limit. While accumulation should not effect spooling, its presence could make repair more difficult and time consuming.

Finally, the drum design does not promote a quick repair or replacement of a cable. The arrangement of the shaft key and conductor feed-thru path to the slip ring assembly are simply too confining for the installation process to occur easily.

\subsection{RECOMMENDED CORRECTIVE ACTION}

Re-design the Shielded Receiver Hoist to improve the cable handling characteristics. Even if the other aspects of the design are not addressed, a re-work of the drum to facilitate installation of a new cable should be completed.

\subsection{JUSTIFICATION/BENEFIT OF CHANGE}

The likelihood of repeated failures (as manifested by a fouled cable) is sufficient to justify the effort. While frequent preventive maintenance measures might reduce the potential of cable fouling, implementation of a procedure could easily. entail as much downtime as a failure, given the inability to easily access the internals of the system.

BENEFIT(s): Re-design of the hoist system will eliminate the potential for re-occurring failures in the sample recovery system and thereby improve system availability.

\subsection{IMPLEMENTATION}

Design, fabrication and testing of a new hoisting system can be accomplished without incumbering the operation of Truck 2 until such time that a complete unit is ready for installation. Furthermore, it should be possible to address and solve all problems without altering the current packaging arrangement.

Thus, the retrofit can be a simple matter of removing the old unit and installing the new unit. Down-time should be limited to no more than a day or two. 


\section{RECOMMENDED ACTIONS TO IMPROVE AVAILABILITY}

OF THE ROTARY MODE CORE SAMPLE SYSTEM

Item No. 1-2

Action Title: Exhauster Pre-Filter

\subsection{DESCRIPTION OF PROBLEM}

Pre-Filter plugging has been a contributor to RMCSS downtime. It is assumed that the plugging was due to moisture condensation or freezing in the filter. The problem occurred during cold weather and although no radiation level problems were found with the pre-filter when it was removed from service, a high pressure drop across the pre-filter had caused Exhauster fan shutdown.

WHC-SD-WM-SARR-031, Rev. 0, assumes use of pre-filter. Permission was obtained to continue sampling activities without the pre-filter by USQ evaluation. This permission is temporary and does not apply to all tanks.

This is only one of several Exhauster availability issues discussed on Recommended Action Sheet 2-3. Please see Sheet 2-3 for more information.

\subsection{RECOMMENDED CORRECTIVE ACTION}

This problem is being worked on a temporary basis by obtaining permission from the TWRS safety program, the Washington State Department of Health, Washington State Department of Ecology, and the Environment Protection Agency to operate the exhauster (at WHC discretion) without an in-riser pre-filter. (Partial resolution Item\#2/Table\#1)

A more permanent resolution to the problem is required. Revisit the reasons the pre-filer was added to the design and verify the assumptions were realistic. Review and update the RMCSS purge gas aerosol study to eliminate over-conservative assumptions that contributed to requirements for a prefilter, and a CAM. (Addition of these components has reduced exhauster availability). (Resolution Item\#2/Table 1). Please see Sheet 2-3 for more information.

\subsection{JUSTIFICATION/BENEFIT OF CHANGE}

Eliminating the requirement for a pre-filter will prevent the cold weather condensation clogging experienced this operating period. The replacement cost for the pre-filter is $\$ 20 \mathrm{~K}$. Removal from the operating requirements removes a single point failure component in the exhauster. The 
WHC-SD-WM-ER-415, Rev. 0

pre-filter could still be used at WHC discretion on those tanks where dust is possible during sampling. This recommendation addresses a permanent solution to the issue.

\subsection{IMPLEMENTATION}

Document changes only. EROM: Requires no RMCSS down time to implement this recommendation. Cost are controlled by administrative issues. 


\section{RECOMMENDED ACTIONS TO IMPROVE AVAILABILITY}

OF THE ROTARY MODE CORE SAMPLE SYSTEM

Item No. $1-4$

Action Title: Damage to Shielded Receiver and Quill Rod by Drill-Rig

\subsection{DESCRIPTION OF PROBLEM}

To perform their intended functions, both the Shielded Receiver and Quill Shaft must be capable of being lowered beneath the horizontal plane of the Drill Table. As a consequence of this requirement, it is possible for the operator to rotate the table with either element extending below the plane of rotation. This aspect, coupled with the presence of stationary structural members supporting the table, the "opposed" location of the receiver and drill head on the table, and the limited visibility produce the potential for bending the receiver tube or the quill shaft during a rotation.

\subsection{RECOMMENDED CORRECTIVE ACTION}

An interlock system should be considered that would prevent table movement when either element is within an interference zone and below the plane of rotation. Such a condition exists, for example, when the shielded receiver is opposite the riser and stowed in its lowest position. In this state, rotation beyond the envelope established by the truck frame rails can result in damage to the tube and supporting hardware. Outside this area(s), however, receiver movement would be unrestricted as required to receive and discharge samplers.

\subsection{JUSTIFICATION/BENEFIT OF CHANGE}

The RMCSS staff is aware of the possible interference and has developed operating protocols to reduce the likelihood of damage. Despite these procedures, however, the potential for damage to critical systems remains particularly when crew experience levels are low, after prolonged shut-downs or standby situations. Reduction and/or elimination of this hazard could prevent an expensive and prolonged shut-down of the RMCSS. 


\subsection{IMPLEMENTATION}

Implementation of this recommended corrective action would require installation of position sensors and associated wiring to interface them with the control system. There should be no changes required to the operating procedure. It is estimated to require approximately $\$ 20 \mathrm{~K}$ to make the fix. Modifications to the equipment could be done at the earliest convenient scheduled maintenance time, thereby not requiring any additional system downtime. 


\section{RECOMMENDED ACTIONS TO IMPROVE AVAILABILITY OF THE ROTARY MODE CORE SAMPLE SYSTEM}

Item No. $1-5$

Action Title: Failure of Remote Latch Mechanism

\subsection{DESCRIPTION OF PROBLEM}

The drive mechanism used in the remote latch unit failed three times during the recent sampling in BY farm and was known to have failed occasionally during prior test periods. While the exact failure mode has not been verified, there are several attributes of the design that suggest plausible failure mechanisms.

First, the travel limits on the latch actuator reside as "hard", mechanical stops which actually cause the drive motor to stall. The stall condition causes a significant increase in motor current, which is then detected with electronics and used to indicate the status of the latch as being either engaged or disengaged (with a sampler). In addition to the high current, the stall also imposes a high rotor torque (as compared to normal run condition) which is multiplied via the gear reduction and finally applied to that portion of the shafting between the motor and the lead screw mechanism. The high torque condition, the load reversals, and load cycle frequency during the retrieval, stowage and sampler installation processes suggest that the failures could be fatigue related.

In addition to the stall situation cited above, the RMCSS remote latch unit operates in a nitrogen environment as created and maintained by the purge gas system. The continuous exposure to nitrogen can have deleterious effects on the performance of lubricants and seal materials - depending upon their composition. If the lead screw lubricant and sleeve 0-Rings were to degrade with exposure to nitrogen, the consequence would be a higher running torque on the shafting. Given the high reduction ratios in the motor unit and the considerable margin in the current sensing system, it is possible that the running stress levels and load reversals quickly exceed the fatigue tolerance of the shafting.

Finally, thermal effects on running clearances and/or induced drift in the motor control circuit cannot be neglected as a causative factor in the failure scenario.

\subsection{RECOMMENDED CORRECTIVE ACTION}

The remote latch unit design should be re-evaluated. It would naturally be desired that the new unit be interchangeable with the existing unit, and can be done when convenient with no impact on sampling time. 


\subsection{JUSTIFICATION/BENEFIT OF CHANGE}

The remote latch unit motor has failed often. In many instances, the total time in service has been well below that experienced with Truck \#1.

\subsection{IMPLEMENTATION}

The hardware costs for a redesigned remote latch unit are TBD, but should be near the cost for an existing unit. Remedial corrective action is being taken as of February 1, 1995. 
WHC-SD-WM-ER-415, Rev. 0

\section{RECOMNENDED ACTIONS TO IMPROVE AVAILABILITY OF THE ROTARY MODE CORE SAMPLE SYSTEM}

Item No. $1-7$

Action Title: Shielded Receiver Positioning System

\subsection{DESCRIPTION OF PROBLEM}

The Shielded Receiver elevation control mechanism is prone to seizure and structural damage. The causes of the problem arise from deficiencies in two areas -

- the hydraulic system used to raise and lower the shield receiver and

- the structural design of the frame work.

With regard to the hydraulic system, the parallel cylinder arrangement is not easily "balanced" to ensure that the cylinders move in unison. Small variations in oil flow split to each cylinder, piston seal performance, or variation in bore diameter can cause one cylinder to move differently than its companion - thereby increasing the potential for misalignment of the crosshead and travel mechanism. Furthermore, the cylinders do not appear to be equipped with "stop tubes", which makes the seals and rod more vulnerable to damage when fully extended.

With regard to the structural system, the arrangement of hardware is such that the distribution of weight is not uniform, which may aggravate the tendency for the cylinders to move out of unison. Furthermore, the design does not have the required rigidity and dimensional uniformity in components to avoid being sensitive to small differences between actuator lengths. As a consequence of creep by an individual actuator, for example, a misalignment can be created that is sufficient to "bind-up" the frame members. This is particularly a problem when the operator wishes to lower the shielded receiver. Under such conditions, the frame is put under a compressive load when the retract side of the cylinders are pressurized. This compressive load tends to cause additional frame distress, which accentuates the binding and may lead to permanent deformation of frame members.

When raising the shielded receiver, the problem is not as pronounced. Even though there may be differences in the instantaneous length of the extending cylinders, the frame is in tension and not subject to buckling. The raise mode, however, does subject the cylinder rods to buckling - particularly as they reach full extension. Here, a small difference in flow split can translate into a significant "cock" of the platform, promoting rod deflection as well as damage to internal and external seals. 
WHC-SD-WM-ER-415, Rev. 0

\subsection{RECOMMENDED CORRECTIVE ACTION}

Consider redesign of the elevation control mechanism used to position the shielded receiver. The scope of the evaluation should include simple ballasting techniques to improve load distribution to the lift cylinders as well as more elaborate approaches involving alternative lifting methods (e.g. electric motors) and structural arrangements.

\subsection{JUSTIFICATION/BENEFIT OF CHANGE}

The potential for major damage to the shielded receiver exists with the current design. Elimination of the binding problem described will improve the general safety of the operation as well as improve the reliability of the system. Smoother operation of the mechanism would instill greater confidence with the operating crew and improved productivity.

\subsection{IMPLEMENTATION}

The new design elevation control mechanism should be fabricated and tested to assure proper operation. Assuming that it is fully interchangeable with the existing mechanism (or nearly so) it can be swapped out with the existing unit during a convenient system downtime. Implementation is estimated to require hardware cost of $\$ 40 \mathrm{~K}$ and 2 weeks for installation. 


\section{RECOMMENDED ACTIONS TO IMPROVE AVAILABILITY OF THE ROTARY MODE CORE SAMPLE SYSTEM}

Item No. $2-1$

Action Title: Spare Drill Assembly Bellows

\subsection{DESCRIPTION OF PROBLEM}

Metal bellows (H-2-89443-2) is part of the bellows assembly located at the top of the drillhead of Trucks 2, 3 and 4 . The bellows must extend and retract to accommodate the 24 inch stroke of the drillhead while withstanding the 90 psig $\mathrm{N}_{2}$ purge pressure applied during rotary sampling operations. There has not yet been any evidence of failure with this bellows, but its design is novel and there is little, or no, experience upon which to judge its reliability. Should it fail, purge gas pressure may be lost, causing equipment shutdown until the bellows can be replaced. Equipment downtime should not pose a problem as long as spare bellows are available. However, the downtime could be as much as eight weeks should the available spares be depleted. There is a total of two spare bellows to sustain the four trucks.

This bellows is unusual in that it operates over a compression/expansion ratio of nearly $4: 1$ and requires guides and supports to prevent squirm of the bellows (because of its long length). Only one vendor fabricates this special bellows, and a minimum of seven weeks is required for the fabrication process. No life cycle tests have ever been performed to verify that they can meet their intended 10K cycle design life, nor have sufficient cycles been accumulated in service up to the present. It is not certain at this time how long one of these bellows may last, and whether sufficient spares are available.

\subsection{RECOMMENDED CORRECTIVE ACTION}

It is recommended that an assessment be made to determine the probability of failure, in order to ascertain the adequacy of available spares on hand. This assessment may best be accomplished by monitoring the cycle life of existing bellows while in service.

\subsection{JUSTIFICATION/BENEFIT OF CHANGE}

As long as truck \#2 is the only unit in operation requiring this bellows, the existing supply of spare bellows should be adequate to assure against extensive downtime due to bellows failure, even without a knowledge of the expected cycle life of the bellows (i.e. the supply of available bellows could last until more spares are procured). However, when trucks \#3 and \#4 
become operational, the quantity of spares becomes questionable. The recommended corrective action would assure against system excessive downtime due to an inadequate quantity of spare bellows.

\subsection{IMPLEMENTATION}

Continue with operation of truck \#2 as is. Tank farm Operations should estimate how many cycles have been accumulated to date on truck \#2 and initiate a means of maintaining an accumulative cycle count of all future bellows cycles (perhaps by installing a simple mechanical counter). This would allow a trending to be established for the bellows life and provide data to determine whether the supply of available spares is adequate when all trucks are in the field. The costs to implement this method of bellows life cycle assessment should be minimal (perhaps $\$ 1 \mathrm{~K}$ ). If it becomes apparent that insufficient bellows cycles will have been accumulated before trucks \#3 and \#4 are operating in the field (and relying on the same spares) it will then be a judgment call as to whether or not to procure additional spares. The more cycle data accumulated, the wiser the judgement call may be made. 
WHC-SD-WM-ER-415, Rev. 0

\section{RECONMENDED ACTIONS TO IMPROVE AVAILABILITY \\ OF THE ROTARY MODE CORE SAMPLE SYSTEM}

Item No. $2-2$

Action Title: Condensation Effects on Sampler Hoist and Grappler Hoist

\subsection{DESCRIPTION OF PROBLEM}

Those hoist electrical components, located external of the hoist box and internal to the weather barrier, are subject to corrosion and freezing due to moisture accumulation. These mechanical and electrical components associated with the sampler hoist are exposed to. large thermal gradients as a consequence of the operating environment and the purge gas flow configuration. These variations not only change the properties of the lubricants and seal materials used, but also promote the formation of moisture (due to condensation) within the confines of the weather box. These factors (i.e. nitrogen exposure, moisture formation and temperature variation) can adversely impact system performance and component reliability. For example, prolonged exposure to moisture can promote corrosion of electrical contacts within limits switches, slip ring assemblies and encoders. Likewise, the presence of moisture during sub-freezing conditions can physically "jam" components - causing failure and/or malfunction.

\subsection{RECOMMENDED CORRECTIVE ACTION}

If warranted, insulate the winch housing and/or redesign the purge gas system routing such that the flow is introduced downstream of enclosure.

\subsection{JUSTIFICATION/BENEFIT OF CHANGE}

Control of enclosure temperatures and/or reduced exposure to nitrogen should reduce condensation and the associated problems of corrosion, freezing of mechanisms as well as reduce performance variations due to changes in the lubricants and seal materials.

\subsection{IMPLEMENTATION}

Approximately $\$ 5 \mathrm{~K}$ for hardware costs and 1 week for modification to existing equipment. 
RECOMMENDED ACTIONS TO IMPROVE AVAILABILITY OF THE ROTARY MODE CORE SAMPLE SYSTEM

Item No. $2-3$

Action Title: Exhauster availability issues

This discussion combines al1 RMCSS Exhauster technical problems from Tables 1 through 8, (1-2, \& 2-3, \& 5-4, \& 5-9).

\subsection{DESCRIPTION OF PROBLEM}

Procedures currently require that the RMCSS Exhauster be operational before the RMCSS can operate in Rotary Mode. The RMCSS \#2 logbooks for the period of Oct 28, 1994 through Feb 1, 1995 show "exhauster down time" of over 25\%. (Previous time periods were mainly devoted to truck acceptance testing and operator training. This period was representative of the active sampling mission experience to date.)

The downtime was largely the result of technical and operational complexity created by the method of implementing requirements springing from regulatory interpretations and regulatory complexity. The basic functions provided to the RMCSS system by the exhauster are: "Maintain tank pressure" (negative with respect to atmospheric), and "Remove particulates" (from exhaust air stream). Interpretations of requirements led to adding the following functions that are of questionable value: "Quantify and Archive Gas Releases" (best available technology), "Quantify and Archive Radiation releases", "Interlock Rotary Mode" (to any alarms generated by exhauster instruments). Additional functions that provide questionable value are currently planned for installation: "Quantify and Archive Hydrogen release levels", "Interlock Drill to Hydrogen Instruments".

Most all of the downtime was symptomatic of three root cause effects. Two practices that resulted in significant downtime problems were: \#1) Use of a single diesel generator as the only power source and \#2) placing the exhauster in standby whenever purge gas was turned off, (24 hour operation was not allowed). An additional problem that significantly contributed to down time of the exhauster was failure to change out gas bottles on the exhaust stack monitor instruments at appropriate times. (Additionally, the gas supply from these bottles does not allow bottle changeout without loss of line pressure.

Whenever AC Power, or Instrument gas supply is 1ost, delay times are encountered in restoring the exhauster to operation. Those delay times were from "freezing of water", failure of components, Calibration and temperature stabilization times. (Attachment - RMCSS Log) 


\subsection{RECOMMENDED CORRECTIVE ACTION}

The following actions have recently been initiated by TWRS Engineering staff to increase exhauster availability. The task team agrees that these actions should be implemented, and will greatly increase availability:

A. Obtain permission from the TWRS Safety Program, the Washington State Department of Health, Washington State Department of Ecology, and the Environment Protection Agency to operate the exhauster continuously 24 hours a day. (Exhauster operation to date has been limited to only those times Rotary Mode was operating). (Partial resolution Item\#3/Table\#2)

B. Obtain permission from groups listed in "A" above, to run (at WHC discretion) without an in-riser pre-filter. (see related items "I" and " $H$ " below). (Partial resolution Item\#2/Table\#1)

C. Place backup instrument gas bottles on a manifold (Rosemont Hydrocarbon Analyzer, zero grade air), so new bottles can be switched in without loosing supply pressure during changeout. (Partial resolution Item\#4/Table\#5).

The task team recommends the following additional steps be taken to reduce complexity and increase the exhauster availability:

D. In addition to the instrument failures that occurred during power-up (0ct 94-Feb 95), several failures have occurred that are freezing temperature related. It is assumed that the existing exhauster heaters and heat-trace could have prevented much of the freeze related delays if a continuous reliable source of power was available.

The team recommends discontinuing use of a Diesel generator as the primary power for the exhauster. The exhauster should be powered from Hanford Electric Power Utilities. The diesel generator should be available for backup power and temporary power. (Partial resolution 2-3, 5-4,5-9, and 1-2)

E. Review the radiation monitoring requirements, and implement any required monitoring with a more reliable and less complicated method. If a "Record Filter" will meet the requirements for the function provided by the AMS-4 Beta CAM, replace the CAM with a "Record Filter". The filters will be sent for analysis to provide a source release value for reports, if that is the driver. HPT's can use portable instruments to perform spot checks when needed, if this unit is removed. (Resolution 5-9).

F. Identify requirements that forced use of Rosemont Hydrocarbon Analyzer. Suggest removal of this instrument if no firm requirements for this complexity can be identified. (Partial resolution Item\#4/Table\#5). 
G. Review all documents related to emission from this exhauster and update them to show a realistic operational duty factor, and list each sampling activity as a "distinct new temporary single emission source". A realistic duty factor should include "down time" for tank to tank equipment moves and maintenance outages. (Assumptions made on operational duty factor of the exhauster, and assumptions treating the exhauster as a "year long single site continuous emission", apparently have forced the installation of several instruments/components in the RMCSS Exhauster that may not be required if the duty factor and temporary location are considered.)

H. Based on the changes in emission assumptions from item "G" above, review the current exhauster implementation of regulatory requirements for the ability to eliminate instruments or reduce required resolution of instruments and still meet the required functions. (Partial resolution Item\#3/Table\#2).

I. Review and update the RMCSS purge gas aerosol study to eliminate over- conservative assumptions that contributed to requirements for a prefilter, and a CAM. (Addition of these components has reduced exhauster availability).

(Partial resolution 5-9 and 1-2).

J. RMCSS is designed to operate in the "Worst Case" condition for all safety and environmental variables found in Hanford waste tanks. Currently all safety and environmental required systems are required to be operational on all tanks for Rotary Mode sampling. The task team suggests that a "Minimum Required Equipment List" be prepared for each tank as part of the work instructions for each specific tank. This "Minimum Required Equipment List" would allow operation to proceed when a component fails in a part of the system that is not on the "Minimum Required Equipment List". (Partial resolution 2-3).

K. Review the current $\mathrm{plans}$ for installing a Safety Class 1 Hydrogen monitor system in the exhauster. Suggest halting all funding on this design and installation, (See justification below).

\subsection{JUSTIFICATION/BENEFIT OF CHANGE}

The following justifications support the corrective actions in Section 2.0

A. During the operating period reviewed, the RMCSS Exhauster often failed to come up after being put on standby or being shutdown. (Attachment - RMCSS Log).

B. Eliminating the requirement for a pre-filter will prevent the cold weather condensation clogging experienced this operating period. The replacement cost for the prefilter is $\$ 20 \mathrm{~K}$. Removes single 
point failure component in the exhauster. The prefilter could still be used at WHC discretion on those tanks where dust is possible during sampling.

C. The Rosemont required a calibration be run on the instrument when running out of fuel source. A constant supply reduces the frequency of calibration delays.

D. During the logbook period Oct 94-Jan 95 the diesel generator shut it's self down at least. 3 times. The Diesel was shut down for maintenance reasons on other occasions. Each time the power was interrupted the exhauster was unavailable from several hours to several days while recalibration of instruments or repairs to exhauster components were made. Operational experience has shown that if power is maintained, the current exhauster configuration will have much greater availability.

E. Removal of this unit resolves Safety Concerns specific to operation of the exhauster on a Hydrogen Watch List Tanks. The Beta CAM probes are considered an ignition source. The AMS-4 Beta CAM has experienced several failures. This particular model is one with little operating experience at Hanford. Information. relayed to the task team indicated that the probes have a history of failure when operated at cold temperatures.

F. See related comments item "A" and " $C$ " above. Most RMCSS Exhauster downtime was due to Rosemont problems, (Attachment - RMCSS Log).

G. Elimination on unneeded technical and operational complexity will increase RMCSS availability.

H. All item except "D" above apply.

I. See item "B" above for temporary solution. This recommendation addresses a permanent solution.

J. Worst Case conditions do not exist on al1 tanks. The appropriate equipment should be use to reduce technical and operational complexity. Failure of an individual device should not stop sampling if it is not required.

K. The planned Hydrogen monitor is needed only for operation on Hydrogen Watch List Tanks. Safety analysis results that have determined that a Safety Class 1 Hydrogen Monitor is required, are driven by the fact that the CAM can't be qualified as intrinsically safe. Removal of the CAM will solve this problem. See item "E" above. All other tanks are still accessible without this complication. 
A11 Hydrogen Watch List Tanks will have a Standard Hydrogen Monitor System installed by May 95. Credit should be taken for knowing the hydrogen levels in the tanks as measured by these devices. A potential problem in assuming that a Safety Class 1 Hydrogen monitor can protect against a "hydrogen gas pocket release" is in implementation. The only intrinsically safe hydrogen monitors currently in use at Hanford are not instantaneous, their outputs exhibit a measurement latency (the output takes one to two minutes to reach $97 \%$ of a impulse increase in hydrogen). These specific monitors were selected because other intrinsically safe hydrogen monitors are not hydrogen specific and respond in unpredictable ways to other gas in the sample stream. The "gas pocket releases" should also take credit for dilution from the 100CFM of nitrogen released at the drill tip by the drill purge system and dilution in the vapor space. 


\subsection{IMPLEMENTATION}

A. To allow 24 hour operation an additional interlock will be placed into the automatic shutdown circuit which will allow an unmanned operation shutdown if any alarm is received. This interlock could be activated by a locking key switch which will have positions for manned and unmanned operation.

EROM Cost: \$5.K, one month for paperwork, one shift to implement (EJ Waldo).

B. EROM: Requires no RMCSS down time or significant added cost to implement this recommendation.

C. Handcart style bottle racks with automatic bottle change over system built directly on to racks. Keep additional bottle rack present at sampling site with more spare bottles. EROM Cost: \$4K. Requires no RMCSS down time to implement this recommendation. Work is underway. (EJ Waldo).

D. Critical loads such as the RMCSS exhauster and the Dril1 truck should be powered from utilities feeds when ever possible.

Hanford Electric utilities engineers were contacted. They say power can be supplied with little effort and time for temporary (90 day) hookups on any tank. 17.8KV distribution lines are near. 200 ampere, 480vac, 3-phase service can provided via transformers as part of the tank preparation work when $480 \mathrm{vac}$ is not already available on the tank. Main fusing and substation relaying is located in permanent locations serving the distribution lines.

The Diesel generator could be used to power temporary use equipment such as the 33KVA breathing air compressor load if capacity at the tank is not adequate to handle the entire RMCSS system load.

EROM: Requires no RMCSS down time or significant added cost to implement this recommendation.

$E, F, H$, and I, Document changes only. EROM: Requires no RMCSS down time to implement this recommendation. Affected devices can be removed during planned outages. Cost are controlled by administrative issues.

J. Incorporate "Minimum Required Equipment List" into sample work plans. EROM: Requires no RMCSS down time or significant added cost to implement this recommendation. 


\section{RECOMMENDED ACTIONS TO IMPROVE AVAILABILITY} OF THE ROTARY MODE CORE SAMPLE SYSTEM

Item No. $2-4$

Action Title: Potential for Cable Fouling on Grapple Hoist

\subsection{DESCRIPTION OF PROBLEM}

The RMCST Grapple Hoist does not have a history of cable fouling. The design, however, could be vulnerable to fouling should sufficient slack develop between the travelling pulley and the cable drum or if the leveler assembly becomes inoperative. Since the grapple hoist is exposed to purge gas flow, causative factors could include the reduced performance of lubricants in rotating components. Furthermore, excessive slack could occur if the load cell used to detect slack during pay-out became inoperative or developed an offset. Either condition could be induced if the load required to shear the pintel pin was abnormally high and produced an "over-range" condition.

\subsection{RECOMMENDED CORRECTIVE ACTION}

The arrangement used to detect a slack cable should be examined for sensitivities that could arise from nitrogen exposure and well as overload of sensing systems during pintel shear. Other factors that may affect development of cable loads should also be taken into consideration (e.g. existing motor current limiters, etc.).

\subsection{JUSTIFICATION/BENEFIT OF CHANGE}

In this instance, the expenditure of a small amount of time to investigate the likelihood of developing a cable tangle would seem well worth the benefits to be gained in having a more reliable system in the field.

\subsection{IMPLEMENTATION}

Consider performing tests on either truck \#3 or \#4 to investigate potential of the grapple hoist to develop a tangle. 


\section{RECOMMENDED ACTIONS TO IMPROVE AVAILABILITY OF THE ROTARY MODE CORE SAMPLE SYSTEN}

Item No. $2-5$

Action Title: Remote Latch Unit Quality and Performance

\subsection{DESCRIPTION OF PROBLEM}

The ability to release and recover a sampler depends upon the dimensional uniformity between the quadra-latch, the core barrel, the Remote Latch Unit (RLU) release plunger and sleeve assembly. Should there be small dimensional variations in component manufacturing and/or assembly that could put the sampler outside the dimensional tolerance envelop of the RLU, then recovery is possible only by pulling the drill string or via the use of a manual retrieval system.

Should drill string withdrawal be the selected as the recovery method, the sampling process will be delayed. Additionally, withdrawal puts the hole in jeopardy - depending upon the waste characteristics and its tendency to "backfill" the hole as the pipe is withdrawn. While manual recovery of a sampler would not require string removal, it could create a multiplicity of safety issues - requiring considerable time and effort to resolve.

\subsection{RECOMMENDED CORRECTIVE ACTION}

Though the possibility may be remote, a plan should be developed to ensure sampler recovery for the core barrel without having to resort to pulling the string or a manual method. As a first step, the plan could involve the analysis of tolerances and the fabrication of a "gauge block" to verify 1 atch uniformity of each empty sampler prior to its release to the field. To provide even greater assurance of recovery, a "special" set of RLU's could be considered, with each unit being configured for a specific situation - above or below the norm.

\subsection{JUSTIFICATION/BENEFIT OF CHANGE}

The likelihood of not being able to recover a sample using the RMCST standard recovery systems and procedures is reduced and/or eliminated.

\subsection{IMPLEMENTATION}

Implementation of this action would not require any system downtime. Hardware costs should not exceed $\$ 15 \mathrm{~K}$. (Recent information indicates that this problem was resolved approximately six months ago) 
WHC-SD-WM-ER-415, Rev. 0

\section{RECOMMENDED ACTIONS TO IMPROVE AVAILABILITY}

OF THE ROTARY MODE CORE SAMPLE SYSTEM

Item No: $2-6$

Action Title: Truck Engine Readiness

\subsection{DESCRIPTION OF PROBLEM}

It was reported that there were occasions when the engine of truck \#2 failed to start, resulting in lost sampling time. The exact cause of the engine difficulties were not documented, but some people have attributed the difficulty to cold weather, and others attribute it to operator unfamiliarity with the truck.

\subsection{RECOMMENDED CORRECTIVE ACTION}

Engines that are not run on a regular basis may exhibit a tenancy to become balky and unreliable, with the problem worse during cold weather. Maintaining the battery at full charge, fresh fuel in the tank, keeping the engine warm with a block heater, regular tune-ups, and occasionally running the engine at fully warmed operating temperatures, are 211 well known techniques for assuring that the vehicle will start when needed. It is recommended that such techniques be implemented for the truck to assure that it is maintained in a state of readiness. This same recommendation also applies to any other engines used in the Rotary Mode Core Sample System (i.e. hydraulic pump engine and generator engine).

If not already available, operating manuals for the truck should be obtained for the benefit of those required to operate the vehicle. This likewise applies to any of the other engines of the RMCSS. Operators should become familiar with these manuals.

\subsection{JUSTIFICATION/BENEFIT OF CHANGE}

Delays due to engines failing to start will be eliminated, thereby minimizing loss of sampling time. (Reference Table 2, item 6)

\subsection{IMPLEMENTATION}

An engine block heater can be obtained at any automotive supply dealer and installed at small cost. A battery charger is also a small cost item and can be easily installed under the hood. When not in use, an extension cord can be connected to the truck to keep the engine warm and the battery charged. 
The cost associated with establishing a minimal routine maintenance for the engines would be slight and could be performed during scheduled downtime for the truck.

Manuals can be obtained from the manufacturers of the truck and other engines for a small fee. 


\section{RECOMMENDED ACTIONS TO IMPROVE AVAILABILITY OF THE ROTARY MODE CORE SAMPLE SYSTEM}

Item No. $3-1$

Action Title: Pressure Surge through 4-Way Hydraulic Control Valves

\subsection{DESCRIPTION OF PROBLEM}

Every time the 4-Way valve for the drill string ram is operated from the HEAD to either the LOWER or the RAISE position, the pressure surges past the pressure regulators (H-2-89442-21) causing a 350 psi to 800 psi pressure spike. This pressure spike exceeds the $230 \mathrm{psi}$ settings of the pressure regulators by $120 \mathrm{psi}$ to $570 \mathrm{psi}$. Although the 4-way valve is actuated manually; the valve automatically snaps open with but a small movement of the valve actuator by the operator, i.e., the operator has no control as to the opening speed of the valve.

Furthermore, the pressure relief provisions of the pressure regulators is so slow that the attained 350 psi to 800 psi pressure reduces at too slow a rate. Pressure spikes of this extent uncalibrates the pressure transducers and gauges and can render them permanently useless. Such pressure spiking will produce similar results with the manual pressure gauges.

This condition is further worsened if the operator has to cycle the 4-way valve from LOWER (or RAISE) to HEAD and back again because the system will again produce a pressure spike of about $100 \mathrm{psi}$ above that of the first pressure spike. Thus for this case, the RAM pressure could rise to $450 \mathrm{psi}$ to 900 psi depending on the extent of pressure attained during the first spike.

\subsection{RECOMMENDED CORRECTIVE ACTION}

\section{Solution 1: (preferred)}

Replace Pump with Electronically Controlled Pump. Problems identified as 3-1, 4-3, and 4-4 that are caused by pressure fluctuations and pressure spikes can be totally resolved by replacement of the Vickers "fixed displacement/fixed set pressure" type pump with one that is an electronically controlled (4 to $20 \mathrm{ma}$ ) "variable displacement/variable set pressure" type pump. This replacement of the pump involves no more of a modification than the addition of electrical wiring and a minimal amount of solid state electronics. All the new functional operations of the new pump will not require the operator to do any more than is currently required by the Tank Farm Work Procedure (WTWP-9457) and no revision to this procedure would be required.

Hydraulic pressure spikes (Problems 3-1 and 4-3) caused by fast operating valves would be totally eliminated by this modification because the pump would 
not stroke up to its set pressure until a specific control valve is actuated open. The electronics control system would ramp the pumping pressure at a rate sufficient to negate any possibility for pressure spikes to occur. Each control valve used to activate any one of the primary functions of the hydraulics system ( $p l a t f o r m$ traverse, platform rotation, shield receiver control, sampler ram cylinders, platform skew movement, and sampler chuck) would activate the pump into a pre-programmed performance state as described above.

\section{Solution 2: (alternative)}

Incorporate inline shock and pulsation suppressors. Inline shock and pulsation suppressors could be placed at various places within the hydraulics system piping to minimize the pressure spikes and pulsations. A comprehensive analysis would have to be conducted to size each of the suppression devices and to establish the most reasonable locations for their placement. This type of modification would substantially negate the problems cited under Items $3-1$, 4-3, and 4-4.

\subsection{JUSTIFICATION/BENEFIT OF CHANGE}

Implementation of Solution 1 will eliminate damage and loss of calibration of hydraulic pressure transducers and pressure gages, and damage to seals within valves and cylinders caused by the undue loads of pressure spikes (Reference problems 3-1 and 4-3). In addition, this change will eliminate the deleterious effects of pump instability and pressure pulsations the occurs when operators idle the pump engine (Reference problem 4-4).

Implementation of Solution 2 is an alternative to Solution 1 , and will likewise substantially negate the adverse effects of pressure spikes and pulsations. Solution 1 is favored because of its certainty for success, whereas some risk is involved with solution 2 .

\subsection{IMPLEMENTATION}

The estimated time for incorporating either Solution 1 or Solution 2 is approximately 3 weeks. The estimated cost for modifications is approximately \$95K for Solution 1 and \$120K for Solution 2 . 


\section{RECOMMENDED ACTIONS TO IMPROVE AVAILABILITY \\ OF THE ROTARY MODE CORE SAMPLE SYSTEM}

Item No. $3-2$

Action Title: Hydraulic Cylinder Leakage

\subsection{DESCRIPTION OF PROBLEM}

Hydraulic cylinders for the drill rig traverse function and the shielded receiver require periodic replacement due to leakage. These cylinders are left loaded at high pressure when not operated. Additionally, they are subject to high pressure loadings due to thermal expansion of the hydraulic oil.

More specifically, the two hydraulic cylinders for the shielded receiver are currently leaking externally and several attempts to replace them have failed because of fit-up problems. Thus far, the leakage from these two cylinders is sufficiently slow to enable their continued use. A possible problem imposed by leakage from these cylinders is discussed under Item 7 of Table 1.

One of the hydraulic cylinders used for drill rig traverse has been replaced because of extensive leakage. Although it is not conclusive as to the quantity of oil leakage from this source, a considerable amount of oil was observed under the truck and two gallons of 0 il had to be added to the hydraulic reservoir.

\subsection{RECOMMENDED CORRECTIVE ACTION}

\section{Solution 1: (Preferred)}

Replace the Vickers "fixed displacement/fixed set pressure" type pump with one that is an electronically controlled (4 to $20 \mathrm{ma}$ ) "variable displacement/variable set pressure" type pump and change mode of shutdown operation. This replacement of the pump involves no more of a modification than the addition of electrical wiring and a minimal amount of solid state electronics. All the new functional operations of the new pump will not require the operator to do any more than is currentiy required by the Tank Form Work Procedure (WTWP-94-57) and no revision to this procedure would be required. Change mode of shutdown operation such that during each time the hydraulics system is shut down, the electronically controlled pump is slowly controlled such that its output pressure being sensed by pilot operated check valves will lower the residual pressures within the sampler chuck and the linear transverse cylinders to that of the set-point pressure for check valve closure. Once this is accomplished, the primary control valve for that particular function (Sampler Chuck and Platform Traverse) should be closed. 
This same procedure applies to the platform rotation and the slew functional segments of the system. However, since piloted check valves do not exist within these segments, the procedure would not require that the pump be slowly destroked. A complete shut-off of the pump before closing the primary control valves for these functional segments would result in residual gage pressures of near zero. It should be noted that incorporation of this pump change would not be necessary to achieve the zero gage residual pressures for these two functional segments. Even after shutting down the entire hydraulics, these two functional segments can be pressure relieved by actuating their respective control valve to its open position.

\section{Solution 2: (alternative)}

Incorporate gas/bladder type accumulators. Pressure in excess of the high residual pressures entrapped throughout the hydraulics system occur due to thermal expansion of the oil that occurs as the ambient temperature increases. The incorporation of an gas type accumulator in each part of the hydraulics system that retains high residual hydraulic pressures after system shutdown will alleviate excessive pressure increase due to thermal expansion.

\section{Solution 3: (alternative)}

Install cylinders of increased capability. Cylinders with multiple seal provisions and higher operational pressure capabilities would enhance the fatigue life of the cylinders and substantially reduce seal leakage, both internal and external.

\subsection{JUSTIFICATION/BENEFIT OF CHANGE}

Each of the above three solutions will minimize the type of hydraulic cylinder leakage as have been previously reported. Solution 1 (preferred) will also correct those problems caused by pressure spikes (Reference problems 3-1, 4-3, and 4-4) as well as eliminating problems caused by trapping high residual hydraulic pressures in cylinders (Reference problem 4-5).

\subsection{IMPLEMENTATION}

Solutions 1 or 3 would require approximately 3 weeks downtime to implement. Solution 2 would require more than a month. 


\section{RECOMMENDED ACTIONS TO IMPROVE AVAILABILITY \\ OF THE ROTARY MODE CORE SAMPLE SYSTEM}

Item No. 3-4

Action Title: Truck Jack Failure

\subsection{DESCRIPTION OF PROBLEM}

Truck 2 was placed on its hydraulic jacks in February (cold day) and left in their pinned and pressurized condition unti1 March 1994 (warm day) at which time one of the leveling jacks failed (seal failure). Seal failure probably occurred due to excess pressure caused by thermal expansion of the hydraulic oil (the failed jack was located on the sunny side of the truck).

\subsection{RECOMMENDED CORRECTIVE ACTION}

Incorporate gas/bladder type accumulators. Pressure in excess of the high residual pressures entrapped throughout the hydraulics system occur due to thermal expansion of the oil that occurs as the ambient temperature increases.

\subsection{JUSTIFICATION/BENEFIT OF CHANGE}

The incorporation of a gas type accumulator in each part of the hydraulics system that retains high residual hydraulic pressures after system shutdown will alleviate excessive pressure increase due to thermal expansion.

\subsection{IMPLEMENTATION}

The implementation of this action should cost approximately $\$ 10 \mathrm{~K}$ and can be accomplished without additional downtime. 


\section{RECOMMENDED ACTIONS TO IMPROVE AVAILABILITY \\ OF THE ROTARY MODE CORE SAMPLE SYSTEM}

Item No. $3-5$

Action Title: Drill-Rig Transversal Creep

\subsection{DESCRIPTION OF PROBLEM}

When in a non-operating mode, the drill-rig will slowly creep in a direction depending on which direction the truck is off-level from a horizontal position. Apparently, the 3-way valve (SOV 3) leaks oil internally as the offlevel gravity load of the platform acts on the hydraulic cylinders.

\subsection{RECOMMENDED CORRECTIVE ACTION}

Incorporate mechanical stop. Linear creeping of the drill-rig only causes a problem when the truck is not operated for long periods of time. One solution to this problem is to incorporate a mechanical stop (such as a structural pin engagement device) to restrain the drill-rig from moving. This device should not be used unless it is known that the truck will not be operated for weeks at a time. This type of drill-rig restraint should be of a break away type so as not to cause damage to the truck in the event the drill-rig is operationally translated with the mechanical stop engaged.

\subsection{JUSTIFICATION/BENEFIT OF CHANGE}

Maintains truck drill-rig in-place to minimize chance of equipment damage during reapplication of hydraulic pressures.

\subsection{IMPLEMENTATION}

Costs and downtime to incorporate this action are minimal. 


\section{RECOMMENDED ACTIONS TO IMPROVE AVAILABILITY \\ OF THE ROTARY MODE CORE SAMPLE SYSTEM}

Item No. 4-1

Action Title: Rubbing and Pinching of Hydraulic Hoses

\subsection{DESCRIPTION OF PROBLEM}

Based on the susceptibility of hoses to flex about and come in contact with structural members of the hydraulics system, they may become "pinched", "crimped", and "frayed" to the point of failure. One hose is known to have already been replaced on the sampler shielded receiver because of leakage. This problem is further discussed under 7 of Table 1.

\subsection{RECOMMENDED CORRECTIVE ACTION}

Implement engineering inspection \& modification. A physical inspection of all the hydraulic hoses on truck No. 2 should reveal whether or not any corrective actions should be taken to circumvent hose failures. The inspection, to be conducted by experienced hydraulics engineers, should include the witnessing of the truck in all modes of its operation. Protective guards, better quality, increased strength, and better routing are the primary design features to be assessed and implemented.

\subsection{JUSTIFICATION/BENEFIT OF CHANGE}

Provides assurance that there is little likelihood of hydraulic hose failure. Such inspection and modification would also prevent the problem of the shielded receiver dropping should a hydraulic hose rupture (Reference 4-6).

\subsection{IMPLEMENTATION}

Implementation costs would be determined by the extend of the modification (e.g. hose replacements, etc.) but would probably be less than $\$ 5 \mathrm{~K}$. The time for implementation would probably be less than 1 week, with no additional downtime if done during scheduled maintenance. Related issue 8-1, electrical cable routing, should be worked with this issue. 
WHC-SD-WM-ER-415, Rev. 0

RECOMMENDED ACTIONS TO IMPROVE AVAILABILITY

OF THE ROTARY MODE CORE SAMPLE SYSTEM

Item No. 4-3

Action Title: Hydraulic Pressure Control

\subsection{DESCRIPTION OF PROBLEM}

Pressure spikes that occur throughout the hydraulic system will be the cause of premature failure of components such as pressure transducers, pressure gauges, and pressure regulators, and seals within valves and cylinders. Seal leakage and pressure transducer failures that have occurred can be attributed to excessive pressure excursions. These problems can occur whether pump is idling or at full rpm.

\subsection{RECOMMENDED CORRECTIVE ACTION}

Replace pump with electronically controlled pump. Problems that are caused by pressure fluctuations and pressure spikes can be totally resolved by replacement of the Vickers "fixed displacement/fixed set pressure" type pump with one that is an electronically controlled (4 to $20 \mathrm{ma}$ ) "variable displacement/variable set pressure" type pump. This replacement of the pump involves no more of a modification than the addition of electrical wiring and a minimal amount of solid state electronics. All the new functional operations of the new pump will not require the operator to do any more than is currently required by the Tank Form Work Procedure (WTWP-94-57) and no revision to this procedure would be required.

Hydraulic pressure spikes caused by fast operating valves would be totally eliminated by this modification because the pump would not stroke up to its set pressure until a specific control valve is actuated open. The electronics control system would ramp the pumping pressure at a rate sufficient to negate any possibility for pressure spikes to occur. Each control valve used to activate any one of the primary functions of the hydraulics system ( $p$ latform traverse, platform rotation, shield receiver control, sampler ram cylinders, platform skew movement, and sampler chuck) would activate the pump into a preprogrammed performance state as described above.

\subsection{JUSTIFICATION/BENEFIT OF CHANGE}

Transducer over-pressurization, cylinder seal damage, etc. or other problems that are caused by pressure fluctuations and pressure spikes can be totally resolved by implementation of this corrective action (Reference problems 3-1, 4-3, and 4-4). 
WHC-SD-WM-ER-415, Rev. 0

\subsection{IMPLEMENTATION}

The time to effect implementation of this corrective action is approximately 3 weeks, at an estimated cost of $\$ 95 \mathrm{~K}$. 
WHC-SD-WM-ER-415, Rev. 0

\section{RECOMMENDED ACTIONS TO IMPROVE. AVAILABILITY \\ OF THE ROTARY MODE CORE SAMPLE SYSTEM}

Item No. $4-4$

Action Title: Main Pump Drive Engine Idle

\subsection{DESCRIPTION OF PROBLEM}

The Vickers hydraulic pump is supposed to operate at about $1200 \mathrm{rpm}$. However, due to noise, Operators idle the engine at about $650 \mathrm{rpm}$ for long periods of time. This low speed condition causes the pump to produce pressure

fluctuations that cause pressure gauges to fluctuate approximately \pm 10 psi. These pulsations are detrimental to the 1 ife expectancy of the transducers, the pressure gauges, and the seal integrity of the entire hydraulics system. This continuous pulsation process will certainly cause the transducers and pressure gauges to loose their reference state of calibration much sooner than currently realized on hydraulics systems devoid of such pulsations.

\subsection{RECOMMENDED CORRECTIVE ACTION}

\section{Solution 1: (preferred)}

Replace pump with electronically controlled pump. Problems that are caused by pressure fluctuations and pressure spikes can be totally resolved by replacement of the Vickers "fixed displacement/fixed set pressure" type pump with one that is an electronically controlled (4 to $20 \mathrm{ma}$ ) "variable displacement/variable set pressure" type pump. This replacement of the pump involves no more of a modification than the addition of electrical wiring and a minimal amount of solid state electronics. All the new functional operations of the new pump will not require the operator to do any more than is currently required by the Tank Form Work Procedure (WTWP-94-57) and no revision to this procedure would be required.

Hydraulic pressure pulsations caused when the gasoline engine drive for the pump is operated in an idle mode $(650 \mathrm{rpm}$ instead of the pump design speed of $1200 \mathrm{rpm}$ ) would be totally eliminated by this modification because anytime the pump operates at a speed below its design operating speed; its controls will automatically destroke the pump such that it will not produce pressure or flow.

\section{Solution 2: (alternative)}

Incorporate inline shock and pulsation suppressors Inl ine shock and pulsation suppressors could be placed at various places within the hydraulics system piping to minimize the pressure spikes and pulsations. A comprehensive 
analysis would have to be conducted to size each of the suppression devices and to establish the most reasonable locations for their placement. This type of modification would substantially negate the problem cited.

\section{Solution 3: (alternative)}

Eliminate the engine idle mode. Another solution for eliminating (or minimizing) pressure pulsations is to require that the engine drive for the pump never be operated at an idle mode and that the speed always be either zero rpm or $1200 \mathrm{rpm}$. This measure would solve problem the problem of pressure spikes caused by the idling mode, but would not solve the problem of pressure spikes due to other causes.

\subsection{JUSTIFICATION/BENEFIT OF CHANGE}

Problems caused by hydraulic pressure spikes due to engine idling would be eliminated by the corrective action identified as solution 1, and would also eliminate those problems caused by other sources of hydrautic pressure spikes (Reference problems 3-1, 3-2 and 4-3) and in addition would resolve high residual pressure problems (Reference problem 4-5). Solution 1 is preferred over the other solutions.

The corrective action identified as solution 2 would also substantially negate the same pressure problems cited, but does not resolve the high residual pressure problem as does solution 1 (Reference problem 4-5).

The corrective action identified as solution 3 would solve the cited problem, but would not solve the problems associated with other sources of hydraulic pressure spikes nor the high residual pressure problem (Reference problems $3-1,3-2,4-3$ and $4-5$ ).

\subsection{IMPLEMENTATION}

The cost associated with solution 1 is approximately $\$ 95 \mathrm{~K}$ and 3 weeks for implementation.

The cost for solution 2 is approximately $\$ 120 \mathrm{~K}$ and 1 shift for implementation. There is no cost nor time to implement solution 3 . 
WHC-SD-WM-ER-415, Rev. 0

\section{RECOMMENDED ACTIONS TO IMPROVE AVAILABILITY OF THE ROTARY MODE CORE SAMPLE SYSTEM}

Item No. 4-5

Action Title: High Residual Hydraulic Pressures

\subsection{DESCRIPTION OF PROBLEM}

Upon shutdown of the hydraulic system, many regions of the hydraulics network are left highly pressurized. The shielded receiver actuators, the hydraulic chuck, the rotating platform motor, the linear traverse actuators, the skew actuator, and the truck hydraulic jacks are not relieved of pressure when the system is shut down. Ambient temperature excursions from day to night and from day to day will further load the structures and seals. A hydraulic jack for the truck has already experience failure believed to be caused by thermal expansion of the hydraulic oil.

\subsection{RECOMMENDED CORRECTIVE ACTION}

\section{Solution 1: (preferred)}

Replace the Vickers "fixed displacement/fixed set pressure" type pump with one that is an electronically controlled (4 to $20 \mathrm{ma}$ ) "variable displacement/variable set pressure" type pump. This replacement of the pump involves no more of a modification than the addition of electrical wiring and a minimal amount of solid state electronics. All the new functional operations of the new pump will not require the operator to do any more than is currently required by the Tank Form Work Procedure (WTWP-94-57) and no revision to this procedure would be required. If, during each time the hydraulics system is shut down, the electronically controlled pump is slowly controlled such that its output pressure being sensed by pilot operated check valves will lower the residual pressures within the sampler chuck and the linear transverse cylinders to that of the set-point pressure for check valve closure. Once this is accomplished, the primary control valve for that particular function (Sampler Chuck and Platform Traverse) should be closed.

This same procedure applies to the platform rotation and the slew functional segments of the system. However, since piloted check valves do not exist within these segments, the procedure would not require that the pump be slowly destroked. A complete shut-off of the pump before closing the primary control valves for these functional segments would result in residual gage pressures of near zero. It should be noted that incorporation of this solution would not be necessary to achieve the zero gage residual pressures for these two functional segments. Even after shutting down the entire hydraulics, these two functional segments can be pressure relieved by actuating their respective control valve to its open position. 


\section{Solution 2: (alternative)}

Incorporate gas/bladder type accumulators. Pressure in excess of the high residual pressures entrapped throughout the hydraulics system occur due to thermal expansion of the $0 i 1$ that occurs as the ambient temperature increases. The incorporation of an gas type accumulator in each part of the hydraulics system that retains high residual hydraulic pressures after system shutdown will alleviate excessive pressure increase due to thermal expansion.

Solution 3: (alternative)

Install cylinders of increased capability. Cylinders with multiple seal provisions and higher operational pressure capabilities would enhance the fatigue life of the cylinders and substantially reduce seal leakage, both internal and external.

\subsection{JUSTIFICATION/BENEFIT OF CHANGE}

All three solutions will resolve the cited problem, however solution 1 will also resolve other problems caused by high spikes of hydraulic pressure (Reference problems $3-1,3-2,4-3,4-3$, and 4-4).

\subsection{IMPLEMENTATION}

Solutions 1 or 3 would require approximately 3 weeks downtime to implement. Solution 2 would require more than a month. 


\section{RECOMMENDED ACTIONS TO IMPROVE AVAILABILITY OF THE ROTARY MODE CORE SAMPLE SYSTEM}

Item No. $4-6$

Action Title: Hydraulic Hose Failure May Cause Shielded Receiver to Drop

\subsection{DESCRIPTION OF PROBLEM}

The relatively heavy shielded receiver when in its elevated position, is susceptible to accidentally dropping at a rate depending on leakage rate through the single hydraulic hose leading to the lift side of the hydraulic cylinders. The leakage could be due to internal leakage through valves or due to external leakage through the hose. A further discussion of the consequence of this problem is included under item 7 of Table 1 .

\subsection{RECOMMENDED CORRECTIVE ACTION}

Engineering inspection \& modification. A physical inspection of all the hydraulic hoses on truck No. 2 should reveal whether or not any corrective actions should be taken to circumvent hose failures. The inspection, to be conducted by experienced hydraulics engineers, should include the witnessing of the truck in all modes of its operation. Protective guards, better quality, increased strength, and better routing are the primary design features to be assessed and implemented.

\subsection{JUSTIFICATION/BENEFIT OF CHANGE}

Provides assurance that there is little likelihood of hydraulic hose failure causing shielded receiver to drop. Such inspection and modification would also prevent the problems caused by other hydraulic hose ruptures (Reference problem 4-1).

\subsection{IMPLEMENTATION}

Implementation costs would probably be less than $\$ 5 \mathrm{~K}$. The time for implementation would probably be less than 1 shift, with no additional downtime if done during scheduled maintenance. 
WHC-SD-WM-ER-415, Rev. 0

RECOMMENDED ACTIONS TO IMPROVE AVAILABILITY

OF THE ROTARY MODE CORE SAMPLE SYSTEM

Item No.

Action Title: Nitrogen and Hydraulic Transducers

\subsection{DESCRIPTION OF PROBLEM}

The Nitrogen and Hydraulic pressure transducers are difficult to calibrate. There are access problems and no instrumentation ports are available for calibration. Calibration ports and the appropriate isolation valves should have been included on the original design. Lack of calibration ports and valves, is one more area where taking a prototype design and duplicating it has caused maintenance problems.

\subsection{RECOMMENDED CORRECTIVE ACTION}

Review all transducer plumbing and access constraints for ease and appropriateness of adding isolation valves and calibration ports so that insitu calibrations and operational verification checks can be made without removing transducers from the plumbing when beneficial.

The team recommends installation of maintenance valves and ports for 8 transducers and 2 gages.

This concept should be incorporated on Trucks \#3 and \#4 during design and fabrication also.

\subsection{JUSTIFICATION/BENEFIT OF CHANGE}

This capability provides troubleshooting and calibration options that currently. do not exist.

Insitu calibrations and operational verification checks can be made without removing eight transducers and 2 gages from the plumbing reducing maintenance time and cost. Easy to verify calibration status of suspect transducers without removing them during trouble shooting.

Addition of these test ports and isolation valves will allow "end to end" calibration and interlock checks. A pressure standard can be applied to the sensor and the interlocks and process parameter values verified. 


$$
\text { WHC-SD-WM-ER-415, Rev. } 0
$$

\subsection{IMPLEMENTATION}

EROM Cost: \$1OK, Installation during maintenance outage, no impact of drilling.

Certain instruments on the RMCSS require calibration every six months. According to entries in the PIC log, that calibration period began $12 / 29 / 94$ and ended 1/17/95. Several factors caused the calibrations to take that long. One of the factors was the weather. Planning for future calibration intervals should avoid the periods of freezing temperatures and near freezing rain conditions, or the truck should be parked in a heated space during the calibration work. 


\section{RECONMENDED ACTIONS TO IMPROVE AVAILABILITY \\ OF THE ROTARY MODE CORE SAMPLE SYSTEM}

Item No. $5-2$

Action Title: Instruments - Status

\subsection{DESCRIPTION OF PROBLEM}

Maintenance personnel do not have easily read source of data for efficient troubleshooting. Interviews with designers of the system point out that the design was for prototype testing purposes only. Funding for the truck design was interrupted causing lack of continuity on the design team. A redesign of the prototype was planned to correct known problems and add diagnostic information display. Decisions use the truck \#2 layout as is and to duplicate that prototype layout and component selection on truck \#3 and \#4 without any redesign, perpetuate this problem.

\subsection{RECOMMENDED CORRECTIVE ACTION}

At this time the options seem somewhat limited. There is not time for a redesign or for taking the truck out of service for any extended time period. The current TWRS sampling plans show no need for the RMCSS after 1997. The current configuration should be maintainable for that three year life span.

Review of requirements for some devices may allow some changes that will provide better access to diagnostic data. See Recommended Action Sheets 6-4 and 5-5.

Fabrication status of Truck \#3 and \#4 should be reviewed for possible incorporation of this concept during fabrication.

\subsection{JUSTIFICATION/BENEFIT OF CHANGE}

Increased availability of RMCSS parameter to operations and maintenance personnel.

\subsection{IMPLEMENTATION}

EROM cost $\$ 200 \mathrm{~K}$ design and materials, 6 month design, one month install and acceptance test. Using an hardened programmable logic controller with Analog I/0, communications ports, and math functions. 
WHC-SD-WM-ER-415, Rev. 0

\section{RECOMMENDED ACTIONS TO IMPROVE AVAILABILITY}

OF THE ROTARY MODE CORE SAMPLE SYSTEM

Item No. $5-3$

Action Title: Hoffer Calibration

\subsection{DESCRIPTION OF PROBLEM}

Hoffer mass flow devices on the Purge gas system are on a twice annual calibration cycle. Past calibration of the Hoffer mass flow devices have required several days to complete. During the process the truck is without one or more of the mass flow monitors(See PIC log, Jan3-17).

\subsection{RECOMMENDED CORRECTIVE ACTION}

Recent information provided to this team attributes the long calibration time in January to new calibration procedures, and training of crafts on the units. The $\mathrm{Cog}$. Eng. estimates future calibrations will take only about 2 hours per unit. Based on that information it may be acceptable to continue "as is". If future reviews indicate problems with Hoffer reliability and calibration delays the following suggestion may be applicable:

a) See Item 6-3 for preferred resolution of Hoffer calibration issues.

b) If recommendation on 6-3 can not be implemented, pre-calibrate spare Hoffer units for quick replacement of those in service on the truck. This pre-calibration method should minimize truck downtime. (Resolves 5-3).

\subsection{JUSTIFICATION/BENEFIT OF CHANGE}

Any method that can reduce sample truck availability needs to be considered. Because Hoffer calibration is required twice annually, and has taken several days to complete calibration of all three units (See PIC log, Jan 3-17), this method should reduce truck downtime.

\subsection{IMPLEMENTATION}

This is a maintenance planning issue only. Reduces RMCSS down time. No additional cost to implement this recommendation if spares are available. If the truck mounted units are replaced by a spare, changes will be required to the calibration documents. This documentation system needs reviewed to identify methods that will allow easy changeout with an identical spare. 
These mass flow instruments require calibration every six months. According to entries in the PIC log, that calibration period began 1/3/94 and ended 1/17/95. Several factors caused the calibrations to take that long. One of the factors was the weather. Planning for future calibration intervals should avoid the periods of freezing temperatures and near freezing rain conditions, or the truck should be parked in a heated space during the calibration work. 
WHC-SD-WM-ER-415, Rev. 0

RECOMMENDED ACTIONS TO IMPROVE AVAILABILITY

OF THE ROTARY MODE CORE SAMPLE SYSTEM

Item No.

Action Title: Monitor Tank Exhaust Gases

\subsection{DESCRIPTION OF PROBLEM}

The Rosemont analyzer has contributed to significant delays in RMCSS delays. Procedures currently require that the RMCSS Exhauster be operational before the RMCSS can operate in Rotary Mode. The RMCSS \#2 logbooks for the period of 0ct 28, 1994 through Feb 1, 1995 show "exhauster down time" of over 25\%. The root cause of Exhauster down time was frequent loss of electrical power and the resultant time to recalibrate the Rosemont and allow temperature stabilization.

An additional problem that significantly contributed to down time of the exhauster was failure to change out gas bottles for the Rosemont analyzer at appropriate times. (Additionally, the gas supply from these bottles did not allow bottle changeout without loss of line pressure.

See Recommended Action Sheet 2-3 for additional information.

\subsection{RECOMMENDED CORRECTIVE ACTION}

The following corrective actions that will increase Exhauster availability are already being taken:

a) P1ace backup gas bottles on a manifold (Rosemont Hydrocarbon Analyzer, zero grade air), so new bottles can be switched in without loosing supply pressure during changeout. (Partial resolution Item\#4/Table\#5). (EJ WaTdo)

b) Obtain permission to operate the Exhauster 24 hours a day. See Recommended Action Sheet 2-3 for more details. (EJ Waldo)

The task team recommends the following additional steps be taken to reduce complexity and increase the exhauster availability:

c) The team recommends discontinuing use of a diesel generator as the primary power for the exhauster. The exhauster should be powered from Hanford Electric Power Utilities. The diesel generator should be available for backup power and temporary power. See Recommended Action Sheet 7-2 for additional information.

d) Identify requirements that forced use of the Rosemont Hydrocarbon Analyzer. Suggest removal of this instrument if no "firm 
requirement" for this complexity can be identified. If a "firm requirement" for the function performed by the Rosemiont unit is confirmed, a device designed for portable field application should be identified. (Partial resolution Item\#4/Table\#5).

\subsection{JUSTIFICATION/BENEFIT OF CHANGE}

The downtime was largely the result of technical and operational complexity created by the method of implementing requirements springing from regulatory interpretations and regulatory complexity.

Elimination of unneeded technical and operational complexity will increase RMCSS availability.

\subsection{IMPLEMENTATION}

In process items:

A. To allow 24 hour operation an additional interlock will be placed into the automatic shutdown circuit which will allow an unmanned operation shutdown if any alarm is received. This interlock could be activated by a locking key switch which will have positions for manned and unmanned operation.

EROM Cost: \$5.K, one month for paperwork, one shift to implement (EJ Waldo).

B. Handcart style bottle racks with automatic bottle change over system built directly on to racks. Keep additional bottle rack present at sampling site with more spare bottles. EROM Cost: \$4K. Requires no RMCSS down time to implement this recommendation. Work is underway. (EJ Waldo).

Additional items:

C. See Recommended Action Sheet 7-2 for additional information on the use of utilities power.

D. Document changes only. EROM: Requires no RMCSS down time to implement this recommendation. The device can be removed during planned outages. Cost are controlled by administrative issues. 


$$
\text { WHC-SD-WM-ER-415, Rev. } 0
$$

\section{RECOMMENDED ACTIONS TO IMPROVE AVAILABILITY \\ OF THE ROTARY MODE CORE SAMPLE SYSTEM}

Item No. 5-5

Action Title: Purge Pressure Transducers

\subsection{DESCRIPTION OF PROBLEM}

Access and calibration problems.

\subsection{RECOMMENDED CORRECTIVE ACTION}

Review entire RMCSS design for proper selection of transducers. Replace with "Smart" transducers where applicable to allow remote zero and span capability. See related issue $5-1$.

\subsection{JUSTIFICATION/BENEFIT OF CHANGE}

Reducing time to calibrate will increase truck availability.

"Smart" transducers provide remote calibration ability and wider calibration range. (Some current transducers no not have zero and span adjustment capability. Those devices are changed out when found out of range).

\subsection{IMPLEMENTATION}

EROM cost: "Smart" transducers cost up to \$1.K more than the current transducers. Total cost determined after transducer review by engineering. 
WHC-SD-WM-ER-415, Rev. 0

\section{RECOMMENDED ACTIONS TO IMPROVE AVAILABILITY}

OF THE ROTARY MODE CORE SAMPLE SYSTEM

Item No.

Action Title: Instrument Cabinets Limited Access to Components

\subsection{DESCRIPTION OF PROBLEM}

Adjustments are difficult to reach, components are hard to remove. Interviews with designers of the system point out that the layout was for prototype testing purposes only. Funding for the truck design was interrupted causing lack of continuity on the design team. A redesign of the prototype was planned to correct known problems in access and component selection areas. Time and funding was not authorized for incorporating those modification into truck \#2. Decisions to duplicate the truck \#2 Tayout "as is" (for the layout and component selection) on truck \#3 and \#4 without any redesign, perpetuate this problem.

During a product development cycle decision makers must allow an open and honest evaluation of the current product vis the current requirements. Duplication of known problems, and temporary modification into follow on units results in "Common Cause" failures and inefficiency, increased fabrication and operational costs, and unnecessary operational and maintenance constraints.

\subsection{RECOMMENDED CORRECTIVE ACTION}

At this time the options are somewhat limited. Resources that should have been used to identify cost effective modifications have been use to duplicate the existing system and propagate "Common Cause" issues to future units. Given the near term milestones of the Tri Party Agreement that the RMCSS must support and the three year life span the trucks are to address, time to make modifications has been used up. There is not time for a redesign or taking the truck out of service for any extended time period.

The current TWRS sampling plans show no need for RMCSS after 1997. The current configuration should be maintainable for that three year life span. A review of requirements for some devices may result in modifications that will provide better access. See Recommended Action Sheets 6-4 and 5-5.

The task team identified options that would improve access and should be considered if the life span of the RMCSS trucks is expected to be more than three years: the drill table is cluttered with a host of components and associated interfaces to operate the RMCSS. As a consequence access to critical components and compartments is difficult. Furthermore, the rotary table and undercarriage are subjected to high structural loads. The task team recommends removal of the engine/torque convertor/hydraulic pump system from 
the drill table and repackage such that the hydraulic pump and prime mover reside as a stand-alone power pack. This action would require the installation of a hydraulic motor to drive the drill head assembly. The new drive could provide control features that are not currently available, such as continuously variable speed control with feedback and faster shutdown. The operator displays could be repackaged for better access and visual

interaction. Operational and maintenance diagnostic interfaces could be added to facilitate trouble shooting. (Table5/Item\#2, Table5/Item\#1) Use of "Smart Transducers". and a programmable controller capable of analog I/O and math functions could reduce the devices in the current system as well as providing remote data display and archival capability. (Table5/Item\#10, Table6/Item\#2)

\subsection{JUSTIFICATION/BENEFIT OF CHANGE}

$N / A$ for three year life cycle.

\subsection{IMPLEMENTATION}

N/A for three year life cycle. 
WHC-SD-WM-ER-415, Rev. 0

RECOMMENDED ACTIONS TO IMPROVE AVAILABILITY

OF THE ROTARY MODE CORE SAMPLE SYSTEM

Item No. 5-7

Action Title: Emergency Shutdown

\subsection{DESCRIPTION OF PROBLEM}

During the team review of the RMCSS it was determined that no "Emergency Stop" push buttons are available to operators. The control system has implemented a emergency stop function via the programmable controller that shuts down the engine for various al arm conditions.

\subsection{RECOMMENDED CORRECTIVE ACTION}

Review truck pinching or crushing hazards and existing shutdown capability. If applicable provide "Emergency Stop" push buttons at key locations, connected to the engine shutdown circuit . (Addresses Item \#7/Table5).

\subsection{JUSTIFICATION/BENEFIT OF CHANGE}

Increase personnel ability to respond to pinching or crushing situations.

\subsection{IMPLEMENTATION}

See section "2.0" above. EROM cost to incorporate $\$ 2 . K, 4$ days truck down time, drawing changes. 
RECOMMENDED ACTIONS TO IMPROVE AVAILABILITY OF THE ROTARY MODE CORE SAMPLE SYSTEM

Item No. $5-8$

Action Title: Rosemont Calibration Gas

\subsection{DESCRIPTION OF PROBLEM}

The Rosemont Hydrocarbon analyzer in the exhauster goes through a bottle of zero grade air every two weeks. When the bottle is replaced the unit must be recalibrated. The gas supply from these bottles does not allow bottle changeout without loss of line pressure. Rotary mode mission delays occur during this process.

\subsection{RECOMMENDED CORRECTIVE ACTION}

Place backup instrument gas bottles on a manifold so new bottles can be switched in without loosing supply pressure during changeout. (Partial resolution for 5-4).

\subsection{JUSTIFICATION/BENEFIT OF CHANGE}

The Rosemont requires a calibration be run on the instrument when it runs out of zero grade air. A constant supply reduces the frequency of calibration delays.

\subsection{IMPLEMENTATION}

Handcart style bottle racks with automatic bottle change over system built directly on to racks are being installed. This will keep an additional bottle rack present at sampling site with more spare bottles. EROM Cost: \$4K. Requires no RMCSS down time to implement this recommendation. Work is underway. (EJ Waldo). 


\section{RECOMMENDED ACTIONS TO IMPROVE AVAILABILITY}

OF THE ROTARY MODE CORE SAMPLE SYSTEM

Item No. $5-9$

Action Title:

Exhauster Beta CAM

\subsection{DESCRIPTION OF PROBLEM}

The AMS-4 Beta CAM has gone out of calibration. Detectors have failed when exposed to cold air. Failures in the unit have caused only limited downtime because permission was granted to operate the RMCSS without it.

See Recommended Action Sheet 2-3 for integrated discussion of issues related to this CAM and the function it performs.

\subsection{RECOMMENDED CORRECTIVE ACTION}

Review the radiation monitoring requirements, and implement any required monitoring with a more reliable and less complicated method. If a "Record Filter" will meet the requirements of the function provided by the AMS-4 Beta CAM, replace the CAM with a "Record Filter". The filters will be sent for analysis to provide a source release value for reports, if that is the reason the device is in the Exhauster. HPT's can use portable instruments to perform spot checks when needed, if this unit is removed as they have done during its extended outage due to failure.

The radiation monitoring requirements are as follows: If the expected unabated off-site dose is greater than $.1 \mathrm{mrem} / \mathrm{year}$ then CAMs are necessary per DOE orders. The figure in our permit is $.5 \mathrm{mrem} /$ year. This figure assumes a conservative source term, 30 cores taken annually, and $1 \mathrm{~kg}$ of dust emitted per core (from the aerosol study). Any of these assumptions could and should be challenged.

\subsection{JUSTIFICATION/BENEFIT OF CHANGE}

Removal of this unit resolves Safety Concerns specific to operation of the exhauster on a Hydrogen Watch List Tanks. One of the drivers for the Safety Class 1 Hydrogen Monitor installation is the CAM probes in the flow stream (per conversation with Safety Assessment Engineering staff). The AMS-4 Beta CAM has experienced failures. This particular model is one with little operating experience at Hanford. Information relayed to the task team indicated that the probes have a history of failure when operated at cold temperatures. 
WHC-SD-WM-ER-415, Rev. 0

\subsection{IMPLEMENTATION}

Document changes only. Requires no RMCSS down time to implement this recommendation. Devices can be removed during planned outages. Cost are controlled by administrative issues. 


\section{RECOMMENDED ACTIONS TO IMPROVE AVAILABILITY OF THE ROTARY MODE CORE SAMPLE SYSTEM}

Item No. $\quad 5-10$

Action Title:

DCI meter failures

\subsection{DESCRIPTION OF PROBLEM}

Digital meters on the truck instrument cabinet fail and need replaced. Possible contributing factors are thermal and power cycling, vibration, and operation at high temperatures during initial power up of system.

\subsection{RECOMMENDED CORRECTIVE ACTION}

It is probable that some of the DCI failures have occurred during power up when the cabinet is not within operating temperature range. See Recommended Action Sheet 6-3 for discussion of possible operating temperature problem.

Frequent supply power cycling caused by the unreliability of the diesel generator may also have contributed to the failures by causing unnecessary thermal and electrical cycles in the instrument cabinet. See Recommended Action Sheet 7-2 for discussion of power problems.

Analysis of vibration issues should have been considered during initial system design. Appropriate meter selection and mounting was also a responsibility of the initial design team. At this time there is no easy way to resolve vibration as a concern.

\subsection{JUSTIFICATION/BENEFIT OF CHANGE}

Decreased failure rates. Also refer to Sheet $6-3$ and 7-2.

\subsection{IMPLEMENTATION}

After recommended corrective actions are taken this issue should be reviewed based on the new operational methods. See Recommended action 5-4. 
WHC-SD-WM-ER-415, Rev. 0

RECOMMENDED ACTIONS TO IMPROVE AVAILABILITY

OF THE ROTARY MODE. CORE SAMPLE SYSTEM

Item No. 5-11

Action Title: Sierra Purge Gas Flow Meter.

\subsection{DESCRIPTION OF PROBLEM}

The Sierra Flow transducers are found to go out of calibration and must be returned to the vendor for repair.

\subsection{RECOMMENDED CORRECTIVE ACTION}

RMCSS Engineering is working with the vendor to replace the units currently used with a newer design.

\subsection{JUSTIFICATION/BENEFIT OF CHANGE}

Reliability should improve.

\subsection{IMPLEMENTATION}

Schedule for receiving new design from vendor and installing units on the RMCSS needs reviewed. 


\section{RECOMMENDED ACTIONS TO IMPROVE AVAILABILITY}

OF THE ROTARY MODE CORE SAMPLE SYSTEM

Item No. 6-1

Action Title: Electrical Connectors

\subsection{DESCRIPTION OF PROBLEM}

The RMCSS has many electrical connectors exposed to the environment. Connectors are often a problem due to internal corrosion after exposure to weather and temperature extremes.

\subsection{RECOMMENDED CORRECTIVE ACTION}

No RMCSS connector problems were identified by the task team. This should be a concern that is addressed during control system redesign and modifications to the existing system. During maintenance activities that remove connectors the connectors should be checked for corrosion and proper location of " 0 " ring seals where applicable.

Review RMCSS \#2 for existing problems that could be corrected with weather shields or connector change out during a maintenance period.

\subsection{JUSTIFICATION/BENEFIT OF CHANGE}

Corrosion in connectors causes intermittent or open circuits and will affect availability of the RMCSS.

\subsection{IMPLEMENTATION}

Assign activity to a regular Preventive Maintenance Program on the RMCSS. 
RECOMMENDED ACTIONS TO IMPROVE AVAILABILITY

OF THE ROTARY MODE CORE SAMPLE SYSTEM

Item No. $\frac{6-2}{}$

Action Title: Remote data monitoring and display.

\subsection{DESCRIPTION OF PROBLEM}

The current instrumentation and control system of RMCSS \#2 does not provide an ability to support data trending for maintenance purposes, nor provides a method to observe RMCSS parameters at in a centralized location or remote location. This increases to time to troubleshoot and reduces the ability to do predictive maintenance.

\subsection{RECOMMENDED CORRECTIVE ACTION}

The current TWRS sampling plans show no need for RMCSS after 1997. The current configuration can be maintainable for that three year life span. A review of requirements for some devices may result in modifications that will provide better access.

See Recommended Action Sheets 5-2, 5-6, 6-4, and 5-5 for related issues.

\subsection{JUSTIFICATION/BENEFIT OF CHANGE}

N/A for three year life cycle.

\subsection{IMPLEMENTATION}

$\mathrm{N} / \mathrm{A}$ for three year life cycle. Issue should be reviewed if need is for more than three years. 


\section{RECOMMENDED ACTIONS TO IMPROVE AVAILABILITY}

OF THE ROTARY MODE CORE SAMPLE SYSTEM

Item No. 6-3

Action Title: Instrument Rack Power-up

\subsection{DESCRIPTION OF PROBLEM}

The RMCSS \#2 logbooks for the last year show random failures of several instrument that were identified shortly after power up of the RMCSS system.

Drawings indicate that power comes up to the air conditioner and the instruments at the same time. Instrument powerup is neither interlocked to correct cabinet operating temperature nor to a operator initiated permissive device.

Failure of air conditioner during attended or unattended powerup periods is not interlocked to instrument power. Instruments could continue to operate in a cabinet without temperature control.

\subsection{RECOMMENDED CORRECTIVE ACTION}

To reduce the failures caused by device power up at high ambient cabinet temperatures, instrument power should be interlocked to cabinet temperature or an operator initiated powerup circuit should be provided and procedures changed appropriately.

Instrument power should be interlocked to high cabinet temperature to prevent device failure due to air conditioner failure.

\subsection{JUSTIFICATION/BENEFIT OF CHANGE}

A failure history on DCI's exists(Table5-10). The potential for future device failure from powerup and operation at elevated temperatures is high.

\subsection{IMPLEMENTATION}

See implementation comments in section "2" above. EROM cost: \$1K, One day truck down time, procedure changes, and drawing change. 


\section{RECOMNENDED ACTIONS TO IMPROVE AVAILABILITY}

OF THE ROTARY MODE CORE SAMPLE SYSTEM

Item No. $6-4$

Action Title: Purge Mass Flow Calibration Difficulty

\subsection{DESCRIPTION OF PROBLEM}

Hoffer mass flow devices on the Purge gas system are on a twice annual calibration cycle. Past calibration of the Hoffer mass flow devices have required several days to complete. During the process the truck is without one or more of the mass flow monitors(See PIC log, 1/3/95 - 1/17/95). The Cog. Eng. contributed most of this time to using new personnel and new calibration procedures.

\subsection{RECOMMENDED CORRECTIVE ACTION}

Replacement of one or more of the Hoffer mass flow systems on all RMCSS trucks should be analyzed. The Mass flow device suggested is a Coriolis Effect type device. Because digital sensing and signal conditioning techniques are used, no calibration is required. See implementation and justification sections below for more information. Analysis should include review of the requirements that lead to the current implementation. Using a new type of mass flow device may eliminate the need for triple redundancy in this measurement. (Resolves 6-4).

This Mass Measurement approach should be considered on the design of any new core dri11 truck.

\subsection{JUSTIFICATION/BENEFIT OF CHANGE}

A Coriolis Effect mass flow device greatly reduces subsystem component count and complexity. This mass flow measurement option is resistant to electrical noise signals, less effected by temperature variations, and provides analog and digital interface options not available with current mass device. This device requires no calibration. Periodic checks can be made to insure the device is still preforming to factor specifications.

Because of the digital interface available on the Coriolis Effect transmitter module, future maintenance, control and monitoring options are possible. 


\subsection{IMPLEMENTATION}

A mass flow sensor CMF100M328NU and transmitter RFT9739E1SU (MicroMotionInc. No. (303) -530-8400) should be purchased and evaluated for use on the RMCSS drill trucks. EROM: Cost per unit is $\$ 7 . K$, drawings, operations, and maintenance procedures would also be affected.

Review of reliability history on the Hoffer units will determine if Hoffer replacement is justified. 
WHC-SD-WM-ER-415, Rev. 0

\section{RECOMMENDED ACTIONS TO IMPROVE AVAILABILITY} OF THE ROTARY MODE CORE SAMPLE SYSTEM

Item No. $\frac{6-5}{}$

Action Title: Instrumentation System Operator Interface

\subsection{DESCRIPTION OF PROBLEM}

The current Instrumentation System Operator Interface was not reviewed from an ergonomic standpoint. Problems exist in the arrangement, location, and method of displaying status information. Operations and engineering personnel assigned to the RMCSS have learned to use the existing displays and no downtime could specifically be identified associated with this problem. One of the inadequacies is the lack of analog value indicators. Digital and Analog representations of process parameters both have a place in a congested display system. Digital displays provide more resolution information than an analog display. Analog displays provide relative information in a from that is easily understood in a shorter period of time. Analog displays can also be marked to show the current value of the process parameter vis established process limits. The current use of digital displays contributes to decrease operator efficiencies and could lead to operator errors.

See comments Recommended Action Sheets 5-6, relating to decisions to duplicate this interface on RMCSS \#3 and \#4.

\subsection{RECOMMENDED CORRECTIVE ACTION}

This issue is largely a Conduct of Operations issue where products of a engineering design organization are going to affect the ability of the operations personnel to perform their tasks. It is recommended that additional analog indications be provided. These analog displays should provide the operator indication of parameter 1 imits/setpoints relative to the current value. Given the current component organization, a review should be made to identify what parameters would provide the most benefit and how to add that information to the current system. Displays that provide both Digital and Analog indications maybe able to fit the existing layout and minimize modification time and documentation impact.

See comments Recommended Action Sheets 5-6.

\subsection{JUSTIFICATION/BENEFIT OF CHANGE}

Provide useful information to the operator in a different form than is currently available. Reduce the potential for operations errors due display type. 
WHC-SD-WM-ER-415, Rev. 0

\subsection{IMPLEMENTATION}

EROM: Costs will be determined by review of operations needs, and ability accommodate needs within existing cabinet constraints. 
WHC-SD-WM-ER-415, Rev. 0

\section{RECOMMENDED ACTIONS TO IMPROVE AVAILABILITY \\ OF THE ROTARY MODE CORE SAMPLE SYSTEM}

Item No. $7-2$
Action Title: RMCSS AC Power Source Rel iability

\subsection{DESCRIPTION OF PROBLEM}

Frequent start up and shutdowns of the diesel generator have contributed significantly to RMCSS system availability. The shutdowns caused a ripple effect in failures of other RMCSS system components. The RMCSS \#2 logbooks for the period of Oct 28, 1994 through Feb 1, 1995 show "diesel generator down time" of over $5 \%$ but the effect was amplified in downtime of the truck and exhauster due to failure of components and calibration requirements, upon restoration of power. (This period was representative of the active sampling mission experience to date.)

Thermal cycling of electronics in equipment cabinets is causing a future problem for the RMCSS system. Because of the constant thermal cycles solder joints in connectors and instruments will begin to fail. Failures of the DCI units have already occurred that are related to the thermal cycling and applying power to the equipment outside of its designed operating temperature range. (Table6/Item\#3, \& Table5/Item\#10)

\subsection{RECOMMENDED CORRECTIVE ACTION}

After a diesel failure on Oct 30 , the RMCSS system power was restored on Nov 10 by connecting to an existing 480VAC utilities service while the generator was being repaired (BR Johns).

The task team recommends discontinuing use of a Diesel generator as the primary power for the RMCSS system. The exhauster and the truck should be powered from Hanford Electric Power Utilities whenever possible. The diesel generator should be available for backup power and temporary power at the discretion of the RMCSS operating crew. Some components such as the breathing air compressor may be best served by using the diesel generator. (Partial resolution Item \#3/Table 6 , \& Item \#10/Table 5 , \& Item \#3/Table 2 , \& Item \#4/Table \#5, Item \#9/Table 5, and Item \#2/Tablel)

Permanent installations of $480 \mathrm{vac}, 3$ phase, 200 ampere services should be installed at all locations where RMCSS sampling will be done, outside the RCA where practical. This is a solution that will provide long term benefits to future projects that will need temporary power at or near the same locations. Specifically, various temporary characterization, sampling and remediation efforts will be in need of power at the same locations. This power installation is a chance to reduce future operating costs and schedules. 


\subsection{JUSTIFICATION/BENEFIT OF CHANGE}

This solution addresses the root cause of much RMCSS process delay experienced to date due to failures. Increased reliability of exhauster and drill truck will result. See discussion of power supply issues in section "D" of the Exhauster availability issues, recommended actions item 2-3.

Continuous $A C$ power availability could be used to power engine block heaters and eliminate or reduce the delays in mission due to "engine fails to start" in cold weather. (Partial resolution Item\#6/Table\#2).

A host of operating and maintenance costs to keep the diesel generator operational should be reduced significantly with this approach. Much of the time the electrical load requirement are well below the rated capacity of the generator and a load bank will be used to dissipate the un-needed capacity.

Other positive consequences of using a utility power feed is: Reduction of overall noise level at the work site, reduction of congestion at the work site, reduction of a system "single point failure" by using the generator as a backup power source.

\subsection{IMPLEMENTATION}

Hanford Electric utilities engineers were contacted(RA VanBaalen). Power can be supplied with little effort and time for temporary (90 day) hookups on any tank. $17.8 \mathrm{KV}$ distribution 1 ines are near. 200 ampere, $480 \mathrm{vac}$, 3phase service can provided via transformers as part of the tank preparation work when 480vac is not already available on the tank. Main fusing and substation relaying is located in permanent locations serving the distribution lines. Permanent installations of $480 \mathrm{vac}$ power will require some modification to the methods that may be used for temporary service.

The Diesel generator could be used to power temporary use equipment such as the 33KVA breathing air compressor load if ampacity at the tank is not adequate to handle the entire RMCSS system load.

EROM: Requires no RMCSS down time or significant added cost to implement this recommendation.

Care must be taken to insure correct phase rotation of each installation before RMCSS powerup (see PIC $\log 11 / 15 / 94$ ). 


\section{RECOMMENDED ACTIONS TO IMPROVE AVAILABILITY \\ OF THE ROTARY MODE CORE SAMPLE SYSTEM}

Item No. 8-1

Action Title: Electrical Cable Rub and Pinch

\subsection{DESCRIPTION OF PROBLEM}

Concern was expressed about potential rub and or pinch points for electrical cables.

\subsection{RECOMMENDED CORRECTIVE ACTION}

Conduct a physical inspection of all the Electrical Cable routes with attention to locations where cables are being subjected to abuse. Also inspect cable strain relief mounting at connectors and exit from enclosures and covers. Correct any problems or potential problems found.

See Item 4-1 for related issue on hydraulic hoses, and 6-1 on connector protection.

\subsection{JUSTIFICATION/BENEFIT OF CHANGE}

Inspection and correction could protect personnel from a shock hazard. Any problems found can be corrected during a scheduled maintenance outage rather than in a high priority remedial maintenance situation.

\subsection{IMPLEMENTATION}

Conduct inspection and implement correction as required. 


\section{RECOMMENDED ACTIONS TO IMPROVE AVAILABILITY \\ OF THE ROTARY MODE CORE SAMPLE SYSTEM}

Item No. $\underline{9-1}$

Action Title: Small Components - Hard to Remove and Repair

\subsection{DESCRIPTION OF PROBLEM}

There is general difficulty in removing and repairing the more intricate components because of their small size and the limited dexterity of technicians fitted with SWP gear.

\subsection{RECOMMENDED CORRECTIVE ACTION}

None

\subsection{JUSTIFICATION/BENEFIT OF CHANGE}

At this stage of the development of the RMCSS system, it would not be cost effective to modify the overall design to improve this condition. Where specific items can be changed without impacting availability of the system, they should be identified by the cog engineer for implementation.

\subsection{IMPLEMENTATION}

Implementation of a plan to improve access to all "hard to repair" items is not recommended. 


\section{RECOMMENDED ACTIONS TO IMPROVE AVAILABILITY \\ OF THE ROTARY MODE CORE SAMPLE SYSTEM}

Item No. $\underline{9-2}$

Action Title: Spare Parts

\subsection{DESCRIPTION OF PROBLEM}

A spare parts list for the system was not available. Spare parts that do exist are not stored at one location. Some are obtained by borrowing from trucks \#3 and \#4. Adequate control of these parts is questionable. An adequate number of the correct spares and the ability to retrieve them when needed needs improvement.

\subsection{RECOMMENDED CORRECTIVE ACTION}

Assign an organization or individual (Maintenance Engineering?) with the sole responsibility of developing and maintaining a comprehensive RMCSS system spares program. This should include the task of providing and maintaining the basis for the spares selected and assuring that spares are procured, warehoused, and controlled in an acceptable manner.

\subsection{JUSTIFICATION/BENEFIT OF CHANGE}

Having the necessary spares available when needed will minimize downtime and improve system availability. Some spares are Safety $\mathrm{Class} 2$ and 3 which require some degree of control to assure the spares meet certain requirements, i.e., do the components installed meet the requirements specified by the cog engineer?

\subsection{IMPLEMENTATION}

See 2.0 above. 
RECOMMENDED ACTIONS TO IMPROVE AVAILABILITY

OF THE ROTARY MODE CORE SAMPLE SYSTEM

Item No. 9-3

Action Title: Purge Gas Blows Sample out of Sampler

\subsection{DESCRIPTION OF PROBLEM}

Concern was express to the Task Team that quality samples have not been obtained when operating in rotary mode with the use of purge gas. The pressure at the drill bit can vary between 20 and 85 psi during sampling. It was postulated that the purge gas flow may blow samples out of the sampler.

\subsection{RECOMMENDED CORRECTIVE ACTION}

The sampler is considered out of scope of this task team, but modification of the purge system may be needed.

Currently the purge system is configured to provide mechanical pressure control with operator controlled flow regulation. The purge gas control system could be reconfigured to provide operator set constant pressure or constant flow control.

\subsection{JUSTIFICATION/BENEFIT OF CHANGE}

Increase sample recovery rate in rotary mode with purge gas flow.

\subsection{IMPLEMENTATION}

See Section 2.0. 


\section{RECOMMENDED ACTIONS TO IMPROVE AVAILABILITY \\ OF THE ROTARY MODE CORE SAMPLE SYSTEM}

Item No. $\underline{9-5}$

Action Title: In Field Cognizant Engineer Support

Significant delays were occasionally attributed to the on-site cognizant engineer not being present in the field.

\subsection{DESCRIPTION OF PROBLEM}

A11 new "one of a kind" type of equipment that is handed over to personnel that have accumulated limited operating time with the new equipment is going to experience higher than average shutdowns. This is true regardless of the level of experience and capability of the operators and regardless of the adequacy of the equipment to perform. During this initial "shakedown" period, time can be saved by having the cognizant engineer in the field to immediately initiate the right changes to equipment and procedures that are determined necessary by the cognizant engineer.

\subsection{RECOMMENDED CORRECTIVE ACTION}

Make it standard operating policy to have the cognizant engineer or the cog's designated representative in the field when the system is scheduled for use.

\subsection{JUSTIFICATION/BENEFIT OF CHANGE}

Availability will be increased. Safety of personnel will be improved.

\subsection{IMPLEMENTATION}

See 2.0 above. 


\section{RECOMMENDED ACTIONS TO IMPROVE AVAILABILITY \\ OF THE ROTARY MODE CORE SAMPLE SYSTEM}

Item No. $\underline{10-2}$

Action Title: RMCSS Operating Crew Training

\subsection{DESCRIPTION OF PROBLEM}

Training and qualification of new operators is completed with a minimum of "hands-on" experience. Lack of experience can result in running equipment to failure with longer down times for component replacement or repair.

\subsection{RECOMMENDED CORRECTIVE ACTION}

Establish an operator certification program that addresses specific push-mode and rotary RMCSS component operator certification. Establish a qualification procedure and criteria for training that increases time of actual on-truck drilling experience.

\subsection{JUSTIFICATION/BENEFIT OF CHANGE}

RMCSS system performance and availability will improve if operating crews are required to have a higher level of hands-on experience before becoming qualified.

\subsection{IMPLEMENTATION}

See 2.0 above. 
RECOMMENDED ACTIONS TO IMPROVE AVAILABILITY

OF THE ROTARY MODE CORE SAMPLE SYSTEM

Item No. $10-3$

Action Title: Infrastructure Inhibits Upgrades

\subsection{DESCRIPTION OF PROBLEM}

The schedule demand on the RMCSS systems is so great, and the cost to make changes so high, that design changes to improve system availability are not implemented until a breakdown and subsequent modification is the only way to make the system operate.

During the interviews that identified the "Known Problems" (1 isted in tables $1,3,5,7, \& 9)$, a common constraint on the design engineers was identified. Although they knew problems existed and the problems would effect truck availability, they had been directed to: \#1) Resolve only those problems on Truck \#2 that were safety related, \#2) Make trucks \#3 \& \#4 just 1ike \#2 so that procedures, training, and documentation change costs would not be incurred.

Safety concerns limit rotary mode sampling to trucks modified with special interlocks and a nitrogen purge system to cool the drill bit. RMCSS \#2 is the only truck modified to operate in rotary mode and take rotary mode samples from Hanford's 177 tanks. Therefore the schedule demands on RMCSS \#2 to be in the field taking samples, and the high costs to make changes have combined to restrict modifications to only two types; remedial, and resolving safety concerns.

Root cause contributors to the current situation have included:

Constantly changing requirements during design and fabrication.

Arbitrary schedule changes during design/fabrication/testing.

Not planning for a redesign of the prototype after initial testing.

Complexity of paper work requirements for planning work.

Constant funding profile fluctuations during the design.

Lack of staff continuity during the development of the truck.

High cost of changing documentation of truck configuration.

High cost of changing the procedures for operating, maintenance, etc. Constraints on how fabrication/modifications were done. No plans for constant process and design improvement. 
WHC-SD-WM-ER-415, Rev. 0

\subsection{RECOMMENDED CORRECTIVE ACTION}

Implement the recommendations for significant availability improvement identified in this document. Although they require "off line" implementation activities, these items have been selected because they contribute little or no impact to RMCSS \#2 downtime to implement. They also have little or no impact on the fabrication schedule for truck \#3 and \#4. Review each of the other problems listed in this document for corrections that will provide positive incremental improvements in availability.

After the currently planned changes are implemented, a follow up review of the current availability by the RMCSS assigned staff should be held at regular intervals. The RMCSS staff should use this new availability data to identify additional items for improvement in the spirit of "Continuous quality improvement". Identify "common cause" defects in the system and correct the problem so the defect does not continue as part of the overhead costs. Establish accountability and authority at the proper levels. The goal should be to resolve root problems not symptoms.

Provide a open forum where improvement ideas are requested from a 11 levels, establish an evaluation process based on fact and visible to all contributing individuals, and implement modifications when product quality will be improved by the change. To plan for a future review of RMCSS availability, guidance should be presented to operations and maintenance personnel so that details important to Availability Assessment are logged.

\subsection{JUSTIFICATION/BENEFIT OF CHANGE}

A number of significant improvements in availability can be made that have minimum impact on schedules. These will require "off-line" resources to develop. If implemented, the savings expected from improved availability will more than offset these costs within a short (one to two year) period.

Provides personnel assigned to the RMCSS a formal method of reviewing operational issues on a regular schedule and an opportunity to participate in correcting those, issues that are determined to be significant.

\subsection{IMPLEMENTATION}

See Table 1-1 and Table 11 of this report for the prioritized list of items. The items at the top of the list are recommended for implementation. A few items at the bottom of the list should be implemented but did not receive a high problem value because modifications are already in progress to resolve those issues.

See 10-4 for suggested follow-up on future availability reviews. 
WHC-SD-WM-ER-415, Rev. 0

\section{RECOMMENDED ACTIONS TO IMPROVE AVAILABILITY}

OF THE ROTARY MODE CORE SAMPLE SYSTEM

Item No. $10-4$

Action Title: New Availability Baseline Needed for Future Assessment

\subsection{DESCRIPTION OF PROBLEM}

The RMCSS Availability Task Team had difficulty in establishing the true system availability of RMCSS \#2. Records that have been maintained have been maintained for purposes other than Availability Assessment.

Several changes in equipment operation are underway, additional changes are being recommended by this task team. Significant changes in availability should result. As part of a continuous process improvement effort, a followup review of availability should be made once these changes are made. The follow-up review of availability would identify any new areas that might provide significant improvements.

To plan for a future review of RMCSS availability guidance should be presented to operations and maintenance personnel so that details important to Availability Assessment are logged.

\subsection{RECOMMENDED CORRECTIVE ACTION}

Operations and Maintenance logs should:

Identify the specific component that is causing a delay, Time the delay or operation started and finished, Separate delay into discernable phases such as, "Work in Shop", "Work on truck", "waiting for paperwork", "looking for tools", "locating spare part", "Sampling in progress", "Beg in System move", "Complete System Setup", "Type of Weather delay".

After the currently planned changes are implemented, a follow up review of availability by the RMCSS crew should be held at regular intervals. The RMCSS crew should use this data to identify additional items for improvement.

Provide a open forum where improvement ideas are requested, evaluated based on fact, and implemented when the product/process will be improved by the change. 


\subsection{JUSTIFICATION/BENEFIT OF CHANGE}

Provides personnel assigned to the RMCSS a formal method of reviewing operational issues and an opportunity to participate in correcting those issues that are determined to be significant.

\subsection{IMPLEMENTATION}

A. Communicate the need for detailed logs to persons who make log entries.

B. Obtain a volunteer to gather, review, and present the log results on availability to other crew members at regular intervals.

C. Provide a method for evaluating and incorporating improvement ideas. 


\section{RECOMMENDED ACTIONS TO IMPROVE AVAILABILITY \\ OF THE ROTARY MODE CORE SAMPLE SYSTEM}

Item No. $10-5$

Action Title: Regulatory Complexity

\subsection{DESCRIPTION OF PROBLEM}

RMCSS System has been designed to operate under worse case no risk conditions for all Hanford tanks.

\subsection{RECOMMENDED CORRECTIVE ACTION}

The task team recommends changing procedures to indicate the "minimum required equipment list" for each tank.

Components that have been added to the RMCSS to provide a function where no clear operational or regulatory requirement exists should be removed from service. See discussion on Recommended Action Sheet 2-3.

\subsection{JUSTIFICATION/BENEFIT OF CHANGE}

RMCSS Logs document time periods where sampling was delayed due to a component failure. After changing the procedure to reflect that the component was not required, sampling was able to resume.

\subsection{IMPLEMENTATION}

EROM Cost: No added operational cost or truck downtime to implement. 


\section{RECOMMENDED ACTIONS TO IMPROVE AVAILABILITY \\ OF THE ROTARY MODE CORE SAMPLE SYSTEM}

Item No. $10-6$

Action Title: Exhauster Hydrogen Monitor

\subsection{DESCRIPTION OF PROBLEM}

A safety $c l$ ass 1 hydrogen monitor system is being designed for installation into the RMCSS Exhauster. Installation will be very expensive in initial installation cost and cost of maintaining the Safety Class 1 system and documentation. WHC Safety Assessment was contacted and told the reason for installing the Hydrogen Monitor is to allow operation on a "Hydrogen Watch List" tank. The CAM that was installed in the Exhauster is considered an ignition source. When Environmental Engineering was ask if a "Record Filter" could perform the same function as the CAM (thereby el iminating the need for the Hydrogen Monitor), it was confirmed that there were other implementation options for the function performed by the CAM that have not been exercised.

\subsection{RECOMMENDED CORRECTIVE ACTION}

Remove the CAM from the Exhauster (see 2-3, \& 5-9).

Halt design, \& procurement. Do not proceed with installation the Hydrogen Monitor, (see 2-3).

Develop a "Minimum Required Equipment List" for each tank (see 10-5).

\subsection{JUSTIFICATION/BENEFIT OF CHANGE}

See Sheets 2-3, 5-9, and 10-5.

\subsection{IMPLEMENTATION PLAN}

EROM cost SAVINGS: \$500K first year (design, procurement, installation, acceptance testing, documentation changes, procedure changes) hydrogen monitor alone. CAM maintenance and repair costs have been significant during 94/95. Credit for this savings should be taken in the 1995 Challenge 170 program.

See Sheets 2-3, 5-9, and 10-5. 
WHC-SD-WM-ER-415, Rev. 0

\section{RECOMMENDED ACTIONS TO IMPROVE AVAILABILITY}

OF THE ROTARY MODE CORE SAMPLE SYSTEM

Item No. $10-7$

Action Title: Mechanical Preventative Maintenance Procedure Not Available

\subsection{DESCRIPTION OF PROBLEM}

The Preventative Maintenance Procedure (PMP) system for the RMCSS is still under development. As they currently exist, the PMP's tend to focus on demonstration/verification of control functions that are vital to safe operation of the system. The non-safety related systems, on the other hand, do not appear to get the periodic inspection that may be needed to achieve greater availability. Furthermore, the demonstration of function does not ensure that the system is free of distress.

The need for frequent inspections of all systems is particularly important for prototypic hardware such as the RMCSS. This is so because many of the components were not necessarily designed or optimized for the conditions under which they are being used. In addition, there is a natural tendency to rely on guidelines established by the various vendors - which increases the risk that a component used to interface systems may get left-out. An example of such a situation could be the rotary union used between the drill pipe and bellows assembly. These aspects do not imply that the hardware is inadequate; it simply means that operating experience may not exist and estimates of performance, service intervals, etc. may not be relevant. Therefore, it is reasonable to assume that components will require service much sooner than expected. An aggressive effort based on frequent inspections should not only help reduce the risk of failure, but also provide the data base needed to refine the procedure and the interva?.

\subsection{RECOMMENDED CORRECTIVE ACTION}

As the PMP system evolves, it should be checked to ensure that critical mechanical components are not neglected, even though their function may not suggest a problem and physical access is difficult. Furthermore, the time required to complete such inspections should be monitored carefully - with lengthy items being scrutinized for opportunities to make corrections that facilitate the process - the premise being if a procedure is made easier, the greater the likelihood it will be performed.

\subsection{JUSTIFICATION/BENEFIT OF CHANGE}

Less system downtime due to unexpected failure of components. 
WHC-SD-WM-ER-415, Rev. 0

\subsection{IMPLEMENTATION}

The costs associated with implementing this action is (TBD) since it is directly related to the amount of hardware to be inspected and the difficulty involved with its inspection (likewise the system downtime). 


\section{RECOMMENDED ACTIONS TO IMPROVE AVAILABILITY}

OF THE ROTARY MODE CORE SAMPLE SYSTEM

Item No. $\frac{10-8}{10}$

Action Title: Calibration of Pressure transducers

\subsection{DESCRIPTION OF PROBLEM}

Calibration is required (due to safety class 2 rating) every six months.

Calibration is difficult due to poor access.

\subsection{RECOMMENDED CORRECTIVE ACTION}

The task team recommends addition of maintenance ports and selection of new transducers where applicable, see Recommended Action Sheet 5-1 and 5-5.

\subsection{JUSTIFICATION/BENEFIT OF CHANGE}

See Sheet 5-1 and 5-5.

\subsection{IMPLEMENTATION}

See Sheet 5-1 and 5-5. 
WHC-SD-WM-ER-415, Rev. 0

\section{RECOMMENDED ACTIONS TO IMPROVE AVAILABILITY}

OF THE ROTARY MODE CORE SAMPLE SYSTEM

Item No. $10-9$

Action Title: Instrumentation self check routine use

\subsection{DESCRIPTION OF PROBLEM}

Inadequate use of self-check routines by operations to determine status of critical instruments before daily drilling takes place. Also, status of setpoint thumbwheel switches needs verified because access to the switches is not limited, and switches could be left in the wrong position.

\subsection{RECOMMENDED CORRECTIVE ACTION}

Change operating procedure to provide a check list of instruments to be checked. (RR Bafus)

\subsection{JUSTIFICATION/BENEFIT OF CHANGE}

May prevent operating to incorrect parameters due to a detectable instrument malfunction.

\subsection{IMPLEMENTATION}

EROM Cost: Engineering, Operating procedure change, Can be implemented within a month. 


\section{RECOMMENDED ACTIONS TO IMPROVE AVAILABILITY \\ OF THE ROTARY MODE CORE SAMPLE SYSTEM}

Item No. $10-10$

Action Title: Calibrated Spares

\subsection{DESCRIPTION OF PROBLEM}

The RMCSS PIC log contains entries defining delay time attributed to instrument technicians on truck doing calibrations, and delays for instruments removed for calibration in shop.

See Recommended Action Sheet 5-3 for a related discussion.

\subsection{RECOMMENDED CORRECTIVE ACTION}

The task team recommends that where applicable and spares are available, spares be pre-calibrated for quick changeout and return the truck to service with the spare installed. This method will keep the calibration time offline.

Care must be taken to insure Safety Class 2 component replacements meet specifications.

\subsection{JUSTIFICATION/BENEFIT OF CHANGE}

Reduce downtime for scheduled calibration periods, and reduce downtime for replacement of failed components by removing calibration times from critical path availability time.

\subsection{IMPLEMENTATION}

EROM: No additional cost. Requires Engineering and Maintenance input to implement. Requires planning to determine which units can be pre-calibrated and returned to spares and which units need to be calibrated just previous to the maintenance opportunity. The task team understands that currently calibration records show both the location of a device as well as the type of device and calibration requirements. Changes may have to be made to records to identify the new location after changeout. This is an infrastructure issue that makes "swap-out" with spares difficult. This issue needs reviewed for possible solutions. 


\section{RECOMMENDED ACTIONS TO IMPROVE AVAILABILITY \\ OF THE ROTARY MODE CORE SAMPLE SYSTEM}

Item No. $10-11$

Action Title: Implement Trending to Supplement Preventative Maintenance

\subsection{DESCRIPTION OF PROBLEM}

The PMP program does not currently include the collection and analysis of operational parameters for the purpose of detecting changes in component performance, If the practice of monitoring these system parameters was established while the RMCSS is "new", the resulting data base could be used as a prognostic tool for predicting component failure as well as providing the means to optimize PM intervals.

\subsection{RECOMMENDED CORRECTIVE ACTION}

Given that the RMCSS is highly instrumented, a study should be conducted to determine if the parameters being monitored have any prognostic value. Where monitoring opportunities of critical systems do not exist, modification of the PMP's should be considered. Potential alteration of a given PMP might include the use of specialized transducers (accelerometers, microphones, etc.) to record levels at test conditions that are easily replicated.

\subsection{JUSTIFICATION/BENEFIT OF CHANGE}

Implementation of this corrective action would minimize the potential for unexpected failure of critical components after significant trending data has been accumulated.

\subsection{IMPLEMENTATION}

The cost of implementation is (TBD) depending upon whether or not any new instrumentation is required for monitoring the selected parameters (1ikewise the amount of downtime required). 
WHC-SD-WM-ER-415, Rev. 0

This page intentionally left blank. 
WHC-SD-WM-ER-415; Rev. 0

\section{APPENDIX B \\ METHODOLOGY AND PRIORITIZATION}

B-1 
WHC-SD-WM-ER-415, Rev. 0

This page intentionaliy left blank. 
WHC-SD-WM-ER-415, Rev. 0

\section{APPENDIX B}

\section{METHODOLOGY AND PRIORITIZATION}

This appendix describes the methodology used by the team to prioritize the RMCSS problems that were found as well as the implementation of their corrective actions. Tables showing the results of the teams findings are included. 


\section{METHODOLOGY USED BY THE TEAM}

In the process of identifying problems (both known and potential) the team interviewed personnel directiy involved with design, testing, training, field operation, and maintenance of the RMCSS, and reviewed RMCSS documentation (e.g. drawings, operating procedures, maintenance procedures, truck log books, etc.). The problems identified by the team are listed in Tables 1 through 10. The team subsequently employed a weighted decision analysis technique to subjectively, and systematically, prioritize and rank the problems according to the degree of impact upon RMCSS availability (see Tables 1A through 10A. Problems were assigned to each team member in accordance with their areas of expertise, and recommendations were made stating what was the best solution, considering implementation time and costs. A weighted decision making process was again employed to account for the severity of the problem and the degree of difficulty in corrective action implementation. This produced prioritized lists of corrective actions considered to be the prime candidates for implementation by TWRS. These lists are shown in Table 11.

The objective of the task team is to recommend cost effective near term improvements to the existing RMCSS to increase overall system availability, particularly for truck 2. To accomplish this objective the task was divided into three phases:

1) Identify known and potential problems with the RMCSS that is likely to affect availability of the RMCSS. This information is shown on Tables 1 through 10 in this appendix.

2) Determine which problems are the most severe. To do this a weighted decision analysis technique (similar to Kepner-Trego) was used to evaluate the severity of the problem relative to frequency of the event, cost impact of each event, downtime of each event, and the events impact on personnel safety. A weight factor (WF) was assigned to each of these considerations based upon its importance relative to the others. Event frequency and cost impact both have a WF of 1 , downtime has a WF of 4 , and personne1 safety has a WF of 7 .

The problem severity is derived as shown in the example below, using the formula: Total $(T)=R F \bullet W F \bullet(C I \bullet W F+T I \bullet W F+S H \bullet W F)$.

where:

$$
\begin{array}{ll}
\text { RF }=\text { Relative Frequency } & \text { (with WF }=1 \text { ) } \\
\text { CI }=\text { Cost Impact } & \text { (with WF }=1 \text { ) } \\
\text { TI }=\text { Time Impact } & \text { (with WF }=4 \text { ) } \\
\text { SH }=\text { Safety Hazard } & \text { (with WF }=7 \text { ) }
\end{array}
$$

Example: for problem 3-2 (i.e. Table 3, Item 2, hydraulic cylinder)

$$
\begin{aligned}
(T) & =5 \bullet 1 \bullet(1 \bullet 1+1 \bullet 4+2 \bullet 7) \\
& =95 \quad \text { (entered in Tables } 3 \text { and } 3 A)
\end{aligned}
$$


See Tables $1 \mathrm{~A}$ through $10 \mathrm{~A}$ for the work done in arriving at the values of

(T) for each problem.

3) Each problem was then ranked in the order in which they should be worked in the tank farms such that the largest increase in RMCSS availability would be gained for the expenditure involved with the corrective action. This was accomplished by multiplying the problem severity factor ( $T$ ) (see above) by an implementation Impact factor (I), where the value of I ranges from 0.1 (for hard fixes requiring I month or more to implement) to 6.0 (for easy fixes which can be implemented in 1 day).

Example: for problem 3-2, the TOTAL $(I \times T)=6.0 \times 95=570$

This TOTAL (I $\times \mathrm{T}$ ) is recorded in Tables $1 \mathrm{~A}$ through 10A for each problem. The higher the value of this TOTAL is, the more the problem and its corrective action should be preferred to be addressed by tank farms to increase RMCSS overall availability.

Table 11, shows the same information as Tables 1A through 10A, except the problems are arranged in descending order of value of their TOTAL ( $T \times I)$.

Table 12, shows the same information as Tables $1 \mathrm{~A}$ through $8 \mathrm{~A}$ (i.e. Technical problems only), except the problems are arranged in descending order of the value of their TOTAL $(T \times I)$.

Table 13, shows the same information as Tables $9 \mathrm{~A}$ and 10A, except the problems are arranged in descending order of the value of their TOTAL ( $\times$ I). 
TABLE 1

LIST OF KNOWN PROBLEMS (MECHANICAL)

Rotary Mode Core Sample System Note 1: Rating of impact on availability for sampling

Note 2: Rating for ease of

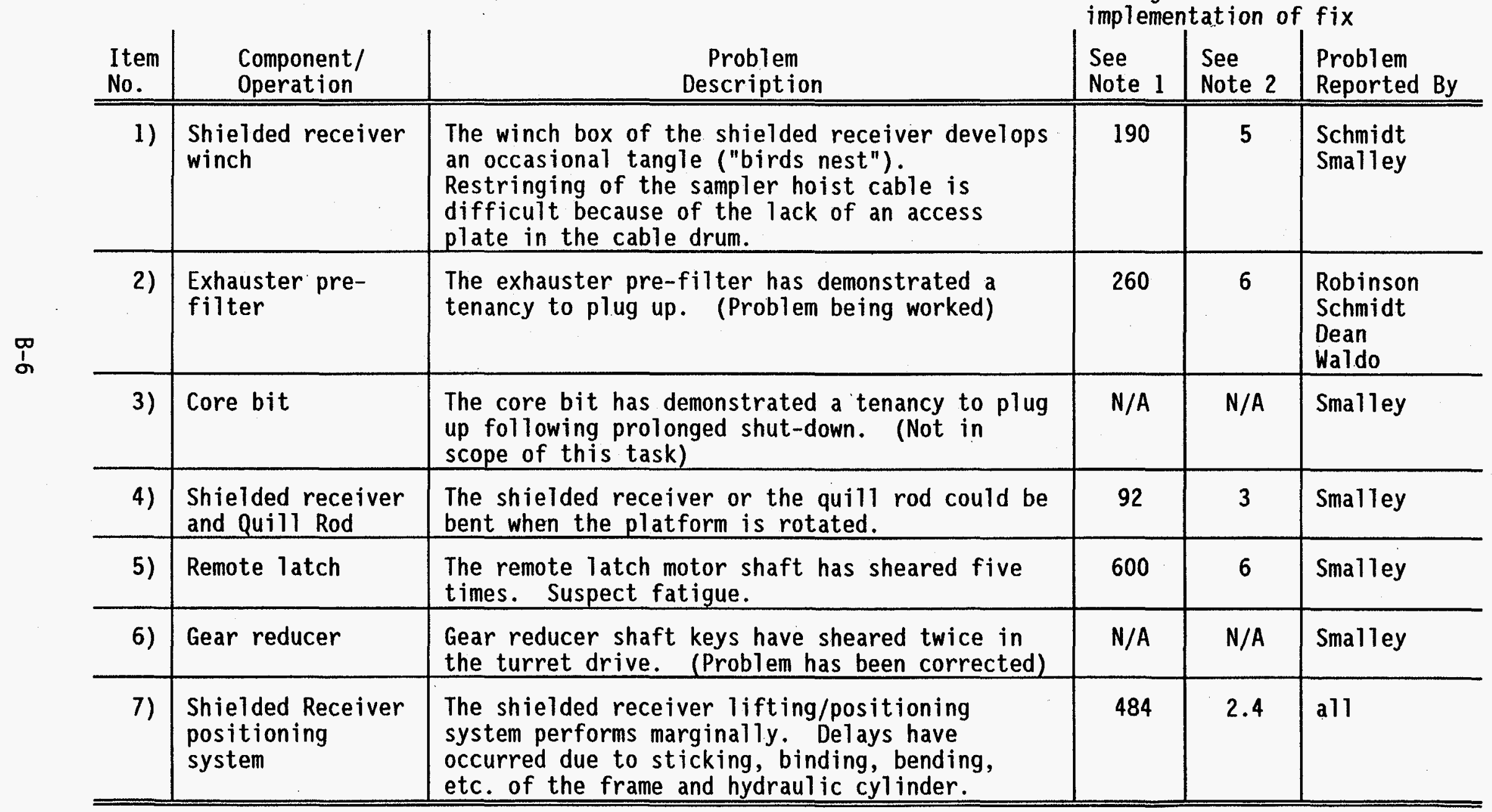


TABLE 2

LIST OF POTENTIAL PROBLEMS (MECHANICAL)

Rotary Mode Core Sample System Note 1: Rating of impact on availability for sampling

Note 2: Rating for ease of implementation of fix

\begin{tabular}{|c|c|c|c|c|c|}
\hline $\begin{array}{l}\text { Item } \\
\text { No. } \\
\end{array}$ & $\begin{array}{l}\text { Component/ } \\
\text { Operation } \\
\end{array}$ & $\begin{array}{c}\text { Problem } \\
\text { Description } \\
\end{array}$ & $\begin{array}{l}\text { See } \\
\text { Note } 1 \\
\end{array}$ & $\begin{array}{l}\text { See } \\
\text { Note } 2 \\
\end{array}$ & $\begin{array}{l}\text { Problem } \\
\text { Reported By } \\
\end{array}$ \\
\hline 1) & $\begin{array}{l}\text { Drill assembly } \\
\text { bellows }\end{array}$ & $\begin{array}{l}\text { The metal bellows at the top of the drill } \\
\text { assembly is a long lead, special source item, } \\
\text { that could cause an eight week delay should it } \\
\text { fail. }\end{array}$ & 18 & 6 & Smalley \\
\hline 2) & $\begin{array}{l}\text { Sampler hoist box } \\
\text { and grapple hoist } \\
\text { box }\end{array}$ & $\begin{array}{l}\text { Corrosion and freezing of hoist electrical } \\
\text { components due to moisture accumulation } \\
\text { internal to the weather barrier (between hoist } \\
\text { box and weather barrier). }\end{array}$ & 36 & 4.5 & Schmidt \\
\hline 3) & Exhauster & $\begin{array}{l}\text { Frequent start up and shut downs of the } \\
\text { exhauster increases the likelihood of } \\
\text { equipment malfunction, reduces time available } \\
\text { for sampling during each shift, and reduces } \\
\text { chances of getting good sample recovery from } \\
\text { the core sample truck. ( } 24 \text { hr continuous } \\
\text { operation may solve part of these problems) }\end{array}$ & 525 & 6 & Waldo \\
\hline 4) & Grapple hoist box & $\begin{array}{l}\text { There is a potential for tangling the hoist } \\
\text { cable in the grapple hoist box. }\end{array}$ & 24 & 5 & Team \\
\hline 5) & $\begin{array}{l}\text { Remote sample } \\
\text { latch unit }\end{array}$ & $\begin{array}{l}\text { Non-uniformity of samplers (although within } \\
\text { tolerance) may present difficulty in being } \\
\text { engaged by remote latch unit. (being worked) }\end{array}$ & 40 & 6 & Team \\
\hline 6) & Truck engine & $\begin{array}{l}\text { Truck engine did not start on occasion, } \\
\text { causing delays in sampling. }\end{array}$ & 60 & 6 & $\log$ book \\
\hline
\end{tabular}


TABLE 3

\section{LIST OF KNOWN PROBLEMS (HYDRAULICS)}

Rotary Mode Core Sample System

Note 1: Rating of impact on availability for sampling

Note 2: Rating for ease of implementation of $f i x$

\begin{tabular}{|c|c|c|c|c|c|}
\hline $\begin{array}{l}\text { Item } \\
\text { No. }\end{array}$ & $\begin{array}{l}\text { Component/ } \\
\text { Operation }\end{array}$ & $\begin{array}{c}\text { Problem } \\
\text { Description }\end{array}$ & $\begin{array}{l}\text { See } \\
\text { Note } 1 \\
\end{array}$ & $\begin{array}{l}\text { See } \\
\text { Note } 2 \\
\end{array}$ & $\begin{array}{l}\text { Problem } \\
\text { Reported By }\end{array}$ \\
\hline 1) & Hydraulic valve & $\begin{array}{l}\text { Large pressure surges occur when the 4-way } \\
\text { hydraulic control valve for push mode is } \\
\text { actuated open. These pressure spikes affect } \\
\text { pressure transducer and pressure gauge } \\
\text { calibrations and subject seals to undue loads. } \\
\text { Pressure spikes are suspect as the cause for } \\
\text { failure of two safety class } 2 \text { pressure } \\
\text { transducers used on the drill string ram. }\end{array}$ & 160 & 1.5 & Smalley \\
\hline 2) & $\begin{array}{l}\text { Hydraul ic } \\
\text { cyl inders }\end{array}$ & $\begin{array}{l}\text { Hydraulic cylinders are periodically replaced } \\
\text { due to external leakage. Higher than expected } \\
\text { failure rate. }\end{array}$ & 95 & 6 & Bogen \\
\hline 3) & Control valves & $\begin{array}{l}\text { Hydraulic valves slam on and off during the } \\
\text { time the platform is rotating. Sudden } \\
\text { platform stopping requires much momentum to be } \\
\text { absorbed in mechanism. (Corrective action was } \\
\text { implemented) }\end{array}$ & $N / A$ & $N / A$ & Bogen \\
\hline 4) & Truck jacks & $\begin{array}{l}\text { While truck \#2 was on its hydraulic jacks for } \\
\text { an extended period of time, the seals in one } \\
\text { hydraulic cylinder failed during hot weather } \\
\text { conditions. None of the other cylinders } \\
\text { failed. }\end{array}$ & 16 & 6 & Smalley \\
\hline
\end{tabular}




\begin{tabular}{|c|c|c|c|c|c|}
\hline $\begin{array}{l}\text { Item } \\
\text { No. } \\
\end{array}$ & $\begin{array}{l}\text { Component/ } \\
\text { Operation }\end{array}$ & $\begin{array}{c}\text { Problem } \\
\text { Description } \\
\end{array}$ & $\begin{array}{l}\text { See } \\
\text { Note } 1 \\
\end{array}$ & $\begin{array}{l}\text { See } \\
\text { Note } 2 \\
\end{array}$ & $\begin{array}{l}\text { Problem } \\
\text { Reported By }\end{array}$ \\
\hline 5) & $\begin{array}{l}\text { Tranversal creep } \\
\text { of drill-rig }\end{array}$ & $\begin{array}{l}\text { When in a non-operating mode, the drill rig } \\
\text { will slowly creep in a direction depending on } \\
\text { which direction the truck is off-level from a } \\
\text { horizontal position. Apparently, the 3-way } \\
\text { valve (SOV 3) leaks oil internally as the off- } \\
\text { level gravity load of the drill rig acts on } \\
\text { the hydraulic cylinders. }\end{array}$ & 12 & 4.5 & Bogen \\
\hline
\end{tabular}


TABLE 4

\section{LIST OF POTENTIAL PROBLEMS (HYDRAULICS)}

Rotary Mode Core Sample System Note 1: Rating of impact on availability for sampling

Note 2: Rating for ease of implementation of $f i x$

\begin{tabular}{|c|c|c|c|c|c|}
\hline $\begin{array}{l}\text { Item } \\
\text { No. }\end{array}$ & $\begin{array}{l}\text { Component/ } \\
\text { Operation }\end{array}$ & $\begin{array}{c}\text { Problem } \\
\text { Description } \\
\end{array}$ & $\begin{array}{l}\text { See } \\
\text { Note } 1 \\
\end{array}$ & $\begin{array}{l}\text { See } \\
\text { Note } 2 \\
\end{array}$ & $\begin{array}{l}\text { Problem } \\
\text { Reported By } \\
\end{array}$ \\
\hline 1) & $\begin{array}{l}\text { Hydraulic hoses } \\
\text { rub/pinch }\end{array}$ & $\begin{array}{l}\text { Concern was expressed about potential "rub" } \\
\text { and/or "pinch" points for hydraulic hoses. }\end{array}$ & 165 & 4.5 & Team \\
\hline 2) & $\begin{array}{l}\text { Redundant } \\
\text { hydraul ic } \\
\text { components }\end{array}$ & $\begin{array}{l}\text { The truck slew movement is redundant to the } \\
\text { platform rotation. Elimination of the } \\
\text { hydraulic components for the slew mode would } \\
\text { reduce clutter and increase reliability. } \\
\text { (operations requests that this feature be } \\
\text { retained) }\end{array}$ & $N / A$ & $N / A$ & Smalley \\
\hline 3) & $\begin{array}{l}\text { Hydraulic pressure } \\
\text { control }\end{array}$ & $\begin{array}{l}\text { Pressure spikes that occur throughout the } \\
\text { hydraulic system will be the cause of } \\
\text { premature failure of components such as } \\
\text { pressure transducers, pressure gauges, and } \\
\text { pressure regulators, and seals within valves } \\
\text { and cyl inders. Seal leakage and pressure } \\
\text { transducer failures that have occurred can be } \\
\text { attributed to pressure excursions. }\end{array}$ & 160 & 1.5 & Team \\
\hline
\end{tabular}




\begin{tabular}{|c|c|c|c|c|c|}
\hline $\begin{array}{l}\text { Item } \\
\text { No. }\end{array}$ & $\begin{array}{l}\text { Component/ } \\
\text { Operation } \\
\end{array}$ & $\begin{array}{c}\text { Problem } \\
\text { Description } \\
\end{array}$ & $\begin{array}{l}\text { See } \\
\text { Note } 1 \\
\end{array}$ & $\begin{array}{l}\text { See } \\
\text { Note } 2 \\
\end{array}$ & $\begin{array}{l}\text { Problem } \\
\text { Reported By }\end{array}$ \\
\hline 4) & $\begin{array}{l}\text { Main pump drive } \\
\text { engine idle }\end{array}$ & $\begin{array}{l}\text { The Vickers hydraulic pump is supposed to } \\
\text { operate at about } 1200 \text { rpm. However, due to } \\
\text { noise, Operators idle the engine at about } 650 \\
\text { rpm for long periods of time. This low speed } \\
\text { condition causes the pump to produce pressure } \\
\text { fluctuations that cause pressure gauges to } \\
\text { fluctuate approximately } \pm 10 \text { psi. These } \\
\text { pulsations are detrimental to the life } \\
\text { expectancy of the transducers, the pressure } \\
\text { gauges, and the seal integrity of the entire } \\
\text { hydraulics system. This continuous pulsation } \\
\text { process will certainly cause the transducers } \\
\text { and pressure gauges to loose their reference } \\
\text { state of calibration much sooner than } \\
\text { currently realized on hydraulics systems } \\
\text { devoid of such pulsations. }\end{array}$ & 24 & 6 & Smalley \\
\hline 5) & $\begin{array}{l}\text { High residual } \\
\text { hydraulic } \\
\text { pressures }\end{array}$ & $\begin{array}{l}\text { Upon shutdown of the hydraulic system, many } \\
\text { regions of the hydraulics network are left } \\
\text { highly pressurized. The shielded receiver } \\
\text { actuators, the hydraulic chuck, the rotating } \\
\text { platform motor, the linear traverse actuators, } \\
\text { the slew actuator, and the truck hydraulic } \\
\text { jacks are not rel ieved of pressure when the } \\
\text { system is shut down. Ambient temperature } \\
\text { excursions from day to night and from day to } \\
\text { day will further load the structures and } \\
\text { seals. A hydraulic jack for the truck has } \\
\text { already experienced failure believed to be } \\
\text { caused by thermal expansion of the hydraulic } \\
\text { oil. }\end{array}$ & 66 & 0.1 & Team \\
\hline 6) & $\begin{array}{l}\text { Hydraulic hose } \\
\text { failure }\end{array}$ & $\begin{array}{l}\text { The hydraulic cylinders of the shielded } \\
\text { receiver can allow the receiver to drop, } \\
\text { should the hoses fail. }\end{array}$ & 85 & 5 & Team \\
\hline
\end{tabular}


TABLE 5

\section{LIST OF KNOWN PROBLEMS (IRC)}

Rotary Mode Core Sample System

Note 1: Rating of impact on availability for sampling

Note 2: Rating for ease of

implementation of $f i x$

\begin{tabular}{|c|c|c|c|c|c|}
\hline $\begin{array}{l}\text { Item } \\
\text { No. } \\
\end{array}$ & $\begin{array}{l}\text { Component/ } \\
\text { Operation } \\
\end{array}$ & $\begin{array}{c}\text { Problem } \\
\text { Description } \\
\end{array}$ & $\begin{array}{l}\text { See } \\
\text { Note } 1 \\
\end{array}$ & $\begin{array}{l}\text { See } \\
\text { Note } 2 \\
\end{array}$ & $\begin{array}{l}\text { Problem } \\
\text { Reported By } \\
\end{array}$ \\
\hline 1) & $\begin{array}{l}\text { Nitrogen and } \\
\text { hydraulic } \\
\text { transducers }\end{array}$ & $\begin{array}{l}\text { The nitrogen and hydraulic pressure } \\
\text { transducers are difficult to calibrate. No } \\
\text { instrumentation ports for nitrogen and } \\
\text { hydraulic transducers. }\end{array}$ & 68 & 1.5 & Bafus \\
\hline 2) & $\begin{array}{l}\text { Instruments } \\
\text { Status }\end{array}$ & $\begin{array}{l}\text { Lack of an overall instrumentation status } \\
\text { display. Maintenance personnel do not have an } \\
\text { easily read, centrally located, source of data } \\
\text { for efficient trouble shooting. }\end{array}$ & 84 & 0.1 & Bafus \\
\hline 3) & Hoffer Calibration & $\begin{array}{l}\text { Excessive difficulty in calibrating the } \\
\text { "Hoffer" units due to lack of cooperation from } \\
\text { vendor and above average number of calibration } \\
\text { problems. }\end{array}$ & 32 & 6 & Schmidt \\
\hline 4) & $\begin{array}{l}\text { Monitor tank } \\
\text { exhaust gases }\end{array}$ & $\begin{array}{l}\text { The Rosemont analyzer drifts, is unreliable } \\
\text { and difficult to calibrate, causing shutdown } \\
\text { of drilling. Start up alignment of exhauster } \\
\text { instrumentation and ancillary equipment is } \\
\text { time consuming and not reliable. Laboratory } \\
\text { class instrumentation is being used in harsh } \\
\text { environments (B\&K analyzer in exhauster). }\end{array}$ & 400 & 6 & $\begin{array}{l}\text { Waldo } \\
\text { Robinson } \\
\text { Schmidt }\end{array}$ \\
\hline 5) & $\begin{array}{l}\text { Purge pressure } \\
\text { transducers }\end{array}$ & $\begin{array}{l}\text { Purge pressure transducers drift, can't be } \\
\text { calibrated and must be replaced when they are } \\
\text { found to be out of calibration. The level of } \\
\text { required calibration accuracy needs to be } \\
\text { checked before on-going calibration is taken } \\
\text { for granted. }\end{array}$ & 32 & 6 & $\begin{array}{l}\text { Waldo } \\
\text { Schmidt } \\
\text { Smalley } \\
\text { Bafus }\end{array}$ \\
\hline
\end{tabular}




\begin{tabular}{|c|c|c|c|c|c|}
\hline $\begin{array}{l}\text { Item } \\
\text { No. }\end{array}$ & $\begin{array}{l}\text { Component/ } \\
\text { Operation }\end{array}$ & $\begin{array}{c}\text { Problem } \\
\text { Description }\end{array}$ & $\begin{array}{l}\text { See } \\
\text { Note } 1\end{array}$ & $\begin{array}{l}\text { See } \\
\text { Note } 2\end{array}$ & $\begin{array}{l}\text { Problem } \\
\text { Reported By }\end{array}$ \\
\hline 6) & $\begin{array}{l}\text { Instrumentation } \\
\text { cabinets }\end{array}$ & $\begin{array}{l}\text { Trouble shooting and repair is impeded by the } \\
\text { limited and restricted access to } \\
\text { instrumentation cabinets (purge gas control } \\
\text { cabinet, Hoffer flowmeter, etc.?) }\end{array}$ & 48 & 0.1 & $\begin{array}{l}\text { Smalley } \\
\text { Schmidt }\end{array}$ \\
\hline 7) & Emergency shutdown & $\begin{array}{l}\text { Manual emergency shutdown button (i.e. "panic" } \\
\text { button) does not exist. }\end{array}$ & 190 & 4.5 & Team \\
\hline 8) & $\begin{array}{l}\text { Rosemont } \\
\text { calibration gas }\end{array}$ & $\begin{array}{l}\text { The Rosemont Hydrocarbon analyzer goes through } \\
\text { a bottle of zero grade air every two weeks. } \\
\text { Operations is then held up waiting for new } \\
\text { bottles to arrive and for calibration of } \\
\text { Rosemont to be performed again. (Problem } \\
\text { being corrected) }\end{array}$ & N/A & $N / A$ & Waldo \\
\hline 9) & Exhauster Beta CAM & $\begin{array}{l}\text { The AMS-4 Beta CAM has demonstrated tenancy to } \\
\text { go out of calibration and be unreliable in } \\
\text { general. }\end{array}$ & 68 & 6 & Waldo \\
\hline 10) & DCI meters failure & $\begin{array}{l}\text { Digital Control Indicators (DCI) meters in the } \\
\text { instrument cabinet on the core sample truck } \\
\text { frequently quit working and need to be } \\
\text { replaced with spares. }\end{array}$ & 80 & 5 & Smalley \\
\hline 11) & $\begin{array}{l}\text { Purge gas flow } \\
\text { meters }\end{array}$ & $\begin{array}{l}\text { The Sierra flow meters frequently breakdown } \\
\text { and need to be replaced with spares. (Problem } \\
\text { being corrected) }\end{array}$ & $N / A$ & N/A & Smalley \\
\hline
\end{tabular}


TABLE 6

\section{LIST OF POTENTIAL PROBLEMS (I\&C)}

Rotary Mode Core Sample System

Note 1: Rating of impact on availability for sampling

Note 2: Rating for ease of implementation of $\mathrm{fix}$

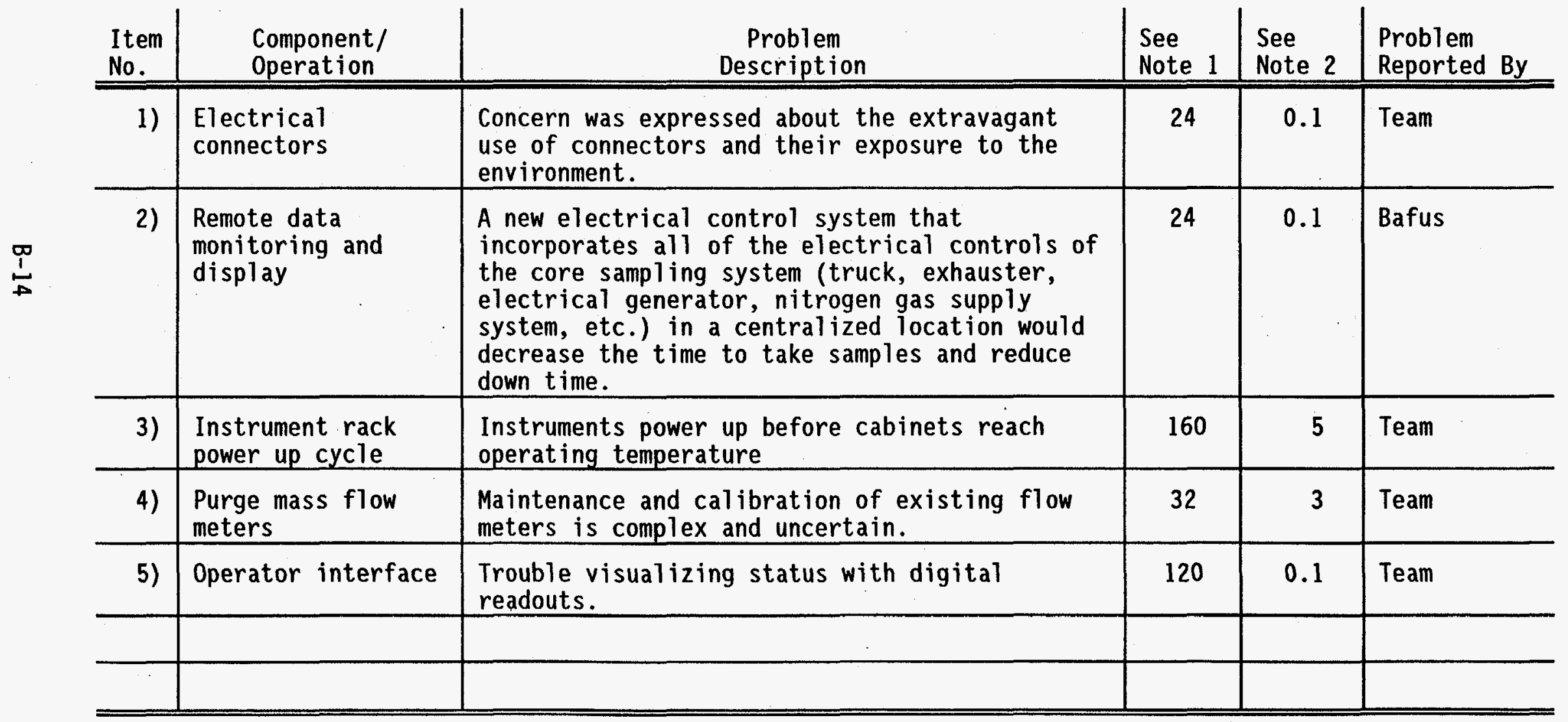


TABLE 7

\section{LIST OF KNOWN PROBLEMS (ELECTRICAL)}

Rotary Mode Core Sample System

Note 1: Rating of impact on availability for sampling

Note 2: Rating for ease of

implementation of $f i x$

\begin{tabular}{|c|c|c|c|c|c|}
\hline $\begin{array}{l}\text { Item } \\
\text { No. } \\
\end{array}$ & $\begin{array}{l}\text { Component/ } \\
\text { Operation } \\
\end{array}$ & $\begin{array}{c}\begin{array}{c}\text { Problem } \\
\text { Description }\end{array} \\
\end{array}$ & $\begin{array}{l}\text { See } \\
\text { Note } 1 \\
\end{array}$ & $\begin{array}{l}\text { See } \\
\text { Note } 2 \\
\end{array}$ & $\begin{array}{l}\text { Problem } \\
\text { Reported By }\end{array}$ \\
\hline 1) & $\begin{array}{l}\text { Generate electric } \\
\text { power }\end{array}$ & $\begin{array}{l}\text { Reliability of diesel motor/generator set } \\
\text { needs to be improved (loose piston rod, etc.). } \\
\text { (Problem being worked) }\end{array}$ & $N / A$ & $N / A$ & Bafus \\
\hline 2) & Power source & $\begin{array}{l}\text { Electrical power source is unreliable. Single } \\
\text { source failure with no backup. }\end{array}$ & 600 & 6 & Johns \\
\hline & & & & & \\
\hline & & & & & \\
\hline & & & & & \\
\hline & & & & & \\
\hline & & & & & \\
\hline & & & & & \\
\hline & & & & & \\
\hline & & & & & \\
\hline & & & & & \\
\hline
\end{tabular}


TABLE 8

LIST OF POTENTIAL PROBLEMS (ELECTRICAL)

Rotary Mode Core Sample System

Note 1: Rating of impact on

availability for sampling

Note 2: Rating for ease of

implementation of $f i x$

\begin{tabular}{|c|c|c|c|c|c|}
\hline $\begin{array}{l}\text { Item } \\
\text { No. }\end{array}$ & $\begin{array}{l}\text { Component/ } \\
\text { Operation }\end{array}$ & $\begin{array}{c}\text { Problem } \\
\text { Description }\end{array}$ & $\begin{array}{l}\text { See } \\
\text { Note } 1 \\
\end{array}$ & $\begin{array}{l}\text { See } \\
\text { Note } 2 \\
\end{array}$ & $\begin{array}{l}\text { Problem } \\
\text { Reported By }\end{array}$ \\
\hline 1) & Electrical cables & $\begin{array}{l}\text { Concern was expressed about potential "rub" } \\
\text { and/or "pinch" points for electrical cables }\end{array}$ & 40 & 4.5 & Team \\
\hline & & & & & \\
\hline & & & & & \\
\hline & & & & & \\
\hline & & & & & \\
\hline & & & & & \\
\hline & & & & & \\
\hline & & & & & \\
\hline & & & & & \\
\hline & & & & & \\
\hline & & & & & \\
\hline & & & & & \\
\hline
\end{tabular}


TABLE 9

\section{LIST OF KNOWN PROBLEMS (OTHER)}

Rotary Mode Core Sample System

Note-1: Rating of impact on availability for sampling

Note 2: Rating for ease of

implementation of fix

\begin{tabular}{|c|c|c|c|c|c|}
\hline $\begin{array}{l}\text { Item } \\
\text { No. } \\
\end{array}$ & $\begin{array}{l}\text { Component/ } \\
\text { Operation } \\
\end{array}$ & $\begin{array}{c}\text { Problem } \\
\text { Description } \\
\end{array}$ & $\begin{array}{l}\text { See } \\
\text { Note } 1 \\
\end{array}$ & $\begin{array}{l}\text { See } \\
\text { Note } 2 \\
\end{array}$ & $\begin{array}{l}\text { Problem } \\
\text { Reported By } \\
\end{array}$ \\
\hline 1) & Small components & $\begin{array}{l}\text { There is general difficulty in removing and } \\
\text { repairing the more intricate components } \\
\text { because of their small size and the } 1 \text { imited } \\
\text { dexterity of techs fitted with SWP gear. }\end{array}$ & 160 & 0.1 & Schmidt \\
\hline 2) & Spare Parts & $\begin{array}{l}\text { Delays in obtaining spare parts have caused } \\
\text { increased downtime on occasion. A spare parts } \\
\text { list for the system was not available. Spare } \\
\text { parts are located at many different locations. } \\
\text { (problem being worked) }\end{array}$ & 560 & 6 & Mouse1 \\
\hline 3) & Purge gas & $\begin{array}{l}\text { Purge gas sometimes blows waste out of the way } \\
\text { and prevents obtaining a full sample. (Out of } \\
\text { scope for team) }\end{array}$ & $N / A$ & $N / A$ & $\begin{array}{l}\text { Lee } \\
\text { Dean }\end{array}$ \\
\hline 4) & Weather & $\begin{array}{l}\text { Wind and rain cause frequent shutdown of } \\
\text { operations. (Problem being addressed) }\end{array}$ & $N / A$ & $N / A$ & $\begin{array}{l}\text { Dean } \\
\text { Lee }\end{array}$ \\
\hline 5) & $\begin{array}{l}\text { In-Field Cog } \\
\text { Engineer Support }\end{array}$ & $\begin{array}{l}\text { Significant delays were occasionally } \\
\text { attributed to the on-site cognizant engineer } \\
\text { not being present in the field. }\end{array}$ & 300 & 6 & $\log$ book \\
\hline
\end{tabular}


TABLE 10

\section{LIST OF POTENTIAL PROBLEMS (OTHER)}

Rotary Mode Core Sample System

Note 1: Rating of impact on availability for sampling

Note 2: Rating for ease of implementation of fix

\begin{tabular}{|c|c|c|c|c|c|}
\hline $\begin{array}{l}\text { Item } \\
\text { No. } \\
\end{array}$ & $\begin{array}{l}\text { Component/ } \\
\text { Operation }\end{array}$ & $\begin{array}{c}\text { Problem } \\
\text { Description } \\
\end{array}$ & $\begin{array}{l}\text { See } \\
\text { Note } 1 \\
\end{array}$ & $\begin{array}{l}\text { See } \\
\text { Note } 2 \\
\end{array}$ & $\begin{array}{l}\text { Problem } \\
\text { Reported By }\end{array}$ \\
\hline 1) & $\begin{array}{l}\text { Equipment needed } \\
\text { for calibration }\end{array}$ & $\begin{array}{l}\text { There is no dedicated equipment for use in } \\
\text { calibrating the RMCSS instruments. Technicians } \\
\text { must borrow instrumentation having sufficient } \\
\text { range and resolution to conduct calibration } \\
\text { and repair of RMCSS instrumentation. (team } \\
\text { concludes this to be not cost effective) }\end{array}$ & $N / A$ & $N / A$ & Schmidt \\
\hline 2) & $\begin{array}{l}\text { RMCSS operating. } \\
\text { crew training }\end{array}$ & $\begin{array}{l}\text { Delays and errors in operation due to serious } \\
\text { errors in judgement. Training for the RMCSS } \\
\text { crew appears to lack sufficient in-field, } \\
\text { "hands-on" education. Needs further } \\
\text { investigation. }\end{array}$ & 120 & 6 & Dean \\
\hline 3) & $\begin{array}{l}\text { Infrastructure } \\
\text { inhibits upgrades }\end{array}$ & $\begin{array}{l}\text { Infrastructure inhibits upgrades. There has } \\
\text { been no real shake-down of truck \#2 design, } \\
\text { obtaining of operating experience or } \\
\text { accumulating "hours" on the equipment. This } \\
\text { may result in inherent flaws being passed on } \\
\text { to trucks \#3 and \#4. (out of scope for team) }\end{array}$ & $N / A$ & $N / A$ & Team \\
\hline 4) & $\begin{array}{l}\text { Need new } \\
\text { availability } \\
\text { baseline }\end{array}$ & $\begin{array}{l}\text { Availability issues were not readily available } \\
\text { to the task team. Establish new bench mark of } \\
\text { availability. (required for future } \\
\text { availability assessments - see item 10-4) }\end{array}$ & $N / A$ & $N / A$ & Team \\
\hline 5) & $\begin{array}{l}\text { Regulatory } \\
\text { complexity }\end{array}$ & $\begin{array}{l}\text { System designed to operate under worse case } \\
\text { "no risk" conditions for all tanks. Consider } \\
\text { using "minimum required equipment } 1 \text { ist" for } \\
\text { each tank. }\end{array}$ & 510 & 5 & Team \\
\hline
\end{tabular}




\begin{tabular}{|c|c|c|c|c|c|}
\hline $\begin{array}{l}\text { Item } \\
\text { No. }\end{array}$ & $\begin{array}{l}\text { Component/ } \\
\text { Operation }\end{array}$ & $\begin{array}{c}\text { Problem } \\
\text { Description }\end{array}$ & $\begin{array}{l}\text { See } \\
\text { Note } 1 \\
\end{array}$ & $\begin{array}{l}\text { See } \\
\text { Note } 2 \\
\end{array}$ & $\begin{array}{l}\text { Problem } \\
\text { Reported By }\end{array}$ \\
\hline 6) & $\begin{array}{l}\text { Exhauster hydrogen } \\
\text { and seismic } \\
\text { monitoring }\end{array}$ & $\begin{array}{l}\text { Technical, operational, and regulatory } \\
\text { complexity is increased if the hydrogen } \\
\text { monitor is added as safety class } 1 \text {. }\end{array}$ & 185 & 6 & Team \\
\hline 7) & $\begin{array}{l}\text { Mechanical PM's } \\
\text { not adequate }\end{array}$ & $\begin{array}{l}\text { Inadequate preventative maintenance to prevent } \\
\text { mechanical equipment failure. }\end{array}$ & 490 & 6 & Team \\
\hline 8) & $\begin{array}{l}\text { Pressure } \\
\text { transducer } \\
\text { calibration }\end{array}$ & $\begin{array}{l}\text { Calibration of pressure transducers is very } \\
\text { difficult. Due to their safety class } 2 \text { rating } \\
\text { they must be cal ibrated every six months. } \\
\text { Lack of test ports prevents insitu checkout } \\
\text { and calibration. Poor access for their } \\
\text { replacement is cause for much of the delay in } \\
\text { truck availability. }\end{array}$ & 32 & 5 & Bafus \\
\hline 9) & $\begin{array}{l}\text { Instrumentation } \\
\text { self-check }\end{array}$ & $\begin{array}{l}\text { Inadequate use of self-check routines to } \\
\text { determine status of critical instruments for } \\
\text { proper operation before daily drilling takes } \\
\text { place, results in higher downtime. }\end{array}$ & 144 & 1.5 & Bafus \\
\hline 10) & $\begin{array}{l}\text { Instrument } \\
\text { calibration/spares }\end{array}$ & $\begin{array}{l}\text { Instrument calibration currently requires } \\
\text { truck down time. Suggest spares be calibrated } \\
\text { for changeout. }\end{array}$ & 32 & 6 & Team \\
\hline 11) & $\begin{array}{l}\text { Preventative } \\
\text { maintenance } \\
\text { trending }\end{array}$ & $\begin{array}{l}\text { No trending is done to assist Preventative } \\
\text { Maintenance in determining when maintenance } \\
\text { should be performed for critical components. }\end{array}$ & 245 & 6 & Team \\
\hline
\end{tabular}


TABLE 1A

(Known Mechanical Problems)

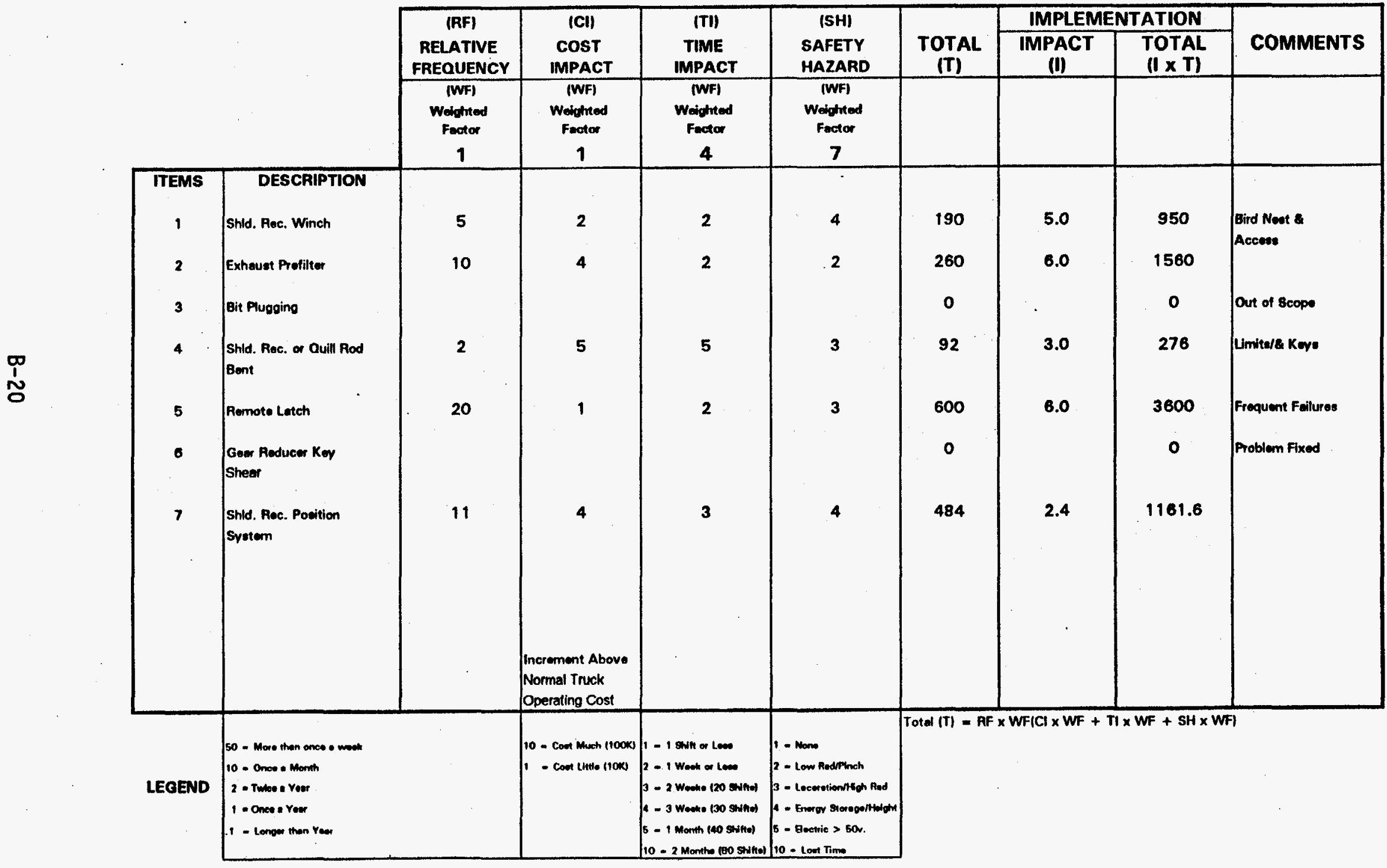


WHC-SD-WM-ER-415, Rev. 0

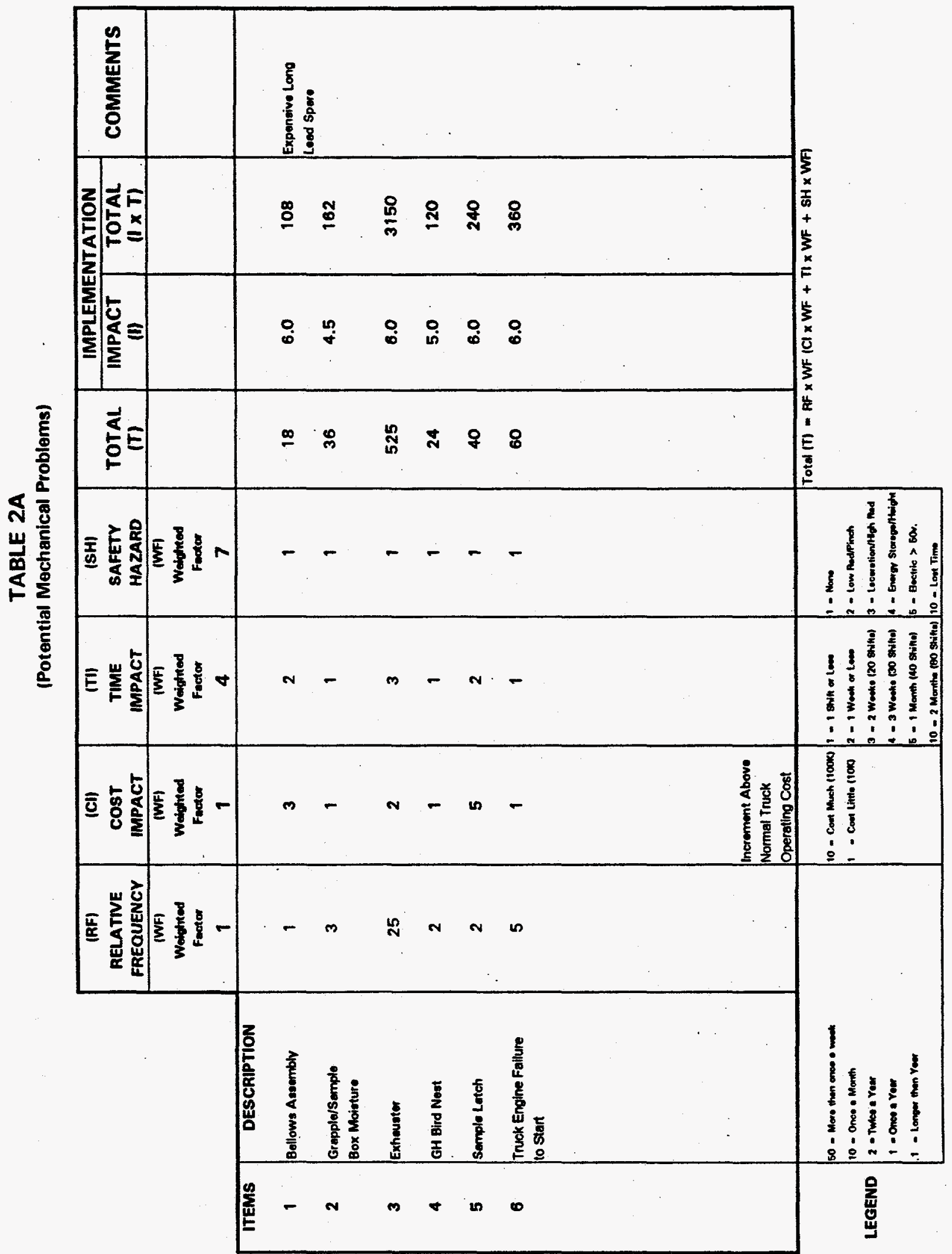


TABLE 3A

(Known Hydraulic Problems)

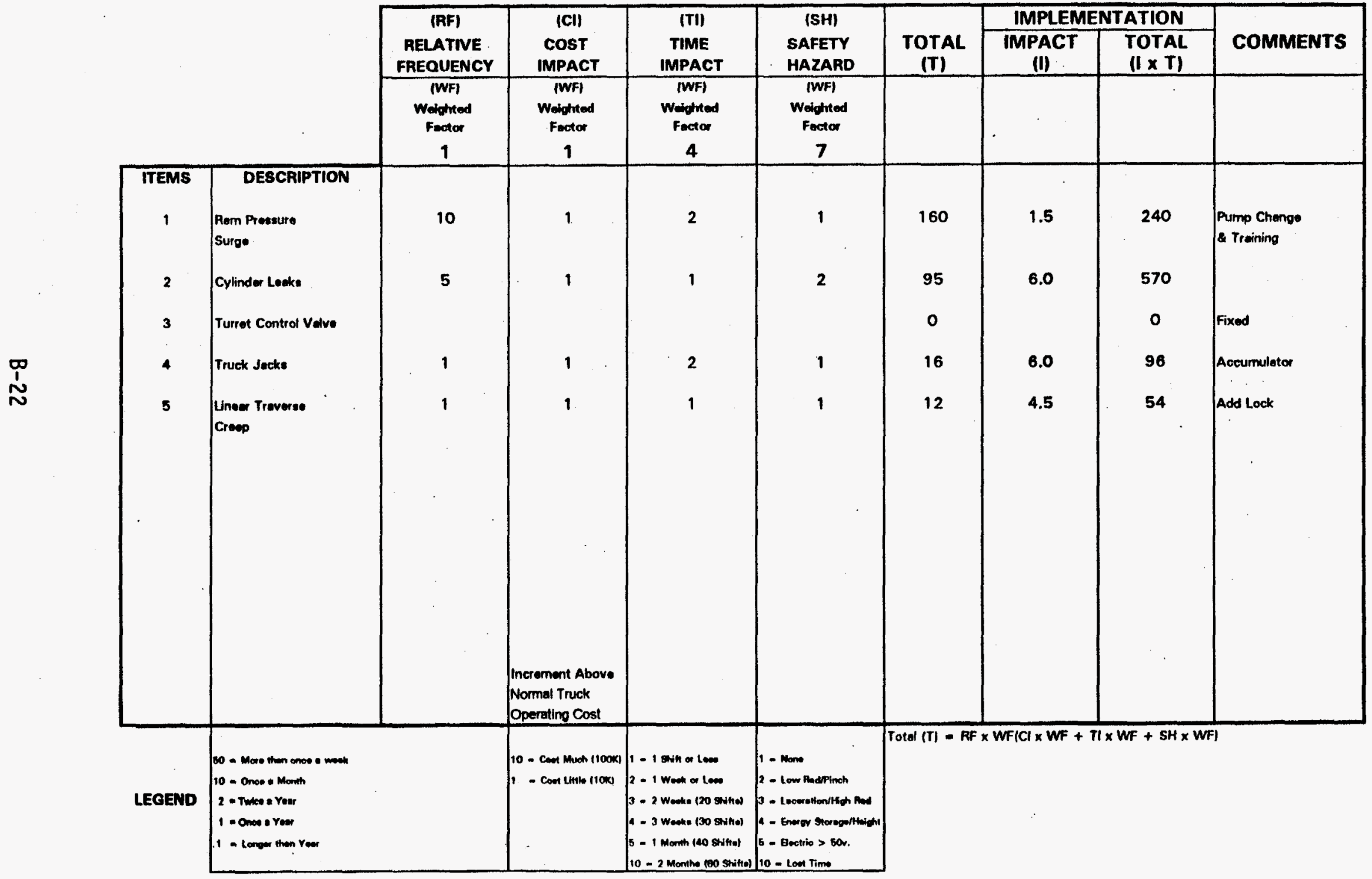


TABLE 4A

(Potential Hydraulic Problems)

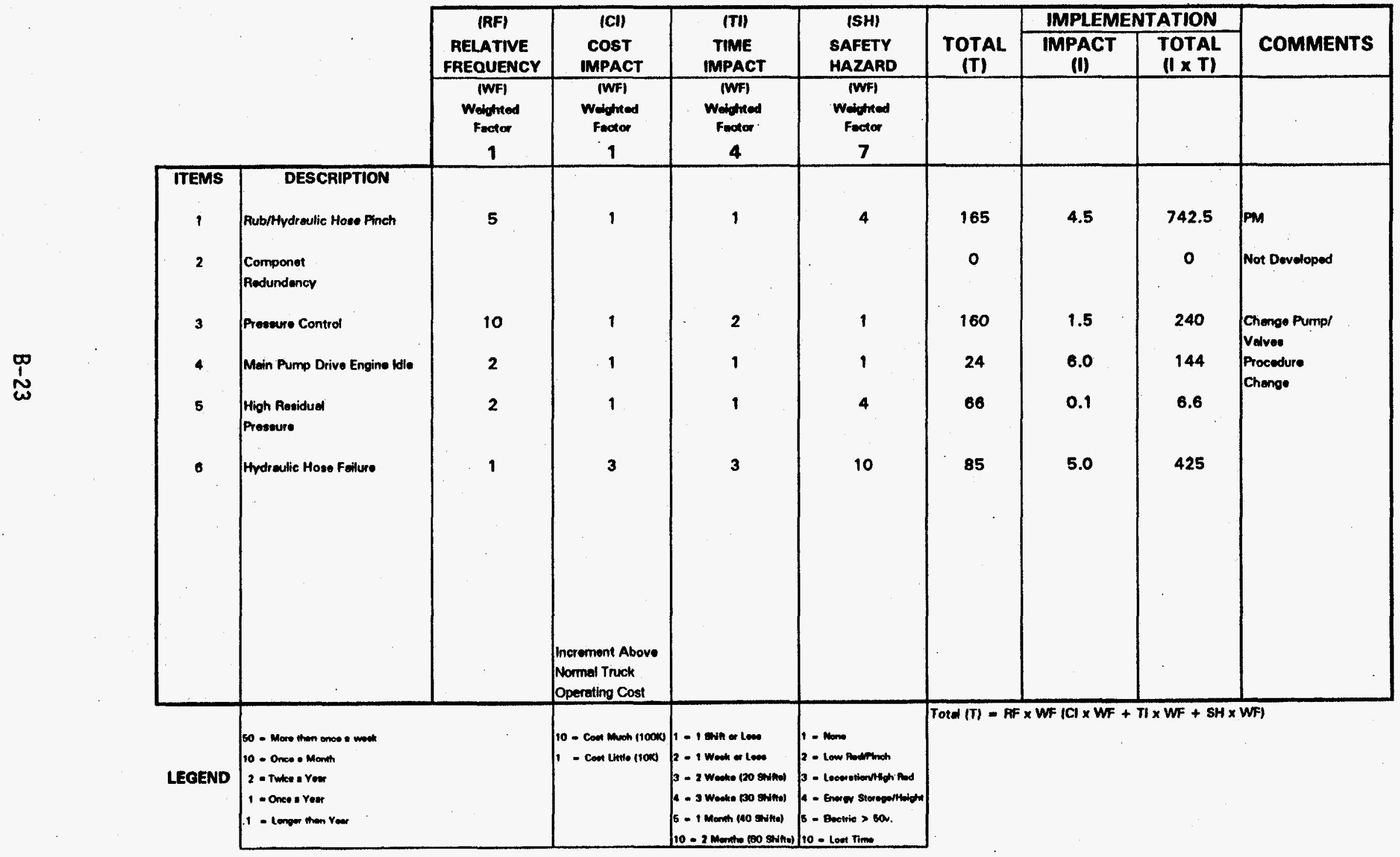


TABLE 5A

(Known I8C Probleme)

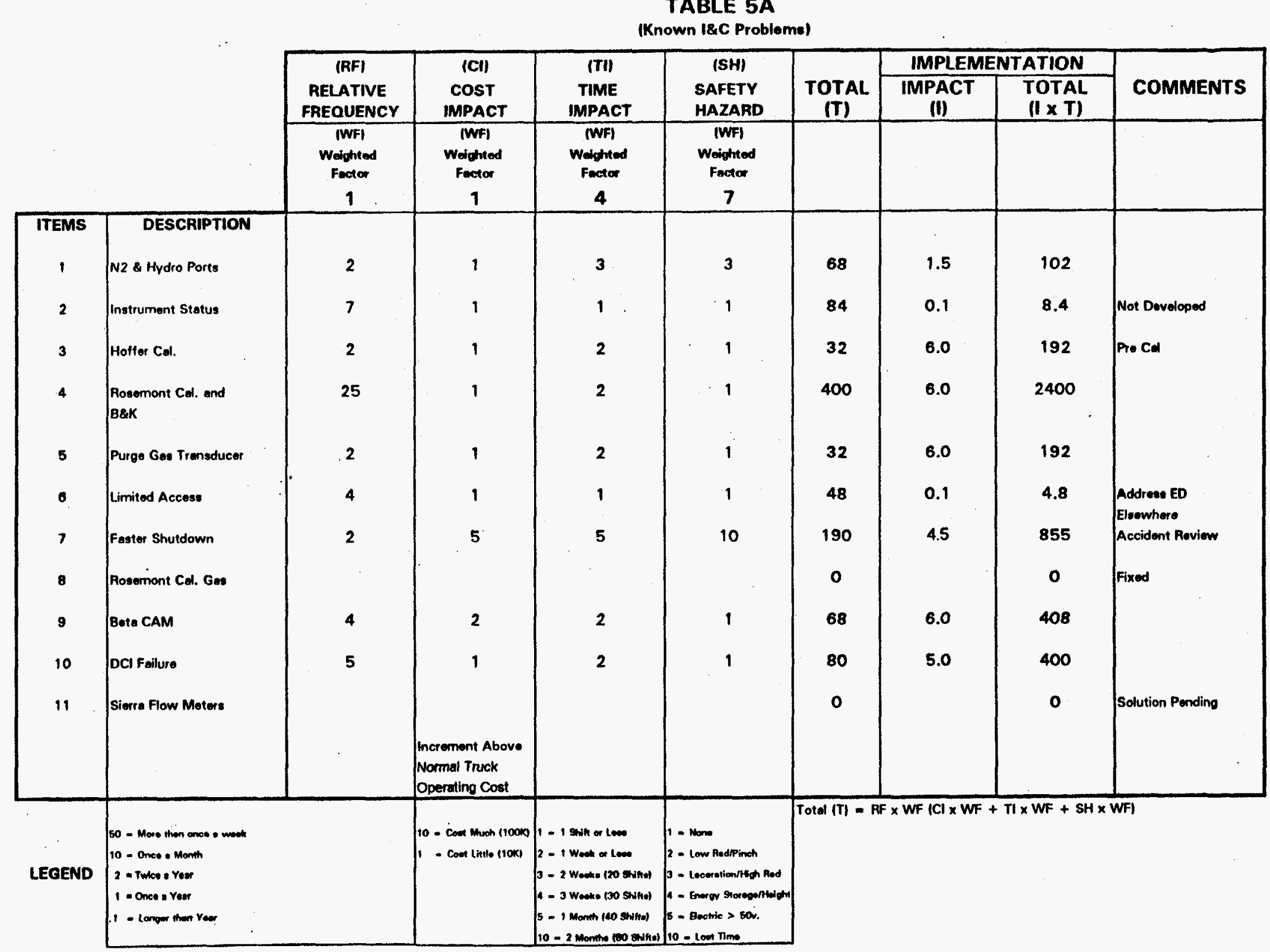


TABLE 6A

(Potential I\&C Problems)

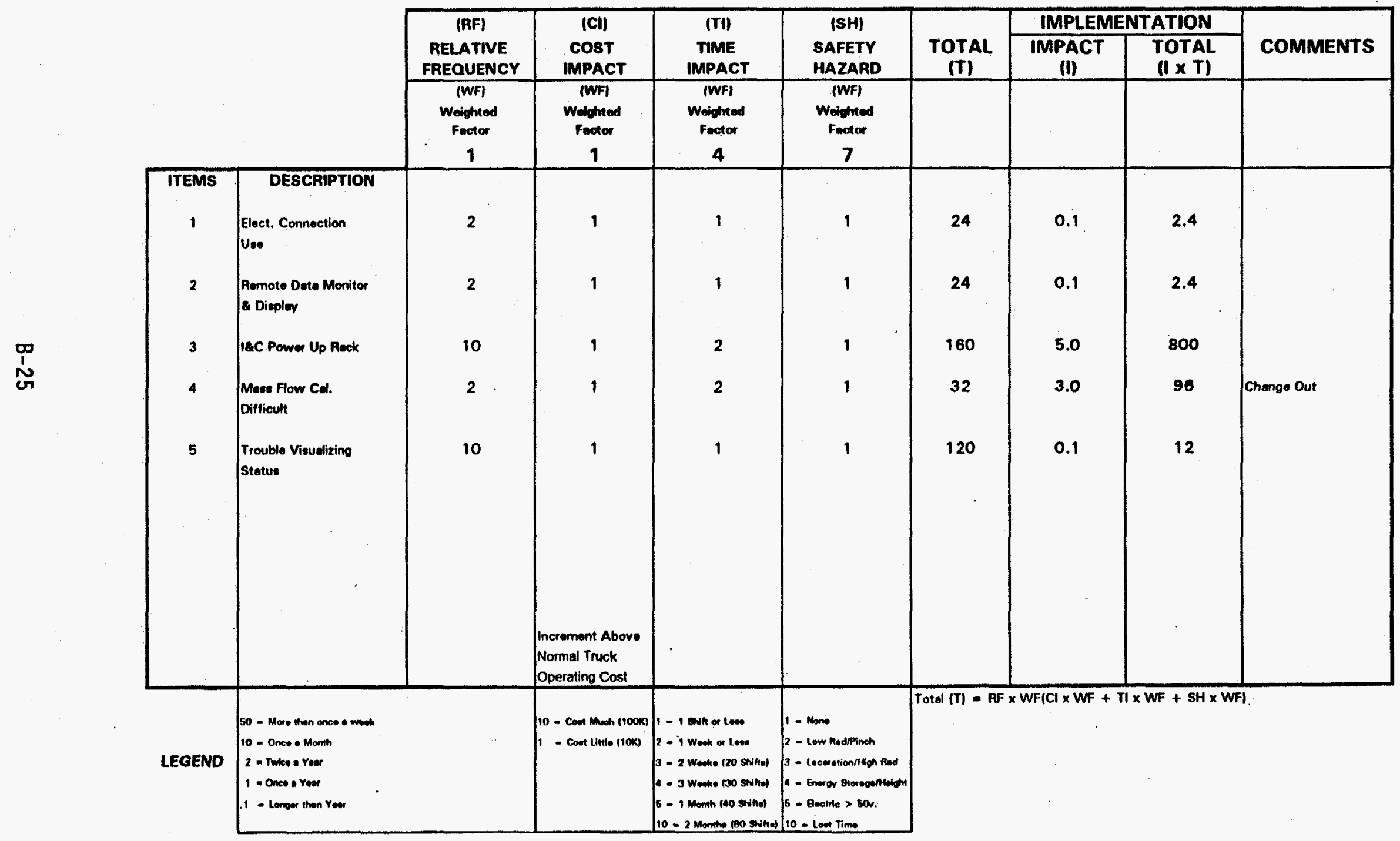


TABLE 7A

(Known Electrical Problems)

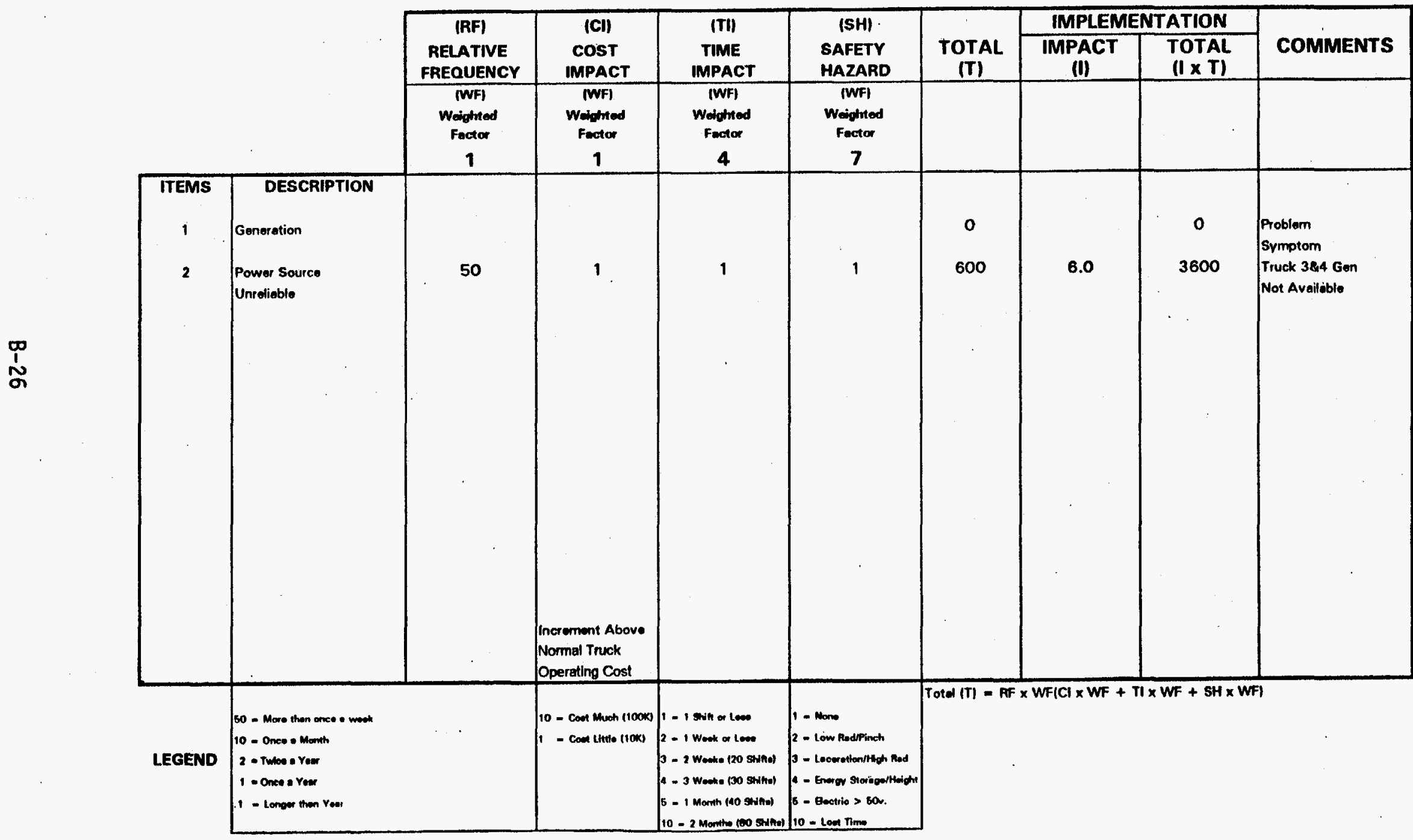


TABLE 8A

(Potential Electrical Problems)

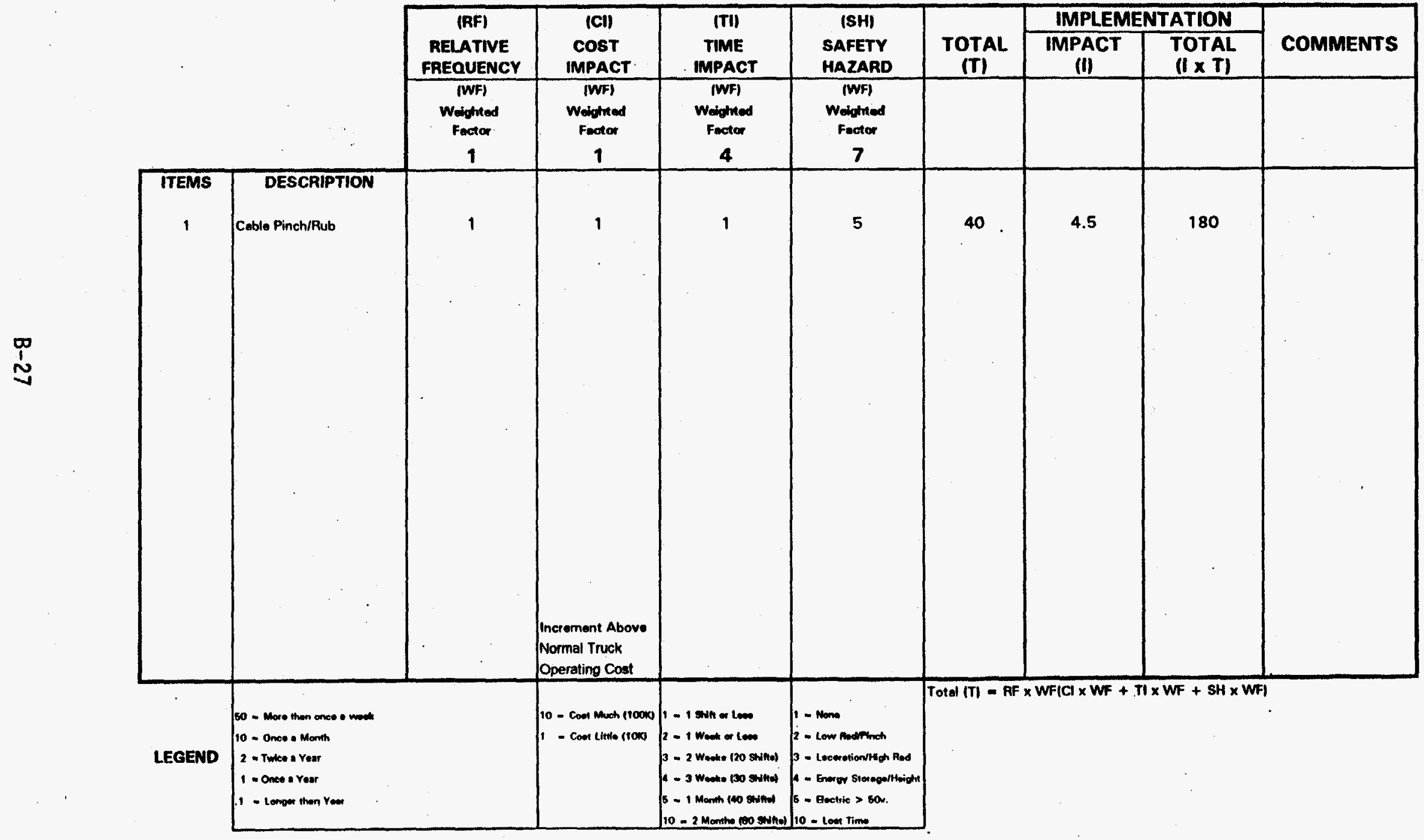


TABLE 9A

(Known Administrative Problems)

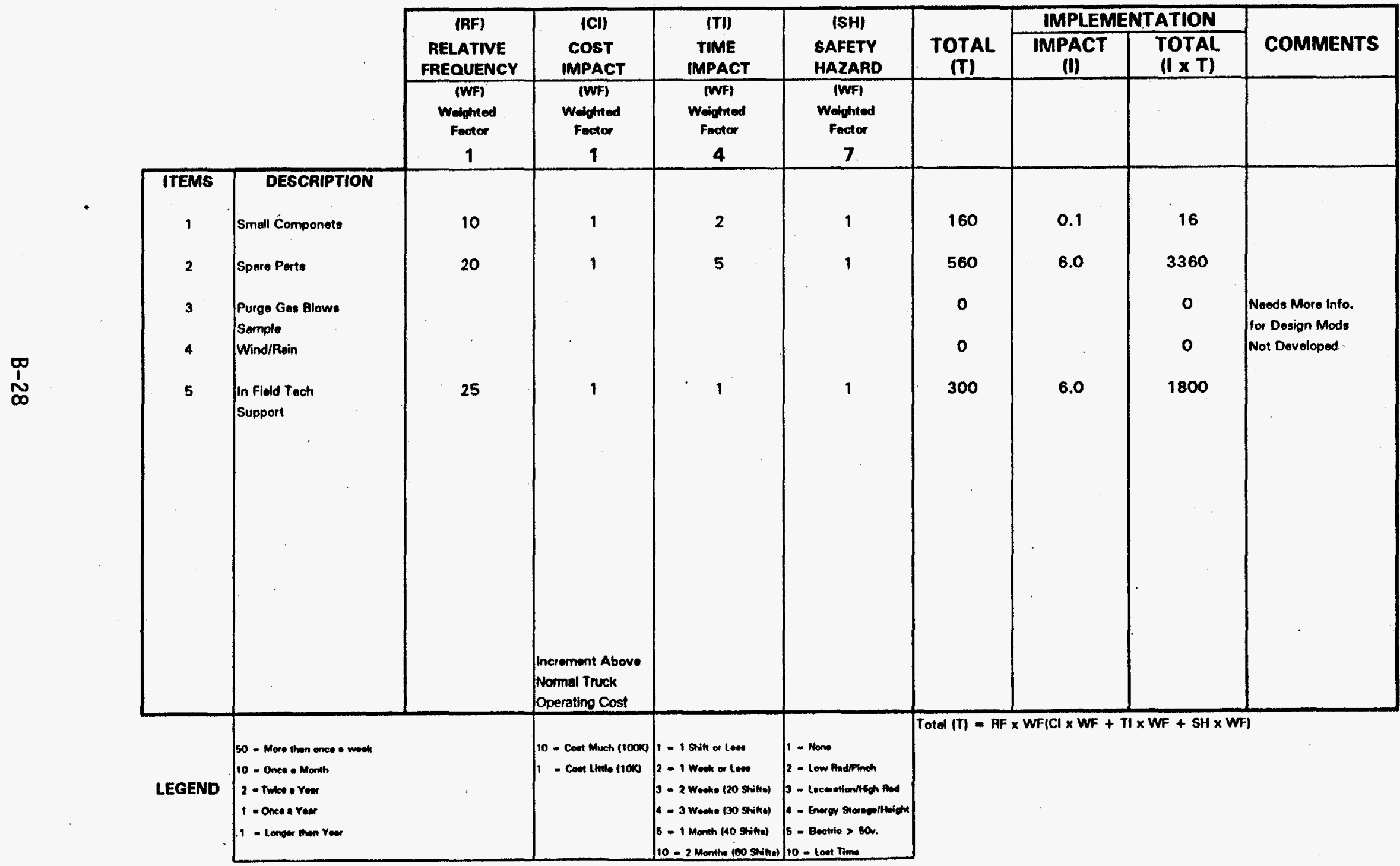


TABLE 10A

(Potential Administrative Problems)

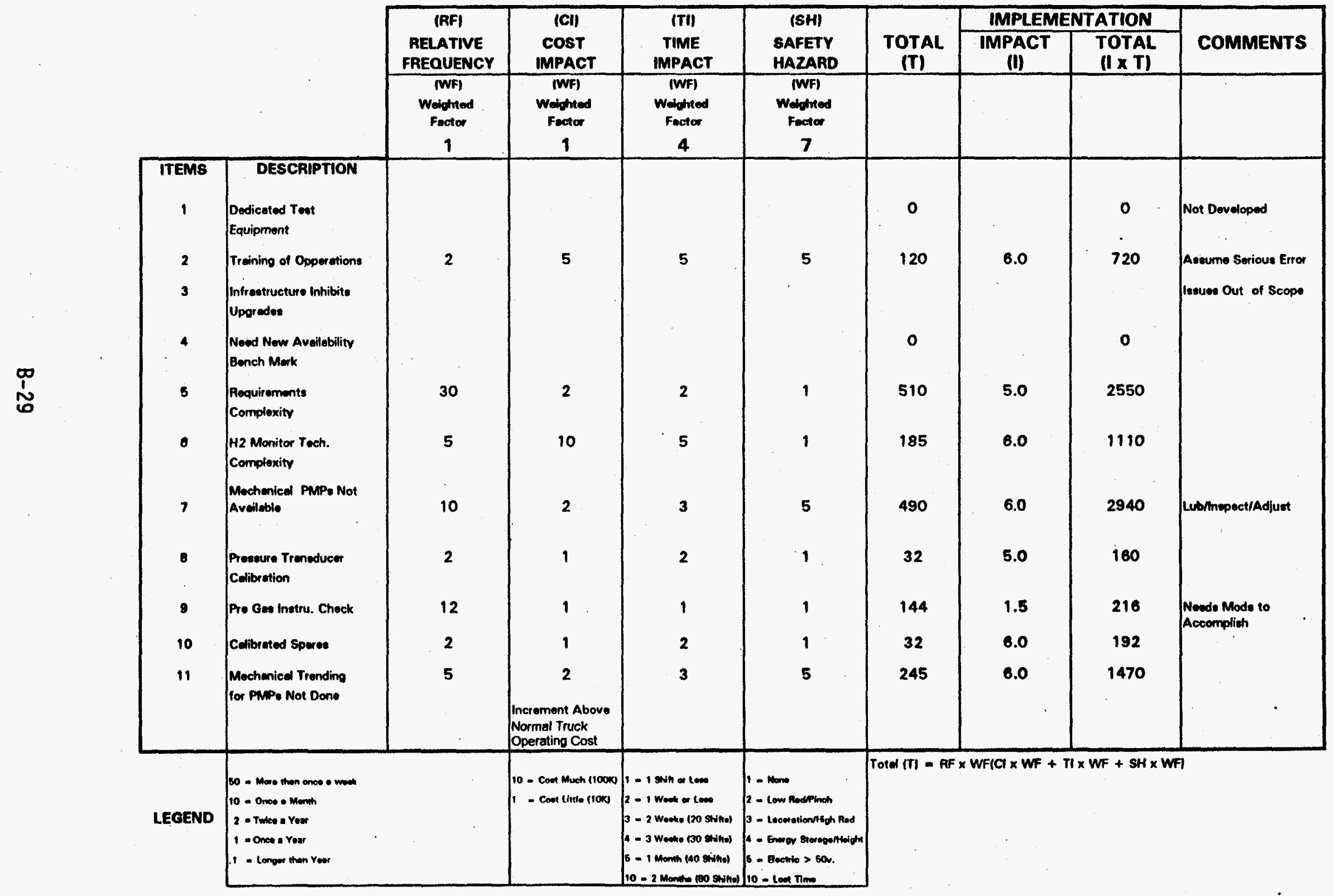


TABLE 11

(TABLES 1 - 10 COMBINED, ORDERED BY IMPACT ON AVAILABILITY)

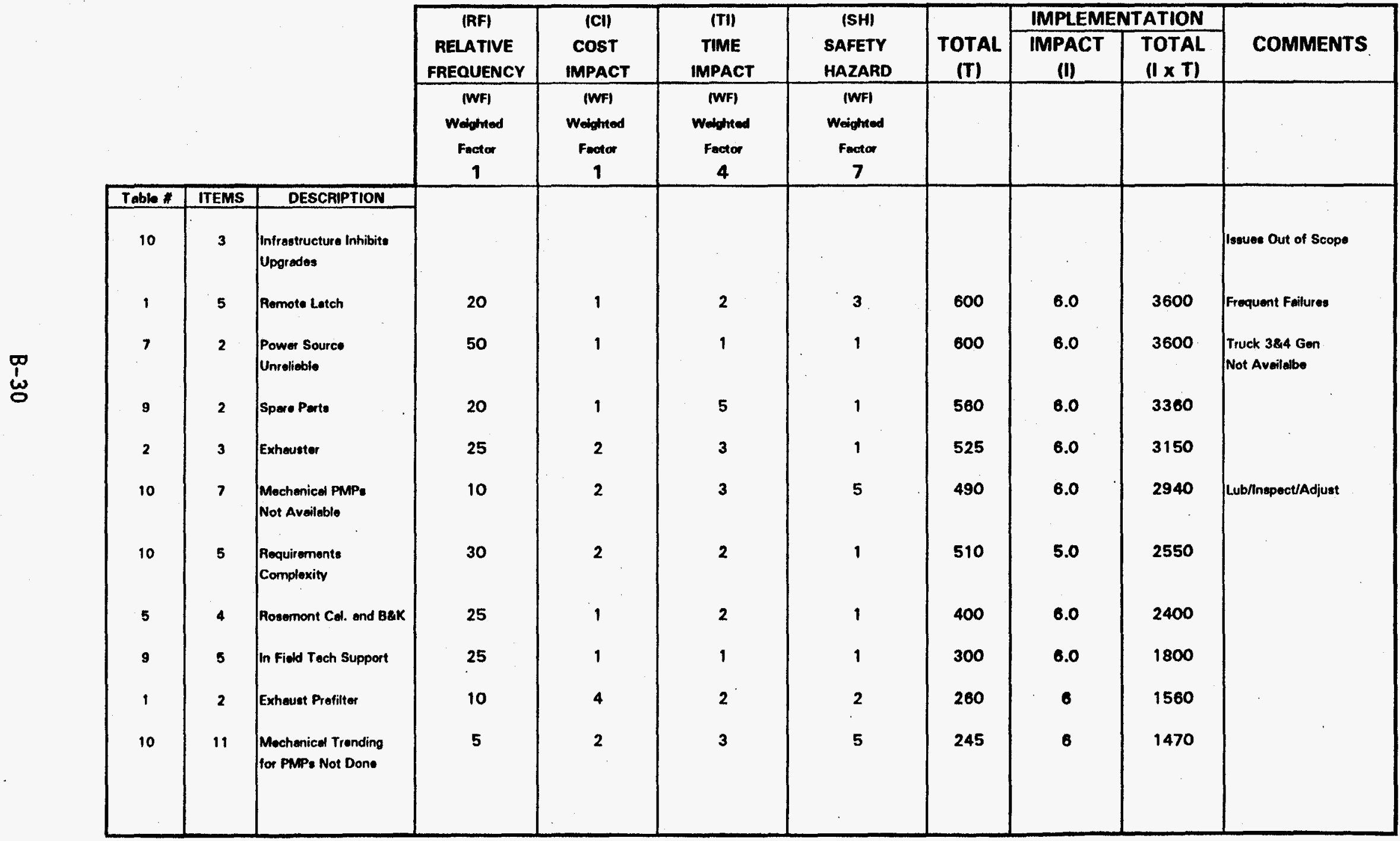




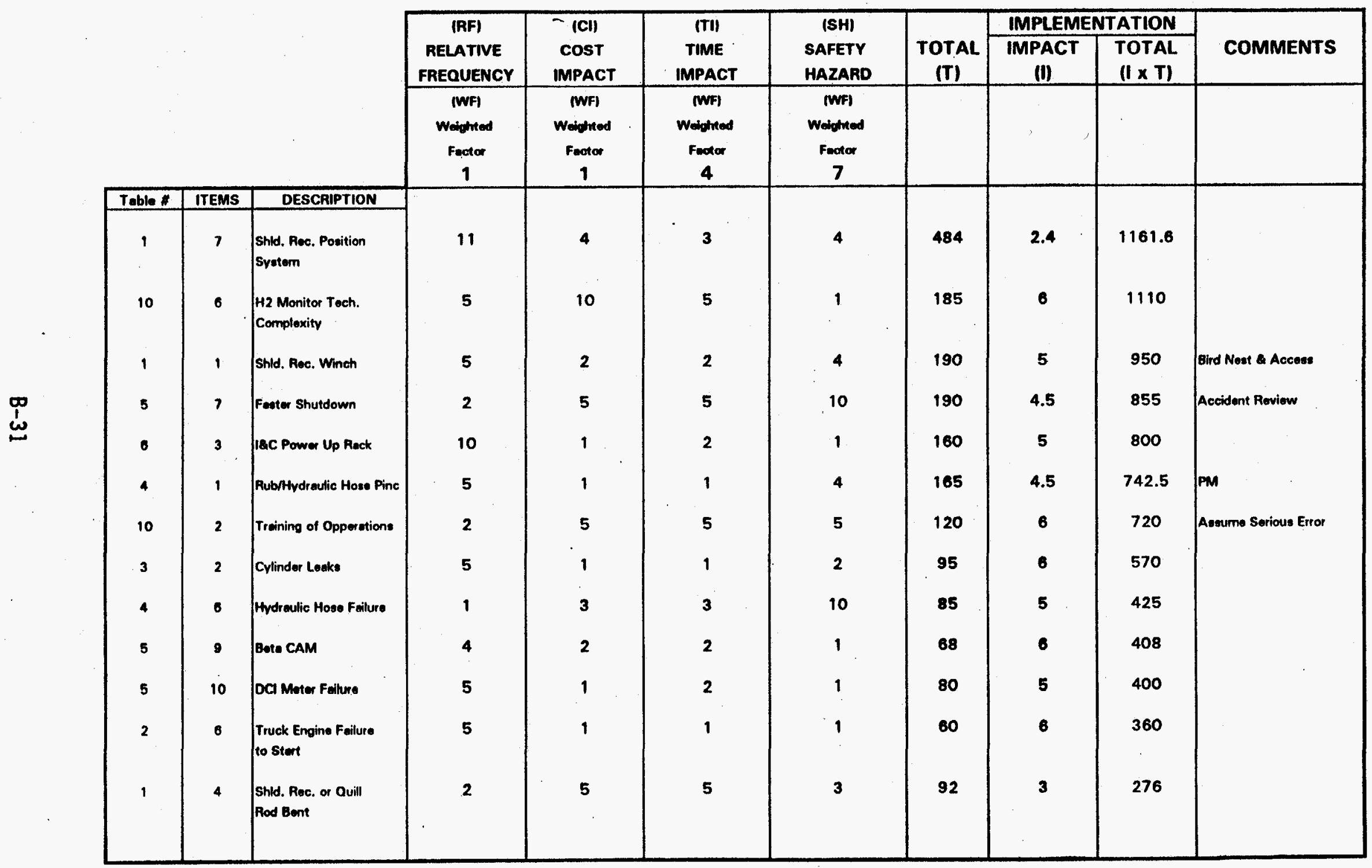




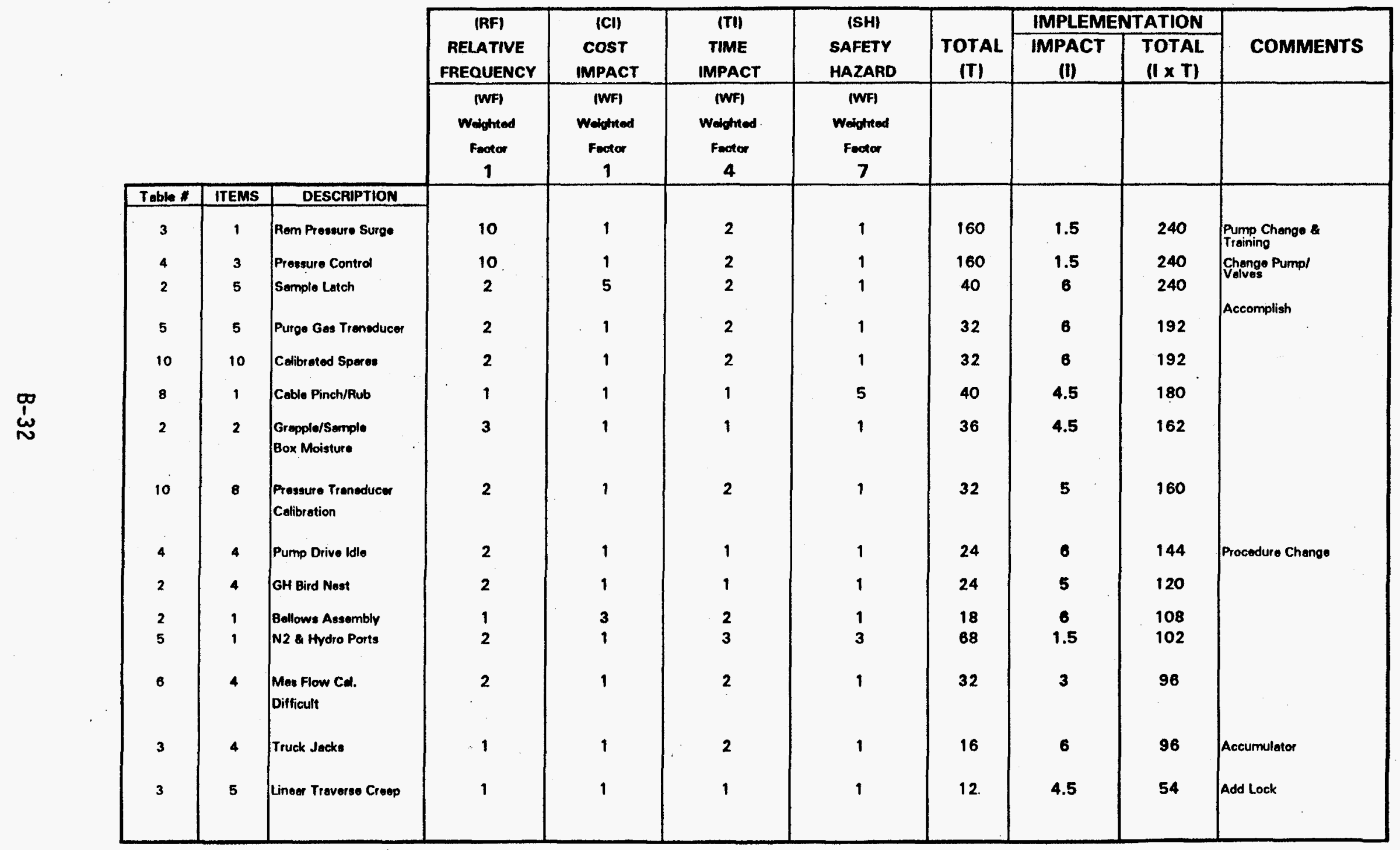




\begin{tabular}{|c|c|c|c|c|c|c|c|c|c|c|}
\hline & & & $\begin{array}{c}\text { (RF) } \\
\text { RELATIVE } \\
\text { FREQUENCY }\end{array}$ & $\begin{array}{c}\text { (CI) } \\
\text { COST } \\
\text { IMPACT }\end{array}$ & $\begin{array}{c}\text { ITII } \\
\text { TIME } \\
\text { IMPACT }\end{array}$ & $\begin{array}{c}\text { [SH] } \\
\text { SAFETY } \\
\text { HAZARD }\end{array}$ & $\begin{array}{l}\text { TOTAL } \\
\text { (T) }\end{array}$ & $\begin{array}{l}\text { TMPLEM } \\
\text { IMPACT } \\
\text { (I) }\end{array}$ & $\begin{array}{l}\text { TATION } \\
\text { TOTAL } \\
(\mid \times T)\end{array}$ & COMMENTS \\
\hline & & & $\begin{array}{c}\text { (WFI } \\
\text { Woighted } \\
\text { Factor } \\
1\end{array}$ & $\begin{array}{c}\text { (WF) } \\
\text { Weighted } \\
\text { Fantor } \\
1\end{array}$ & $\begin{array}{c}\text { (WF) } \\
\text { Weighted } \\
\text { Factor } \\
4\end{array}$ & $\begin{array}{c}\text { (WF) } \\
\text { Weighted } \\
\text { Fontor } \\
7\end{array}$ & & & & \\
\hline Table * & ITEMS & DESCAIPTION & & & & & & & & \\
\hline 9 & 1 & Small Componets & 10 & 1 & 2 & 1 & 160 & 0.1 & 16 & \\
\hline 6 & 5 & $\begin{array}{l}\text { Troublo Visuelizing } \\
\text { Stetus }\end{array}$ & 10 & 1 & 1 & 1 & 120 & 0.1 & 12 & \\
\hline 5 & 2 & Instrument Statur & 7 & 1 & 1 & 1 & 84 & 0.1 & 8.4 & \\
\hline 4. & 5 & High Residual Presesure & 2 & 1 & 1 & 4 & 66 & 0.1 & 6.6 & \\
\hline 5 & 6 & Limited Accoss & 4 & 1 & 1 & 1 & 48 & 0.1 & 4.8 & Address ED \\
\hline 0 & 1 & Elect. Connection Uso & 2 & 1 & 1 & 1 & 24 & 0.1 & 2.4 & \\
\hline 6 & 2 & Remote Data Monitor & 2 & 1 & 1 & 1 & 24 & 0.1 & 2.4 & \\
\hline 1 & 3 & Bit Plugging & & & & & 0 & - & o & Out of Scope \\
\hline 1 & 6 & $\begin{array}{l}\text { Geer Roducer Kov } \\
\text { Shoor }\end{array}$ & & & & & 0 & & 0 & Problom Fixed \\
\hline 3 & 3 & Turret Control Valve & & & & & 0 & & 0 & Fixed \\
\hline 4 & 2 & Componet Rodundency & & & & & 0 & & 0 & Not Developed \\
\hline 5 & 11 & Sierra Flow Moters: & & & & & 0 & & 0 & Solution Pending \\
\hline 7 & 1 & Generation & & & & & 0 & & 0 & Problem Symptom \\
\hline 10 & 1 & $\begin{array}{l}\text { Dedicated Tout } \\
\text { Equipment }\end{array}$ & & & & & 0 & & 0 & Not Developed \\
\hline
\end{tabular}




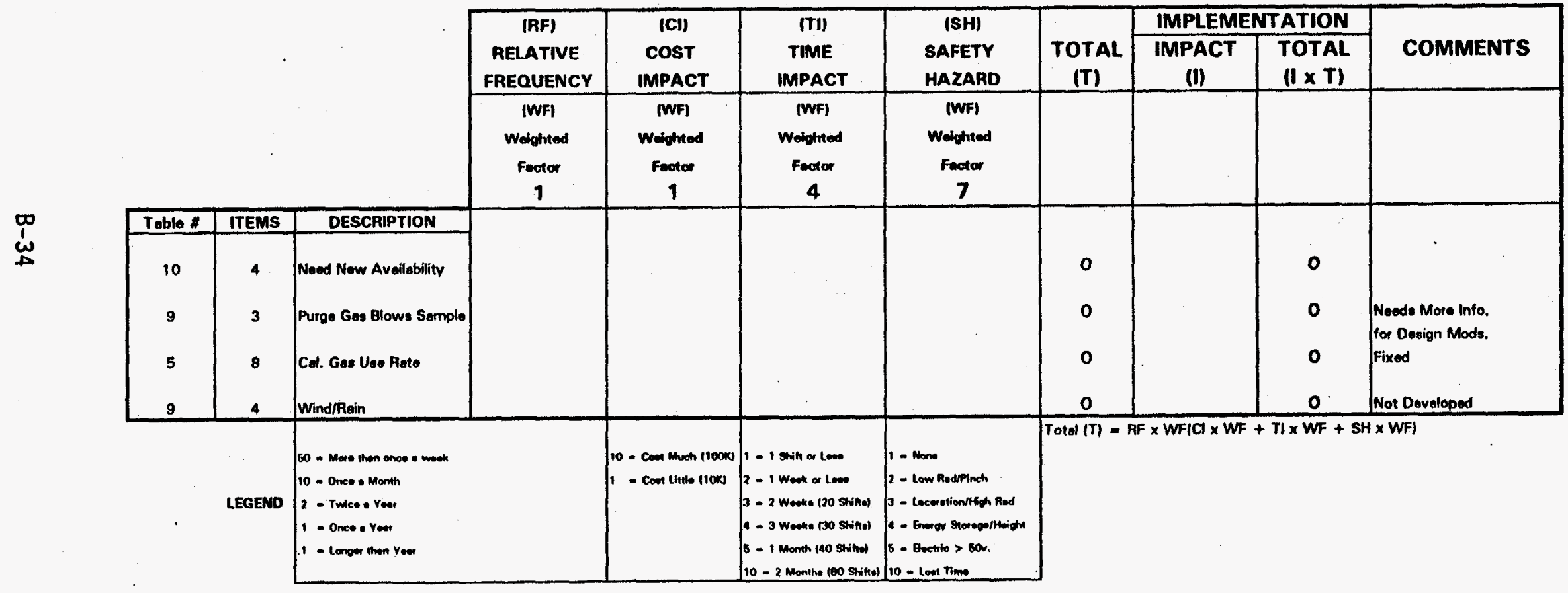


TABLE 12 - TECHNICAL

(TABLES 1 - 8 COMBINED, ORDERED BY IMPART ON AVAILABILITY)

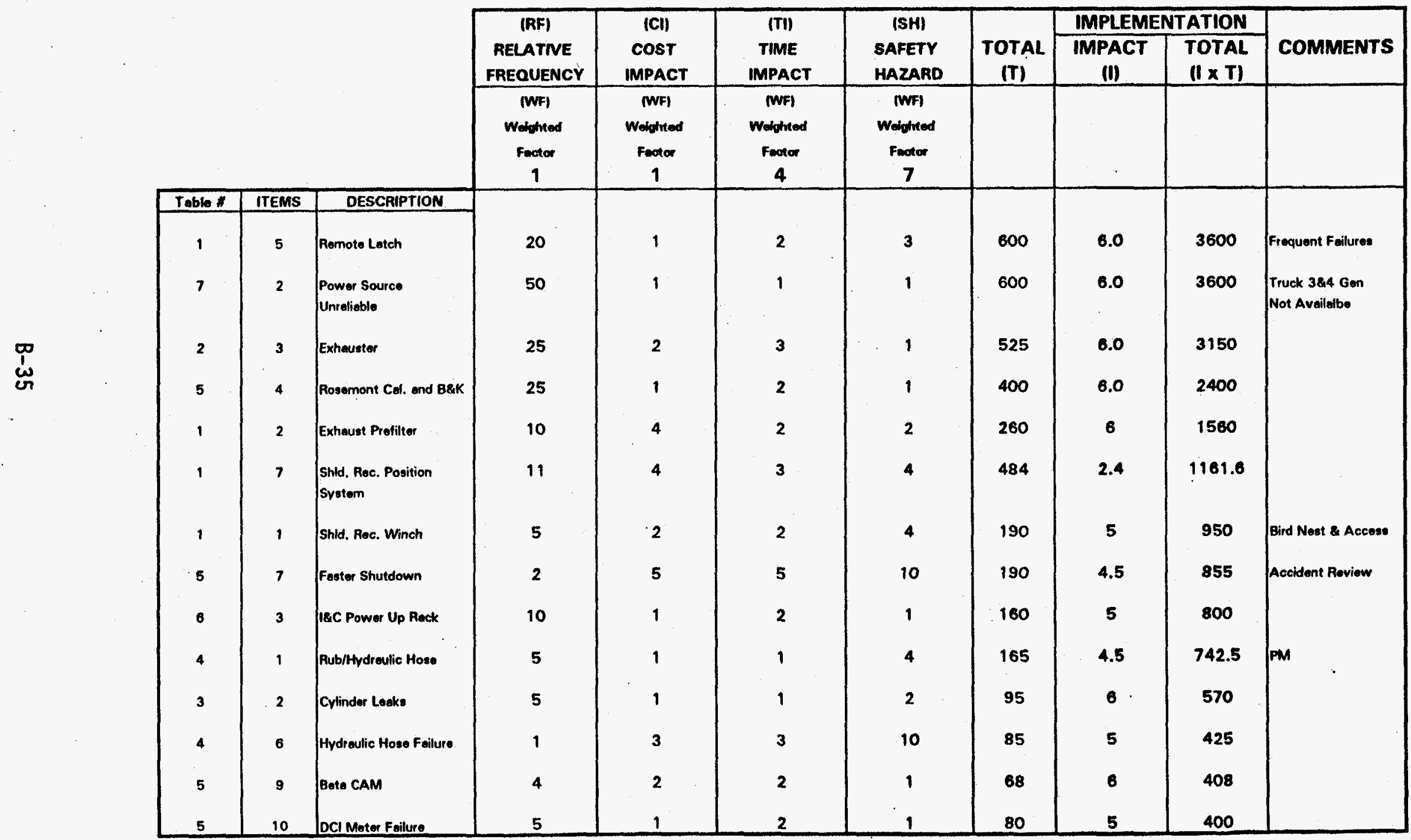




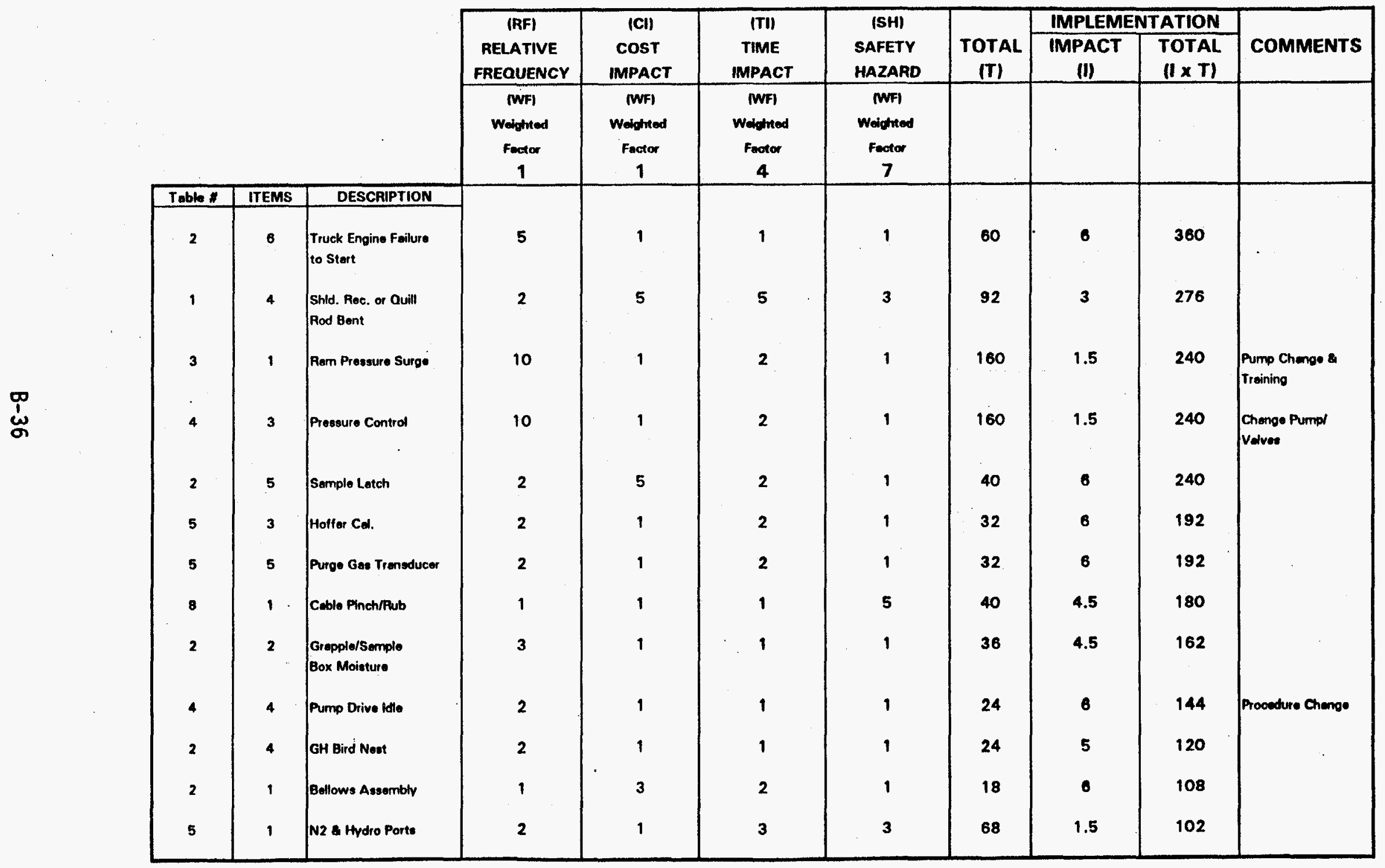




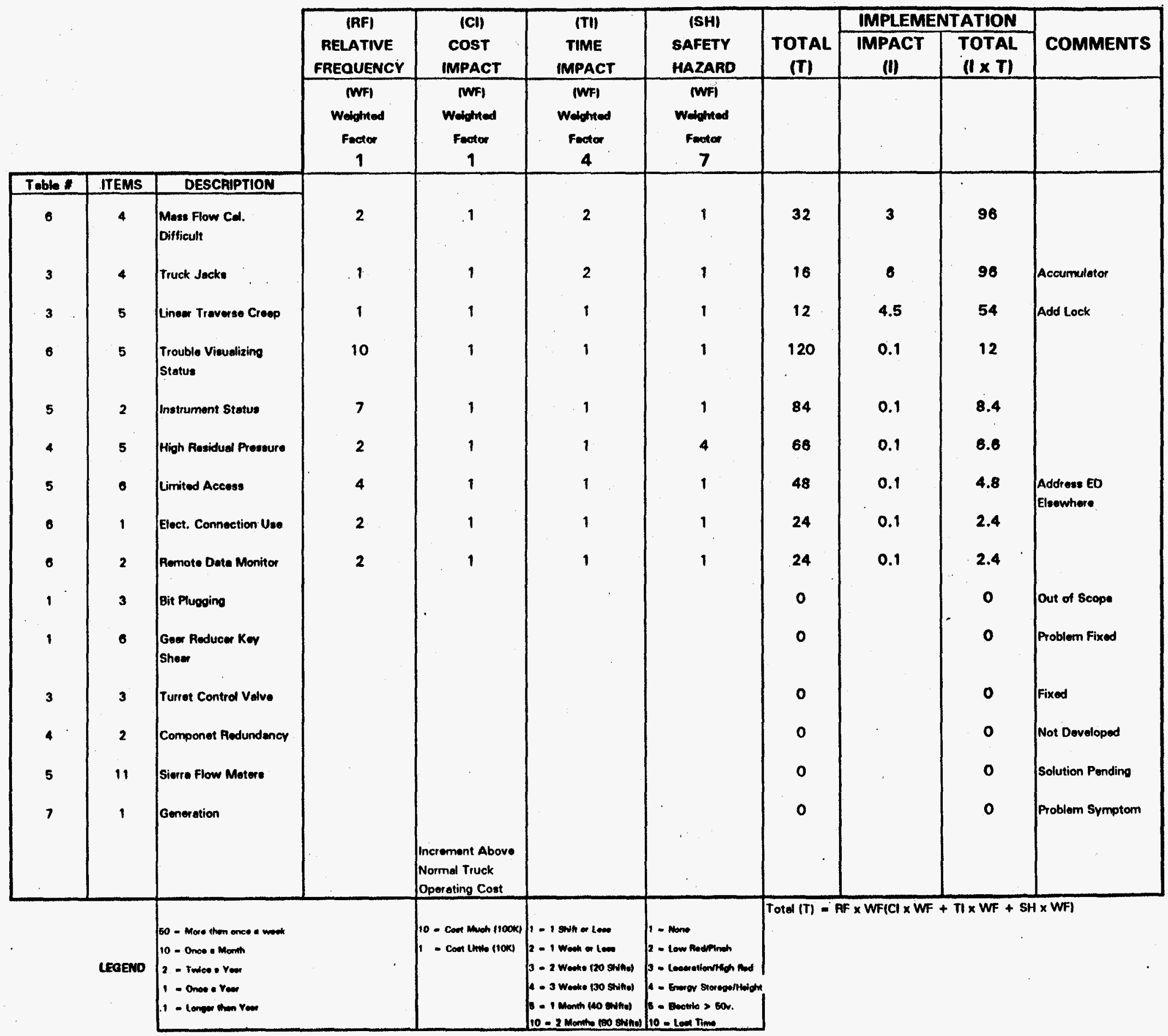


TABLE 13 - ADMINISTRATIVE

(TABLES 9 - 10 COMBINED, ORDERED BY IMPACT ON AVAILABILITY)

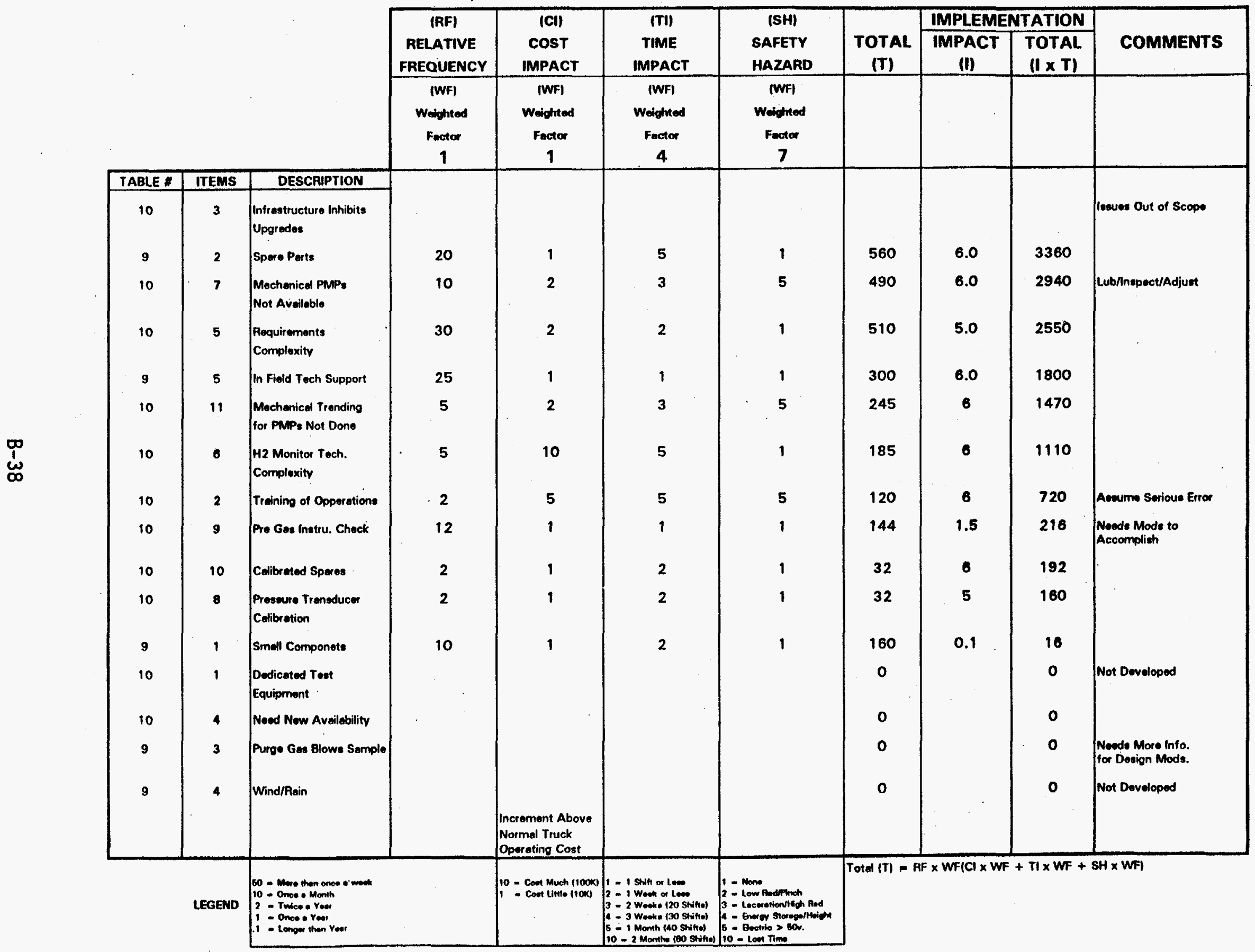


WHC-SD-WM-ER-415, Rev. 0

APPENDIX C

DOWNTIME HISTORY OF RMCSS

C-1 
WHC-SD-WM-ER-415, Rev. 0

This page intentionally left blank. 


\section{WHC-SD-WM-ER-415, Rev. 0 \\ APPENDIX C}

\section{DOWNTIME HISTORY OF RMCSS}

This section presents RMCSS \#2 data obtained from the following operations logbook:

Notebook Number: WHC-N-927-1

Title: Rotary Truck Core \#2 Sampling Operations Logbook \#1

Period documented: $3 / 29 / 94$ through $1 / 20 / 95$

The pages that follow in this section provide a visual representation of the logbook entries during tank sampling from 10/21/94 through 1/30/95. Previous times documented in the logbook were devoted to training and testing.

Data extracted from the logbook is summarized and presented on three charts. A "time line" representation of the logbook provides status of the key RMCSS System Components. Note: Sampling occurs when the system is not available for rotary-mode because samples are obtained in push-mode. RMCSS ability to operate in rotary-mode is also indicated.

SUMMARY OF LOGBOOK INFORMATION

Days not available due to failure $(10 / 21 / 94-1 / 30 / 95)$

\begin{tabular}{|c|c|}
\hline $\begin{array}{l}\text { Breathing Air Compressor } \\
\text { Switch } \\
\text { 0il Teak } \\
\text { Down unknown cause }\end{array}$ & $\begin{aligned} \frac{18}{1} \text { days } \\
15 \text { day } \\
15 \text { days } \\
2 \text { days }\end{aligned}$ \\
\hline $\begin{array}{l}\text { Exhauster failures } \\
\text { Rosemont } \\
\text { Gas bottles } \\
\text { CAM } \\
\text { Freezing } \\
\text { (prefilter/probes/pump) }\end{array}$ & $\begin{array}{l}\frac{26}{10} \text { days } \\
1 \text { days } \\
6 \text { days } \\
9 \text { days }\end{array}$ \\
\hline $\begin{array}{l}\text { Diesel generator } \\
\text { Batt } \\
\text { Low } 0 i 1 \\
\text { Thrown Rod } \\
\text { Down unknown }\end{array}$ & $\begin{array}{l}\frac{25}{1} \text { days } \\
2 \text { day } \\
20 \text { days } \\
2 \text { days }\end{array}$ \\
\hline $\begin{array}{l}\text { Rotary Truck } \\
\text { Platform } \\
\text { Remote Latch } \\
\text { Won't start } \\
\text { Shielded receiver }\end{array}$ & $\begin{array}{l}\frac{10}{2} \text { days } \\
6 \text { days } \\
1 \text { days } \\
1 \text { day }\end{array}$ \\
\hline
\end{tabular}


WHC-SD-WM-ER-415, Rev. 0

Administrative downt ime

Weekends/Holidays

Paperwork delay

Weather

personnel

Radiation levels

PMP Calibration
55 days

32 days

4 days

2 days

2 days

1 day

14 days

103 days are in the period 10/21/94-1/30/95. The total number of days of failures listed above is 134 because during several time periods multiple units were down at the same time. 
RMCS PIC LOG

October 21 - February 1

\section{Sampling Period (Oct. 21 - Feb. 1)} RMCSS \#2

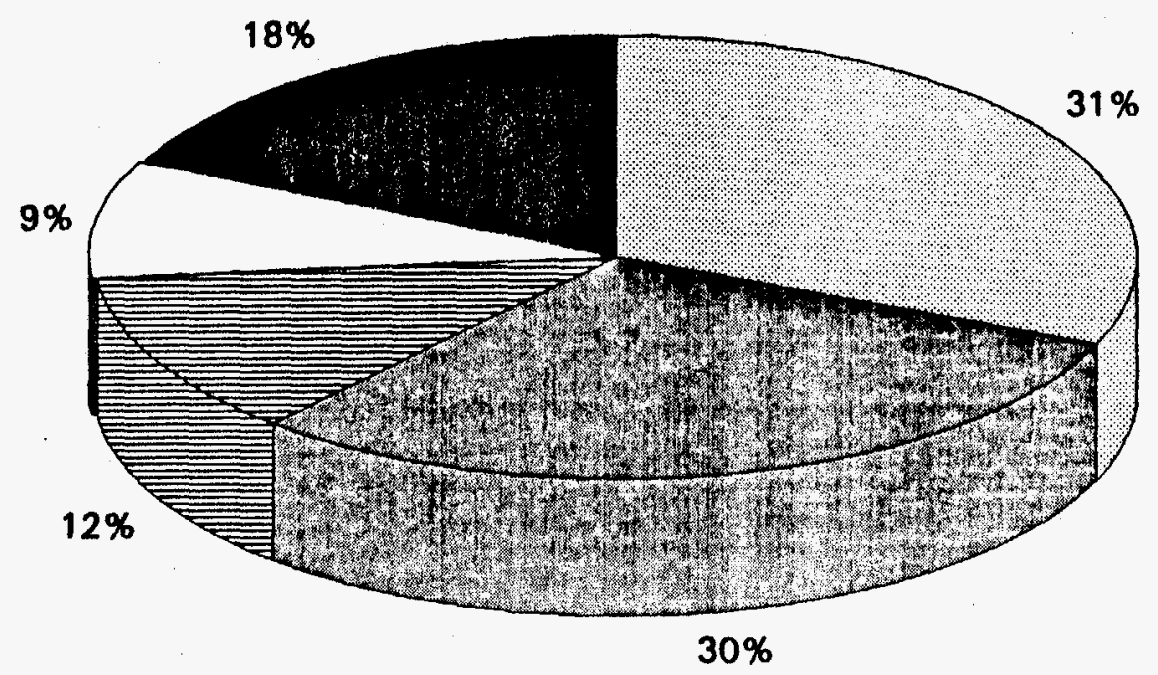

Failures Made Unavailable

Available but Idle, Weekend/Holidays

目 Available but Idle, PMP's/Calibration

$\square$ Moving to New Location

Sampling Activities 
RMCSS PIC LOG

October 21 - February 1

79 Total Days of Failure

I

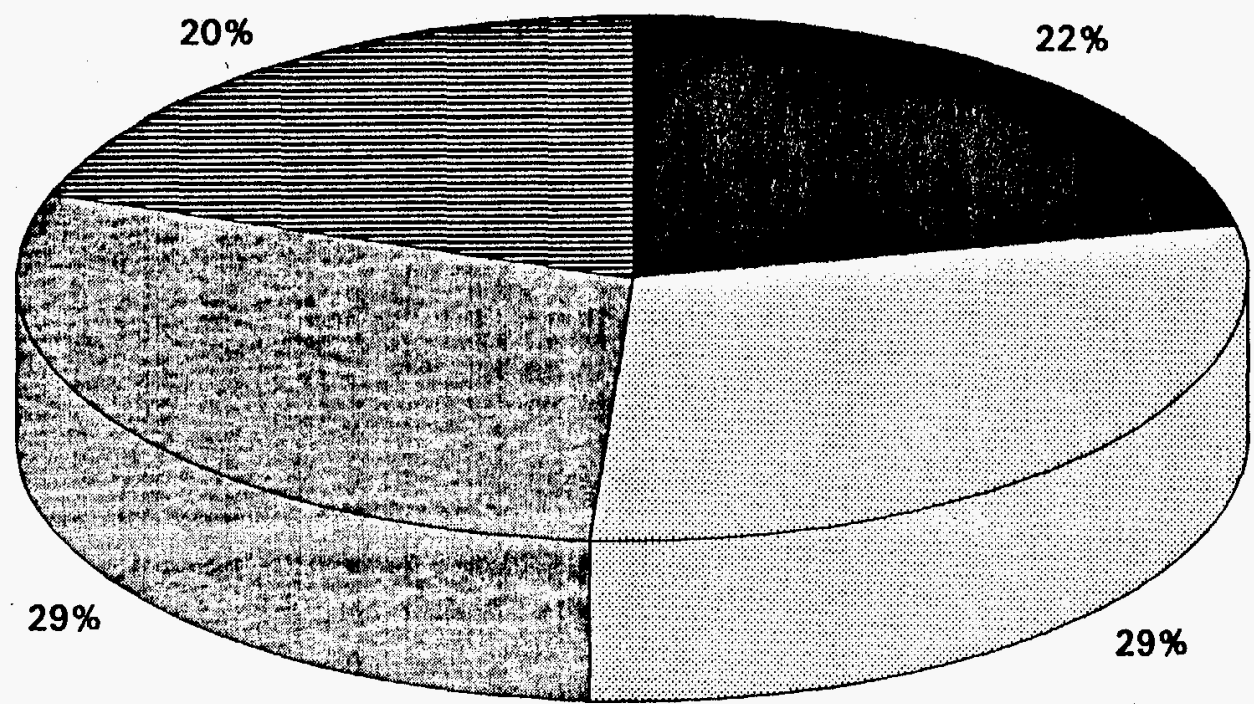

Breathing Air Compressor

Exhauster

Diesel Generator

畕 RMCS Truck 
WHC-SD-WM-ER-415, Rev. 0

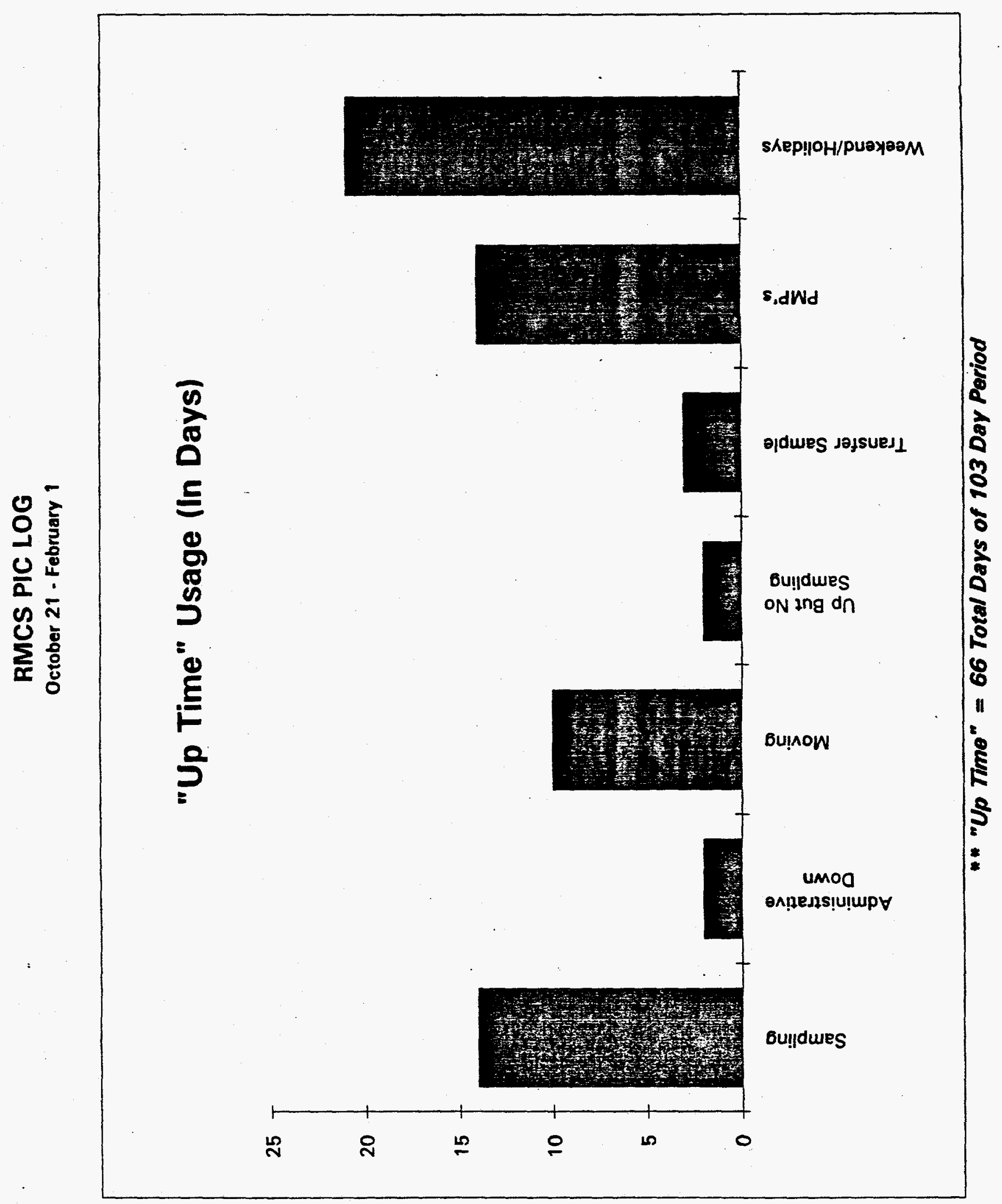


RMCS PIC LOG

October 21 - February 1

Total Down Time (In Days)

$\stackrel{1}{1}$

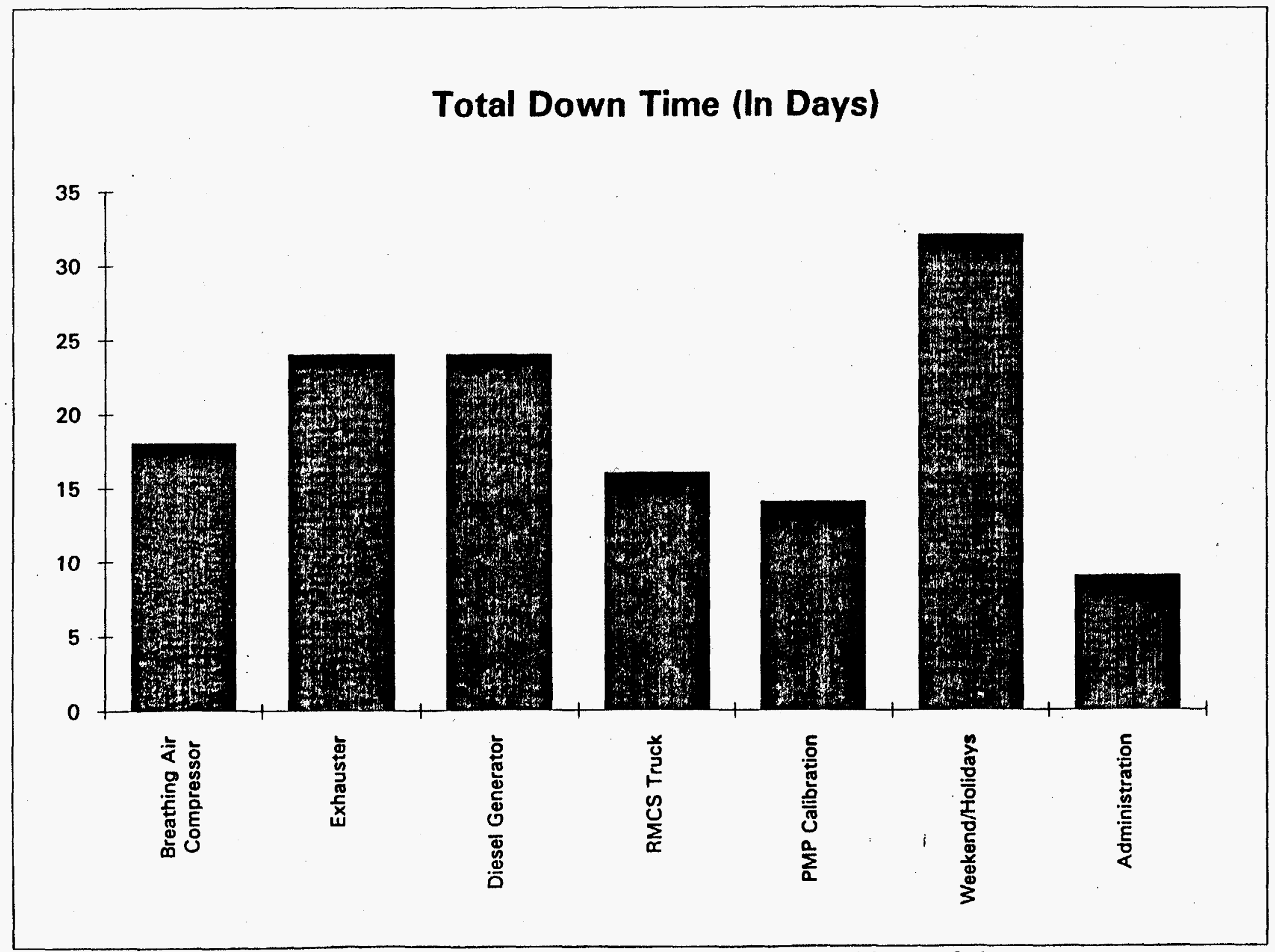

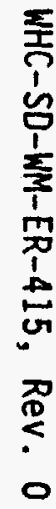

* Multiple units were down at the same time. Period had 103 days. 
- Lamod ou ol anp uMOp walsks $\nabla l$ -sj!edas sof use t 10 zno panou jolesauag jasa!d $\varepsilon l$ -sụedas jof uset to lno panou sossasduo $\forall \cdot 8$ 乙L

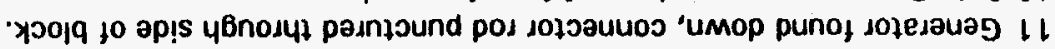
- Aepintes no yjom ou 'umop mazsAs ol

sped eneds sol buppen elgepeneun jowosied joddins pepoon syers popoon spol youscodod soypoom

:sepnjoul cho6ejes

Aopo dobops enpeassupupy $=V$

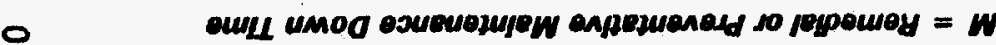

- lamod ou ol anp umop walsks 6

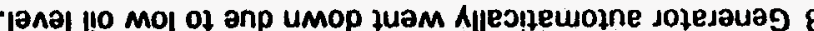

'quomasoy uo paxjom sue!̣!uyja $\perp L$

-suolnpuos puin Buons of anp paddols y10M 9

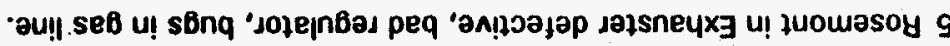

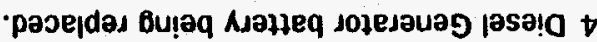
-dnias buịa wəis^s $\varepsilon$

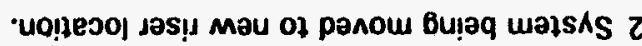

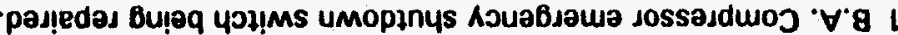

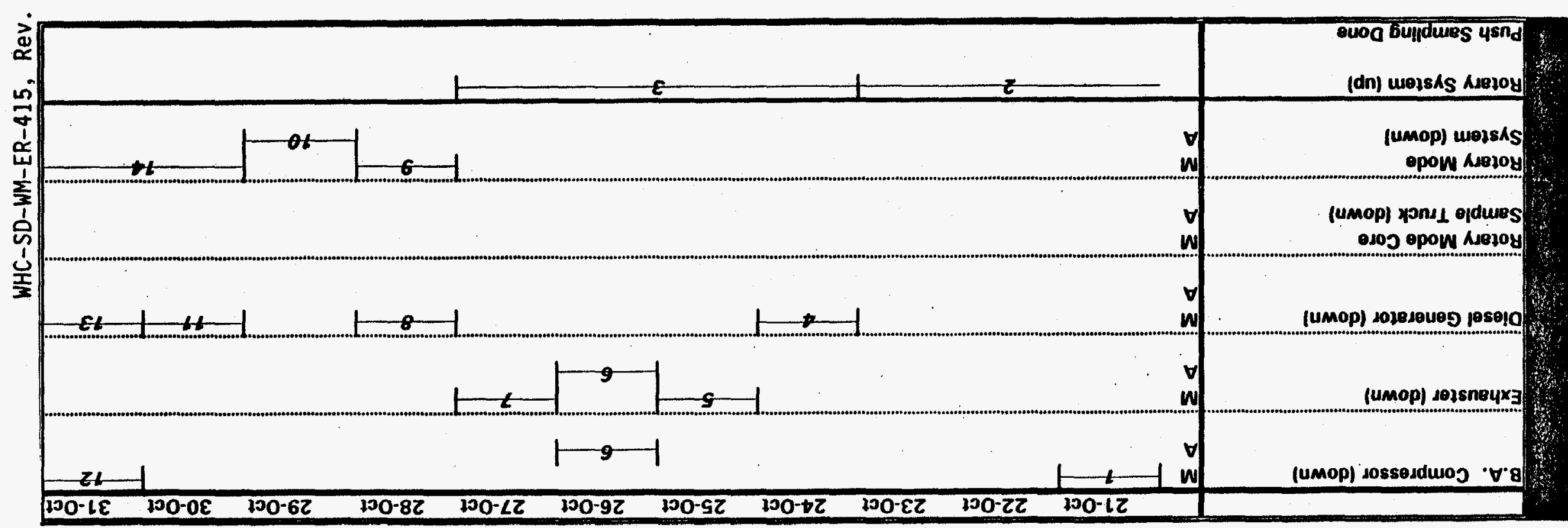

I Nsensqaj - IZ saqoiso

פ07 Jld Sowy 
sped oseds sos bupyeM

olqupenown jowosied woddins

pepoen syes

popoon spool

ysomveded

seyjeop

:sepnjoul dNo6ejes

sa!l!!!n wojy dn pasamod matsAs $9 \mathrm{l}$

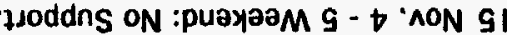

-Jamod ou ol anp umop watsks ti

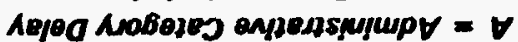

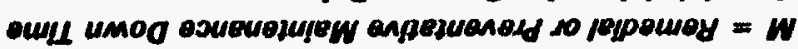

-suledas lof uset to tno panou jolesauag jasạc $\varepsilon$

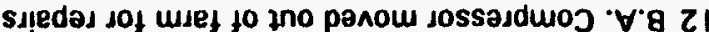

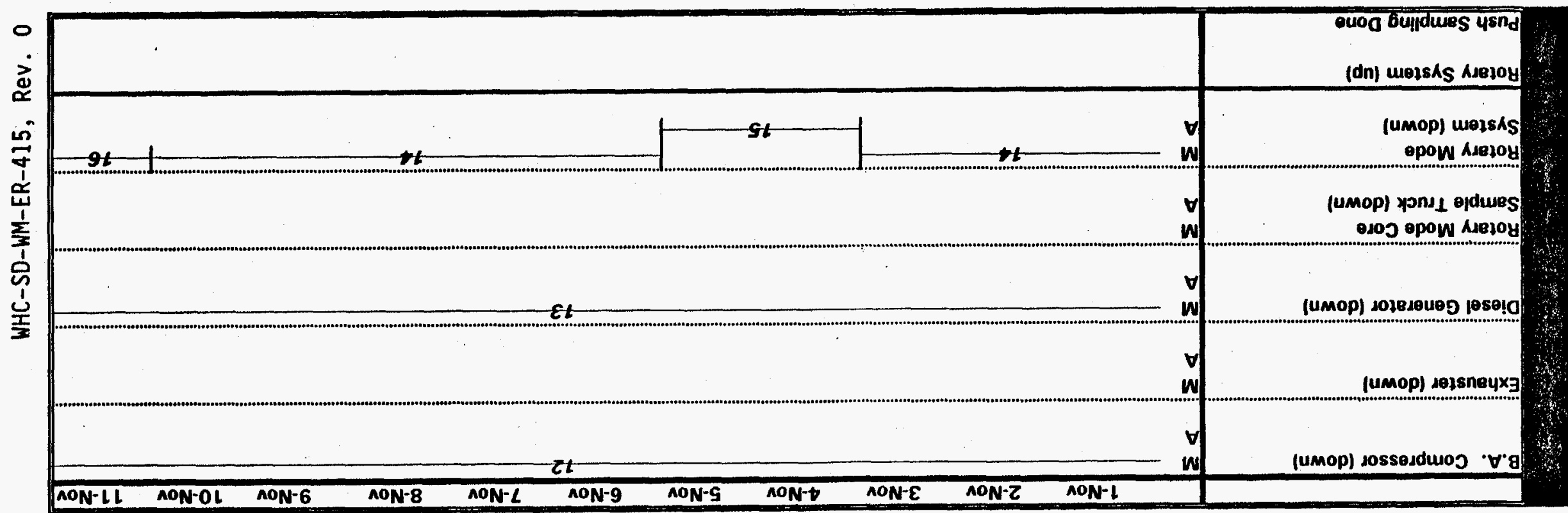

I Asensqaj - IZ jaq0100 507 Jld SOWY 
RMCS PIC LOG

October 21 - February 1

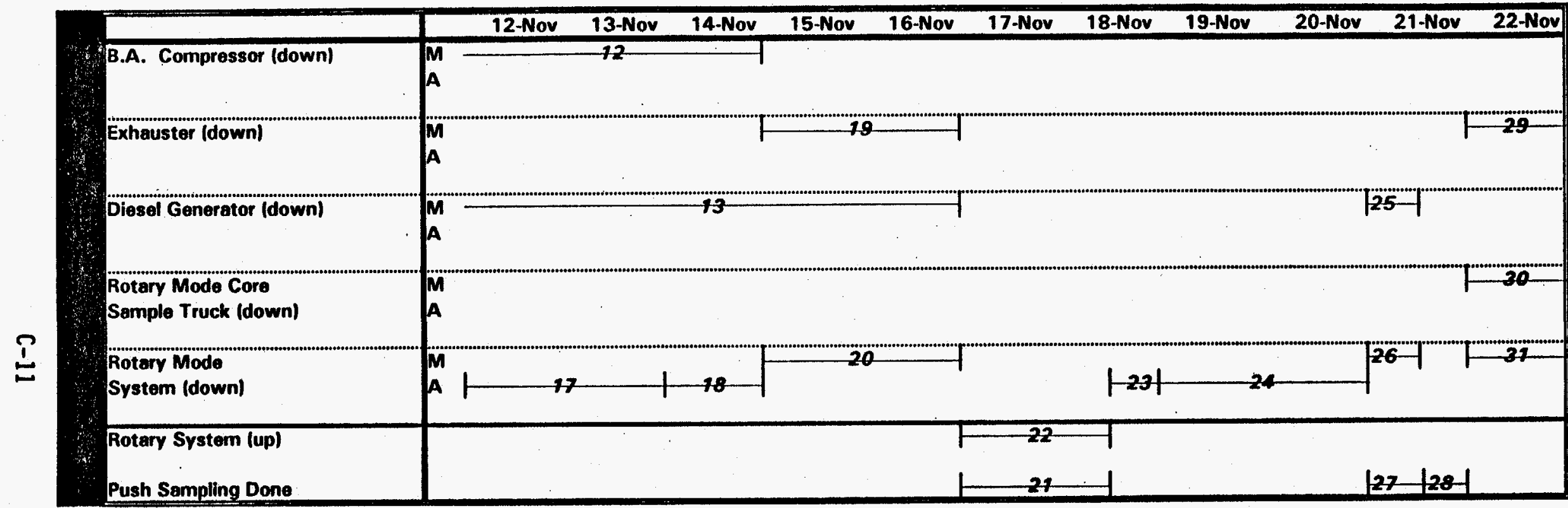

17 Nov. 12 - 13 Weekend: No Support.

18 Unable to enter farm due to high RAD problem.

19 B\&K will not calibrate, AC 3 Phase Rotation wrong, bottle on Exhauster empty.

20 System down due to Exhauster problems.

21 Samples 94-024 and 94-025 taken.

22 System up sufficiently for push mode.

23 System down - Cognizant Engineer unavailable for work plan red-lining.

24 Nov. 19 - 20 Weekend: No Support.

25 . Diesel Generator down for short peroid due to low oil.

26 Breathing Air system down due to Generator problem.

27 Sample 94-026 taken lon utilities powerl.

28 System up and running.

29 Exhauster down due to freeze-up.

30 Truck down due to platform rotations problem.

31 System down due to Truck problem.
$\boldsymbol{M}=$ Remedid or Provontotivo Maintenance Down Time

$A=$ Administrotivo Cotogary Dolay Catagory Includias:

Woother

Paporwork

Tooks Noodod

Crafts Noodod

Support Porsonof Unovallablo

Watting for Spare Parts 
RMCS PIC LOG

October 21 - February 1

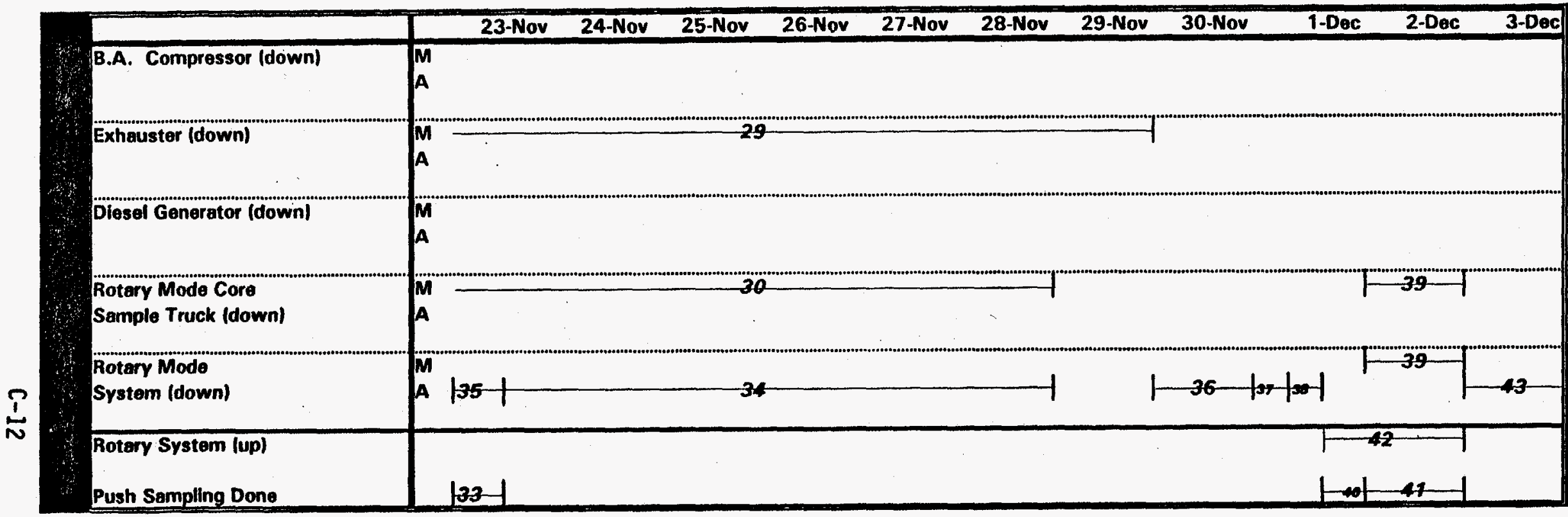

29 Exhauster down due to freeze-up.

30 Truck down due to platform rotations problem.

32 Sample 94-027 taken.

33 System sufficiently up for push mode.

34 System down due to Truck problem and Thanksgiving Holiday.

35 Delays due to wind.

36 System up and running.

37 Delays due to wind.

38 System up and running.

39 System down due to broken remote latch on Truck.

40 Sample 94-028 taken.

41 Sample 94-029 taken.

42 System up in push mode.

43 Dec. 3 - 4 Weekend: No Support.
$M=$ Remed a or Preventative Maintenance Down Tme

A = Administrotive Category Delay

Catagory Includes:

Woather

Paperwark

Tools Noedod

Crafts Neoded

Support Persond Unavallable

Walting for Spare Parts 


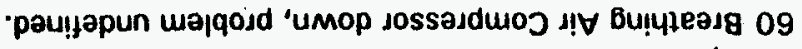
- sopesauag of anp umop warsks 69

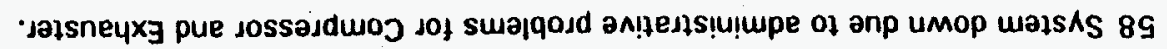

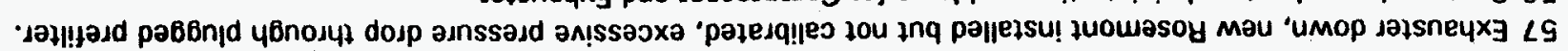

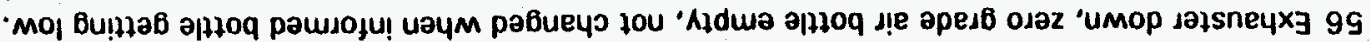
'jossajdwoכ

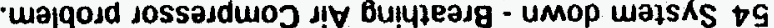
?uoddns oN :puәyәәM OL - 6 'כ20 $\varepsilon 9$

Swed asods $10 \%$ GuppM ergeponeun jowosied leoddns pepaon syoro popeon spool youmsedod soypoom

:sepnjou Araboios

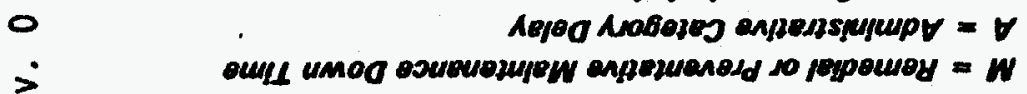

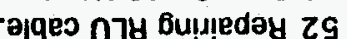

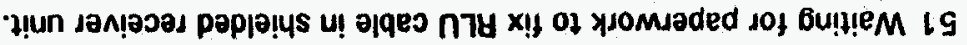
umop ł!un dәn!əoas pәp|ә!чS OS

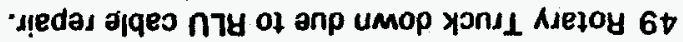

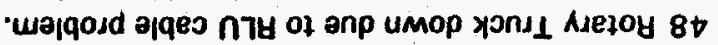

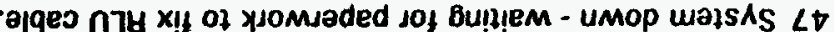

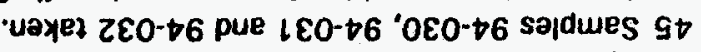
Butuuns pue dn walshs to

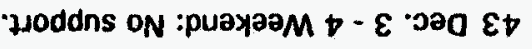



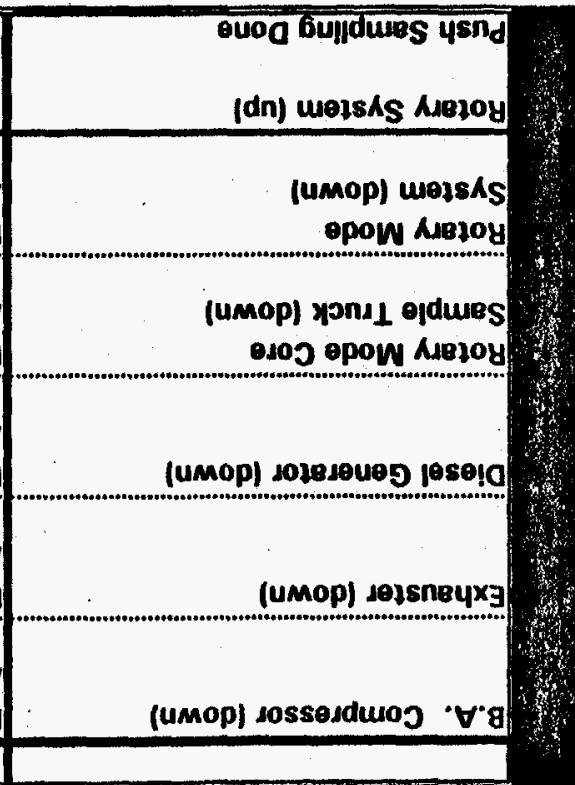

1 Asensqay - IZ saqoioo

פo7 Jld SJWr 
RMCS PIC LOG

October 21 - February

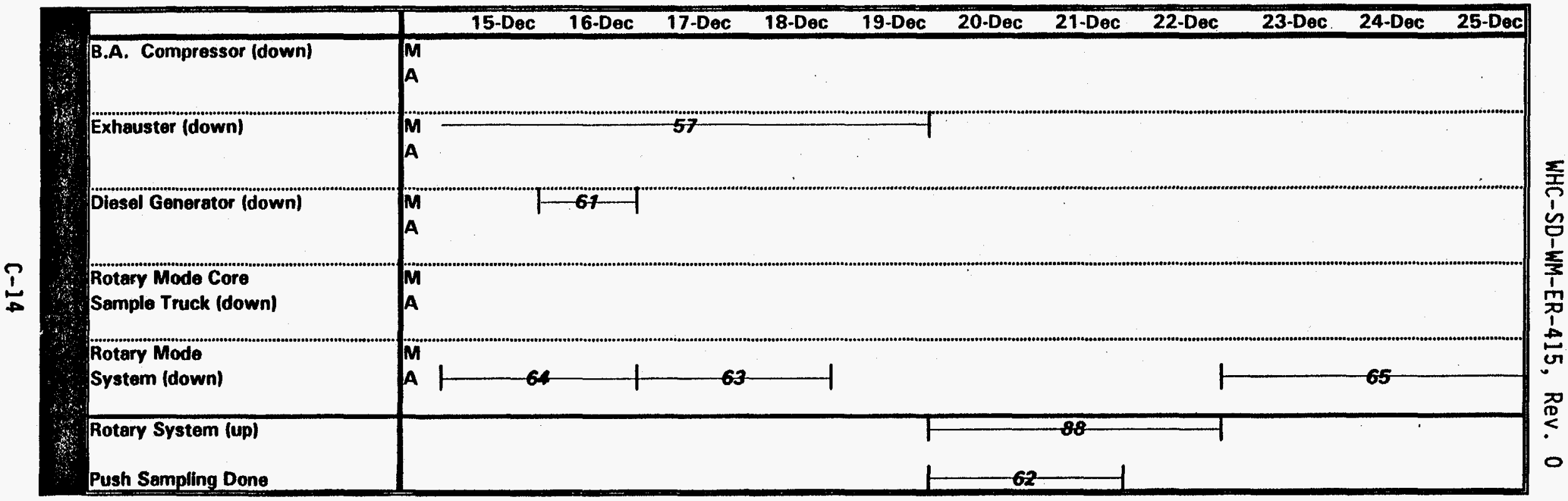

57 Exhauster down, new Rosemont installed but not calibrated, excessive pressure drop through plugged prefilter.

61 Generator down for repair.

62 Samples 94-033, 94-034, 94-035 and 94-036 taken.

63 Dec 17 - 18 Weekend: No support.

64 System up in Push Mode only.

65 Dec 23 - 27 Christmas: No work.

88 Rotary capable period.
$M=$ Romedial or Preventative Malntenance Down Time

$A=$ Administrative Cotegory Delay

Catagory Includes:

\section{Weathor}

Paporwork

Tools Nooded

Crafts Neoded

Support Personel Unavallablo

Waiting for Spare Parts 
RMCS PIC LOG

October 21 - February 1

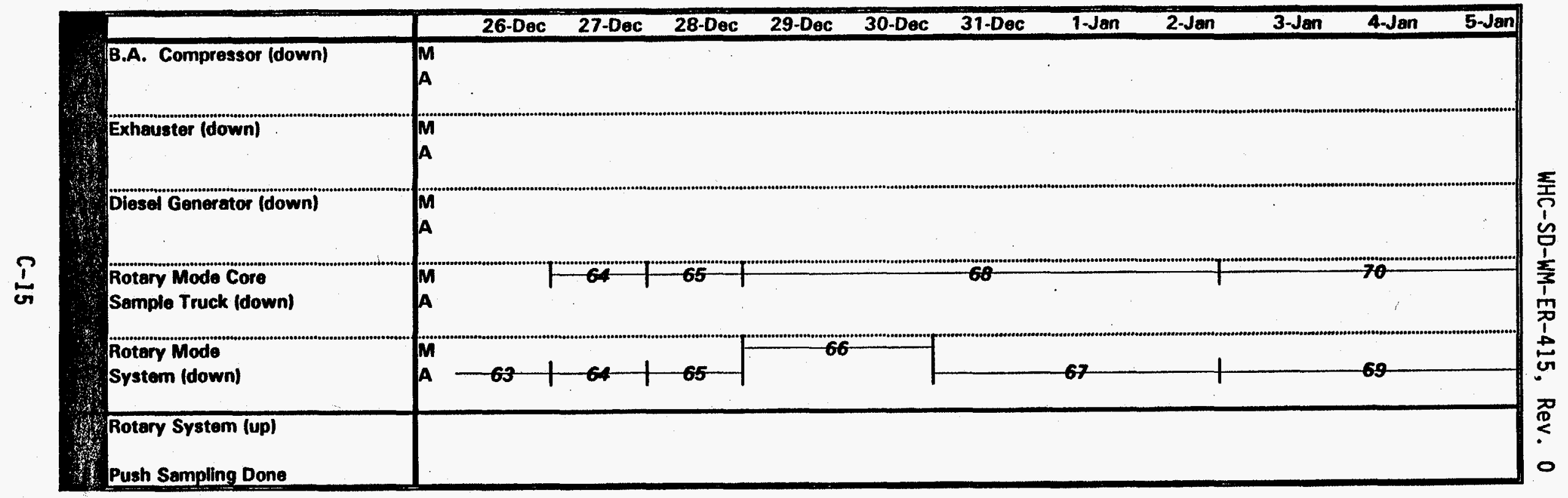

63 Dec. 23 - 27 Christmas: No Work.

64 System down due to Preventative Maintenance.

65 System down - Truck would not start.

66 System down due to Truck problem.

67 Dec. 31 - Jan. 2: New Years Holliday.

68 Removed gauges and transducer for calibration.

69 System down due to Truck.

70 Removed Hoffer from instrument panel for calibration.
$M=$ Remedial or Preventathe Maintenance Down Timo

$A=$ Administrative Category Dolay

Catagory Inc/udes:

Weather

Paperwork

Tools Needed

Crafts Needed

Support Personel Unavallablo

Waiting for Spare Parts 
RMCS PIC LOG

October 21 - February 1

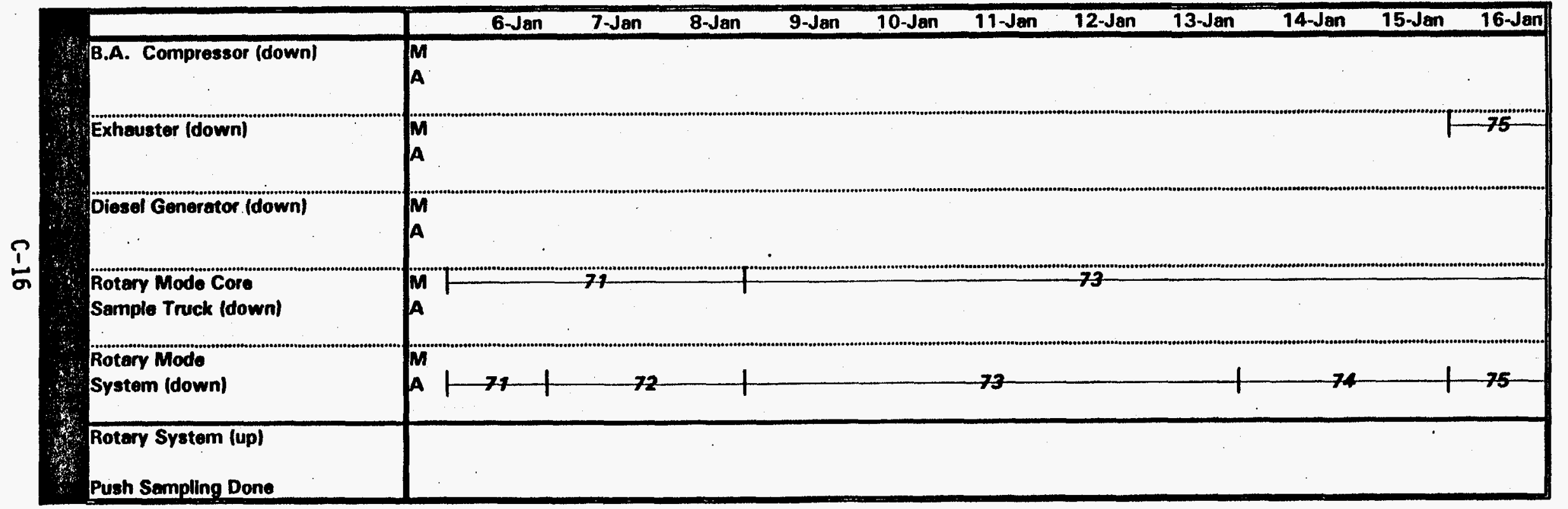

71 Replaced Hoffer, pulled 2 Hoffer for calibration

72 Jan. 7 - 8 Weekend: No support.

73 Installed $\$ 2$ Hoffer back in place and pulled other Hoffer for calibration.

74 Jan. 14 - 15 Weekend: No support.

75 Exhauster down due to repairs to Beta CAMS.
$M=$ Remedial or Preventative Maintenance Down Time

$A=$ Administrative Cotegory Delay Catagory Includes:

Woather

Paporwork

Toots Noeded

Crafts Needed

Suppont Porsonel Unavailablo

Walting for Spare Parts 
RMCS PIC LOG

October 21 - February 1

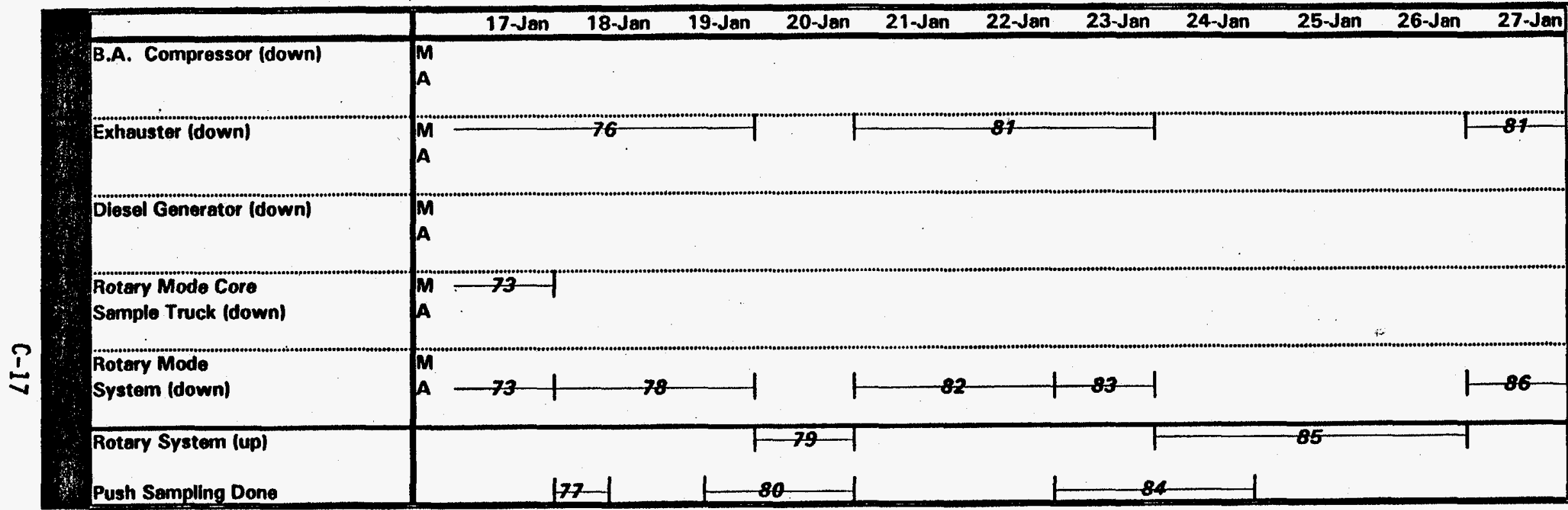

73 Installed $* 2$ Hoffer back in place and pulled other Hoffer for calibration.

76 Exhauster down due to repairs to Beta CAMS.

77 Sample 95-001 taken in push mode.

78 System up in push mode.

79 Rotary Mode available.

80 Sample 95-002, 95-003, 95-004, 95-005, 95-006, 95-007, 95-008 taken.

81 System up but Exhauster being moved.

82 Jan. 21 - 22 Weekend: No support.

83 System up in push mode.

84 Sample 95-009 and 95-010 taken.

85 Rotary Mode available.

86 System up in push mode.

87 Shielded receiver won't lower.
$M=$ Romodid or Provemtative Maintenence Down Timo

A = Administrativo Category Delay Cotagory Includes:

Weathor

Paperwork

Tools Noeded

Crafts Neoded

Support Porsonel Unavailablo

Watting for Spare Parts 
WHC-SD-WM-ER-415, Rev. 0

This page intentionally left blank. 
WHC-SD-WM-ER-415, Rev. 0

APPENDIX D

CONTACTS AND RESPONSIBLE PERSONS 
WHC-SD-WM-ER-415, Rev. 0

This page intentionally left blank. 
WHC-SD-WM-ER-415, Rev. 0

APPENDIX D

CONTACTS AND RESPONSIBLE PERSONS

February 10, 1995

CONTACTS

\begin{tabular}{|c|c|c|}
\hline Name & Description & Data \\
\hline R.J. (Roy) BT anchard & $\begin{array}{l}\text { RMCSS Mgr } \\
\text { (Design) } \\
\end{array}$ & $\begin{array}{l}373-1248 \\
\text { R1-17 } \\
\end{array}$ \\
\hline G.W. (GaTen) Wilson & $\begin{array}{l}\text { Cog Engr Truck \#1 } \\
\text { (Design) }\end{array}$ & $\begin{array}{l}373-1340 \\
\mathrm{R} 1-17\end{array}$ \\
\hline G.J. (Greg) Bogen & $\begin{array}{l}\text { Cog Engr Truck \#2 } \\
\text { (Design) }\end{array}$ & $\begin{array}{l}373-5822 \\
R 1-17 \\
\end{array}$ \\
\hline J.L. (Jeff) Smalley & $\begin{array}{l}\text { Cog Engr Trucks \#3 \& \#4 } \\
\text { (Design) }\end{array}$ & $\begin{array}{l}372-0886 \\
\mathrm{R} 1-17 \\
\end{array}$ \\
\hline E.J. (Eric) Waldo & $\begin{array}{l}\text { Cog Engr Tank Exhauster } \\
\text { (Field) }\end{array}$ & \begin{tabular}{|l}
$373-4065$ \\
$57-12$ \\
\end{tabular} \\
\hline R.R. (Ron) Bafus & $\begin{array}{l}\text { Cog Engr Truck I\&C } \\
\text { (Fie1d) }\end{array}$ & $\begin{array}{l}373-1741 \\
\text { Pager } 85-7452 \\
\text { S2-02 }\end{array}$ \\
\hline J.D. (Jim) Robinson & $\begin{array}{l}\text { Cog Engr Exhauster } \\
\text { (Design) }\end{array}$ & $\begin{array}{l}376-4777 \\
\text { H5-09 }\end{array}$ \\
\hline G.N. (Nick) Boechler & & $\begin{array}{l}373-3041 \\
\text { R1-17 } \\
\end{array}$ \\
\hline A.P. (Andy) Mousel & $\begin{array}{l}\text { Cog Engr Truck \#2 and } \\
\text { Purge Trailer } \\
\text { (Field) }\end{array}$ & $\begin{array}{l}373-2278 \\
57-12\end{array}$ \\
\hline A.B. (Andy) Cockrell & $\begin{array}{l}\text { Cog Engr Truck \#1 } \\
\text { (Field) }\end{array}$ & $\begin{array}{l}373-4189 \\
57-12 \\
\end{array}$ \\
\hline T.D. (Ted) Jarecki & $\begin{array}{l}\text { Cog Engr Trucks \#3 \& \#4 } \\
\text { (Field) }\end{array}$ & $\begin{array}{l}373-5741 \\
\text { S7-12 } \\
\end{array}$ \\
\hline J.D. (Jim) Criddle Jr. & Site Monitoring & $\begin{array}{l}\begin{array}{l}376-9224 \\
L 7-06\end{array} \\
\end{array}$ \\
\hline G.V. (Jerry) Delisle & Maintenance (ICF-KH) & $\begin{array}{l}376-1866 \\
\mathrm{~L} 7-05 \\
\end{array}$ \\
\hline S.J. (Susan) Eberlein & Mgr. Charact. Support & $\begin{array}{l}376-5029 \\
\text { S7-31 } \\
\end{array}$ \\
\hline G.L. (Greg) Thompson & Operations Procedures & $373-5685$ \\
\hline L.J. (Lynda) Careaga & Work Procedures & $373-0115$ \\
\hline
\end{tabular}


WHC-SD-WM-ER-415, Rev. 0

\begin{tabular}{|c|c|c|}
\hline Name & Description & Data \\
\hline K.A. (Kathy) Brinson & Maintenance Procedures & $372-2869$ \\
\hline H.J. (Harry) Schmidt & $\begin{array}{l}\text { Inst. Tech } \\
(M 0674)\end{array}$ & $373-6124$ \\
\hline L.L. (Larry) Dean & Operations & $\begin{array}{l}373-3483 \\
57-03\end{array}$ \\
\hline J.S. (Jim) Lee & Operations & $\begin{array}{l}373-0258 \\
S 7-03\end{array}$ \\
\hline P.H. (Pete) Thomsen & $\begin{array}{l}\text { Maintenance Mgr } \\
\text { (Instrument Techs.) }\end{array}$ & $373-7777$ \\
\hline J.S. (John) Schofield & Field Cog Mgr & $\begin{array}{l}373-2245 \\
R 1-67\end{array}$ \\
\hline M.C. (Mike) Jones & PIC for Trucks \#3 \& \#4 & $\begin{array}{l}373-5630 \\
S 7-03 \\
\end{array}$ \\
\hline D.E. (Dave) Melville & PIC for Truck \#2 & $\begin{array}{l}373-0257 \\
57-03\end{array}$ \\
\hline G.M. (Gary) Crummel & $\begin{array}{l}\text { Cog Engr Tank Farm } \\
\text { Environmental }\end{array}$ & $\begin{array}{l}373-5175 \\
\mathrm{R} 1-51\end{array}$ \\
\hline G.A. (George) Stanton. & Sampling Plan & $\begin{array}{l}373-5590 \\
57-31\end{array}$ \\
\hline R.H. (Robert) Stubbs & Field Engineer & $373-4460$ \\
\hline E.J. (Gene) Walter & Failure Modes Analyst & $376-1558$ \\
\hline P.J. (John) Marte11 & Exhauster Effluents & $\begin{array}{l}373-5415 \\
\mathrm{~T} 1-30\end{array}$ \\
\hline J.E. (Jim) Dunks & $\begin{array}{l}\text { Exhauster Electrical } \\
\text { and I\&C }\end{array}$ & $\begin{array}{l}376-8973 \\
\mathrm{~L} 4-90 \\
\end{array}$ \\
\hline B.R. (Bruce) Johns & Electrical & $373-3429$ \\
\hline J. (Joe) Guerra & Operations & $376-0662$ \\
\hline D.C. (Dan) Hartley & Operations & $373-1483$ \\
\hline P.A. (Patty) Katsel & Operations & $376-0662$ \\
\hline J.E. (John) Corbett & TWR/Eng & $372-2001$ \\
\hline D.B. (Bruce) Klos & TWR/WTO & $373-3574$ \\
\hline W.F. (Bill) Zurhoff & TWR/ENG & $373-1003$ \\
\hline B.H. (Bruce) Morrison & KHC/ETS & $372-1860$ \\
\hline A.D. (AI) olguin & TWR/WTO & $373-5282$ \\
\hline
\end{tabular}


WHC-SD-WM-ER-415, Rev. 0

\begin{tabular}{|l|l|l|}
\hline \multicolumn{1}{|c|}{ Name } & \multicolumn{1}{|c|}{ Description } & \multicolumn{1}{|c|}{ Data } \\
\hline W.W. (BiT1) Jenkins & Team Leader & $\begin{array}{l}\text { 373-2009 } \\
\text { (FAX) 373-2240 } \\
\text { Pager 85-3111 } \\
\text { S2-24 }\end{array}$ \\
\hline J.D. (Jerry) Potter & $\begin{array}{l}\text { Team Coordinator } \\
\text { (Mechanical) }\end{array}$ & $\begin{array}{l}376-3708 \\
\text { (FAX) 376-7327 } \\
\text { N1-21 }\end{array}$ \\
\hline K.L. (Ken) Bennett & $\begin{array}{l}\text { Team member } \\
\text { (I\&C and Electrica1) }\end{array}$ & $\begin{array}{l}\text { 372-3665 } \\
\text { (FAX) 376-7327 } \\
\text { Pager 85-7303 } \\
\text { N1-21 }\end{array}$ \\
\hline A.C. Rogers (SwRI) & $\begin{array}{l}\text { Team Member } \\
\text { (Mechanical, } \\
\text { Rel iability) }\end{array}$ & $\begin{array}{l}\text { (210) 522-2374 } \\
\text { FAX (210) 522-5122 }\end{array}$ \\
\hline J. (Jim) Burkes (SWRI) & $\begin{array}{l}\text { Team Member } \\
\text { (HydraulicS) }\end{array}$ & $\begin{array}{l}\text { (210) 522-2634 } \\
\text { FAX (210) 522-5606 }\end{array}$ \\
\hline B. (Ben) Cross (SWRI) & $\begin{array}{l}\text { Team Member } \\
\text { (Electrical, systems) }\end{array}$ & $\begin{array}{l}\text { 735-6288 } \\
\text { (FAX) 736-9532 } \\
\text { BCROSSCONEWORLD. OWT.COM }\end{array}$ \\
\hline
\end{tabular}


WHC-SD-WM-ER-415, Rev. 0

This page intentionally left blank. 